\title{
WILLMORE WILDERNESS PARK FIRE MANAGEMENT PLAN
}

Alberta Community Development (CD)

Alberta Sustainable Resource Development (SRD)
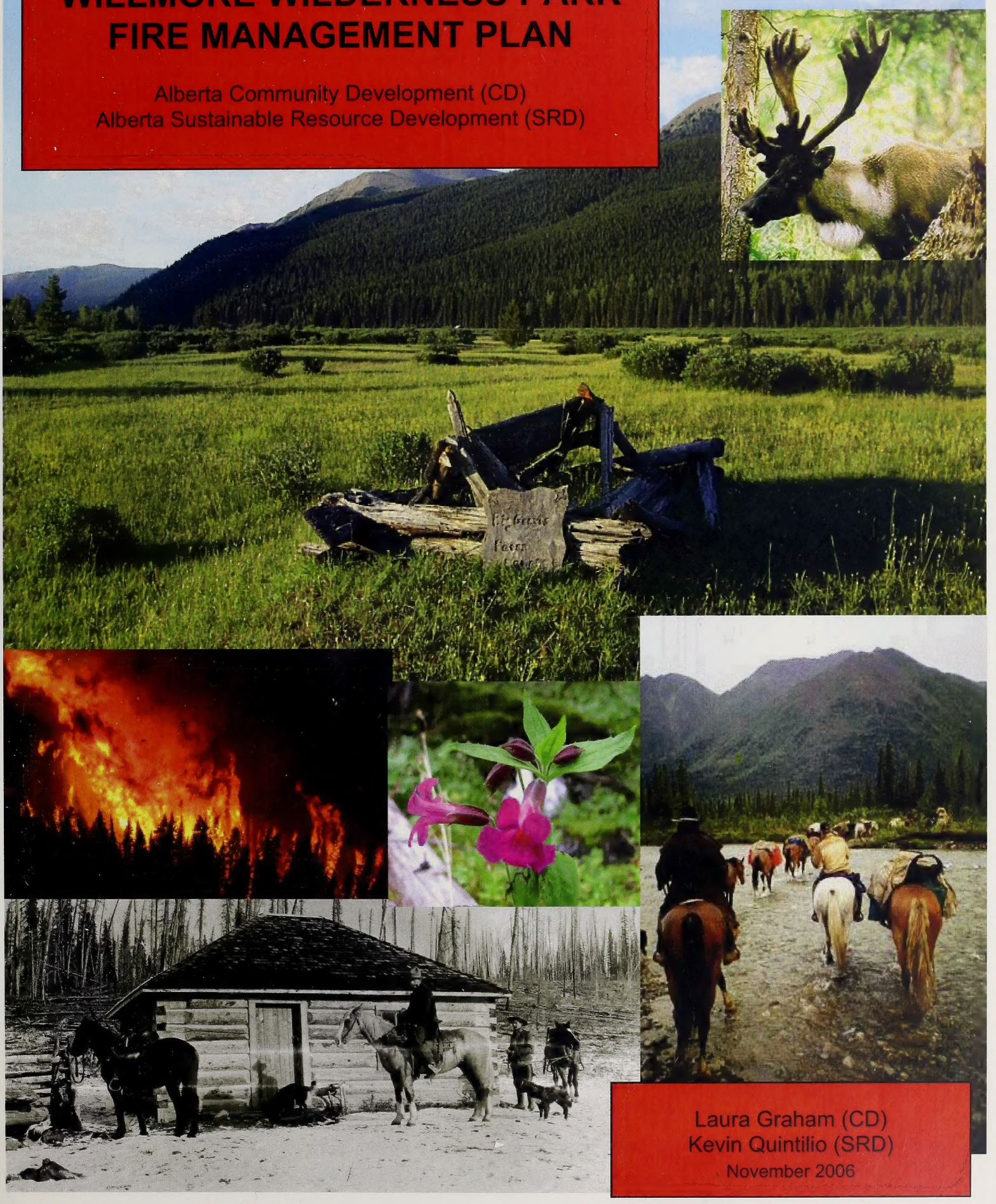
I

[

[

[

I

(

[

(

[

I

I

I

I

I

[ 


\title{
WILLMORE WILDERNESS PARK FIRE MANAGEMENT PLAN
}

\author{
Alberta Community Development (CD) \\ Alberta Sustainable Resource Development (SRD) \\ Laura Graham (CD) \\ Kevin Quintilio (SRD)
}

November 2006 


\section{TABLE OF CONTENTS}

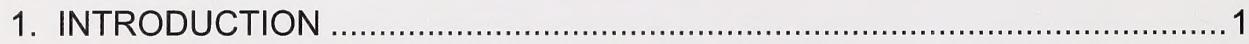

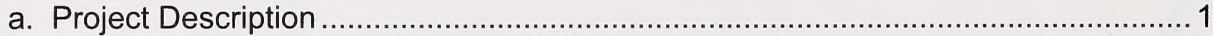

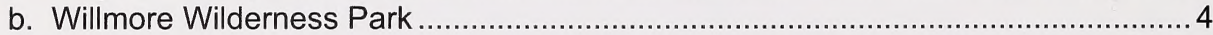

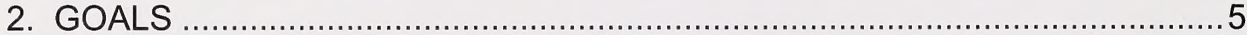

a. Ecological Integrity and Protection of Landscape Values ................................... 5

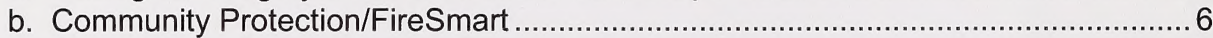

c. Forest Health/Mountain Pine Beetle Control ...................................................

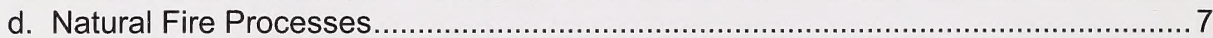

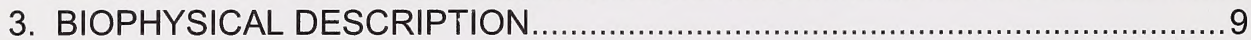

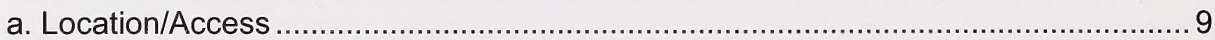

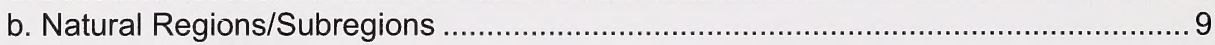

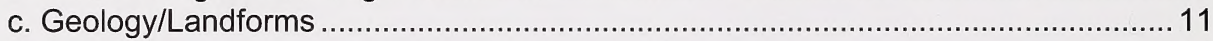

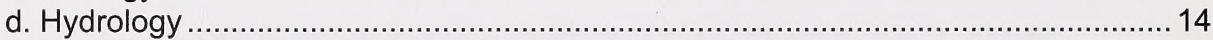

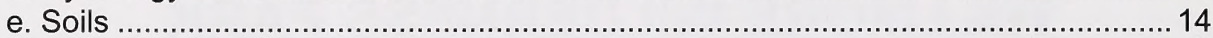

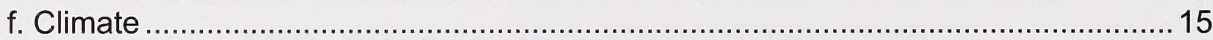

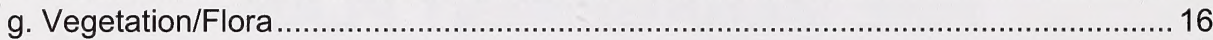

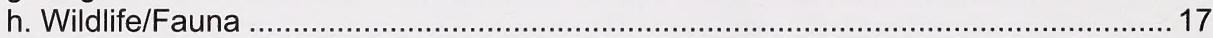

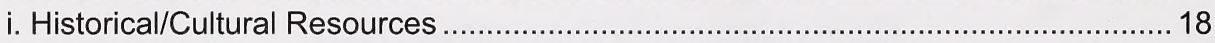

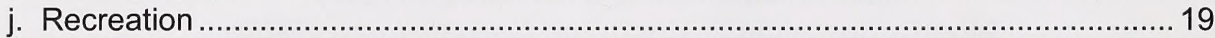

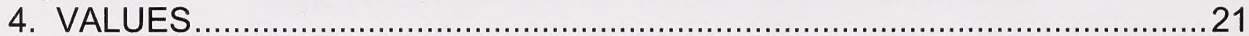

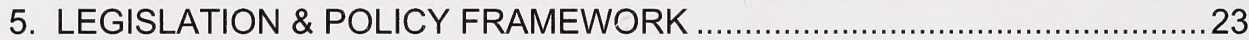

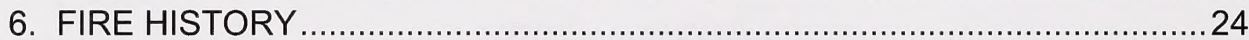

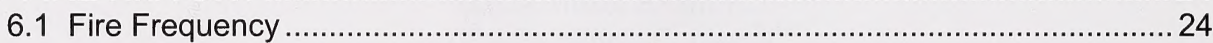

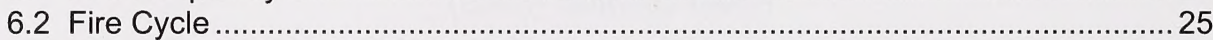

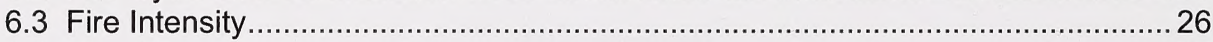

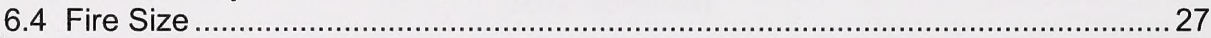

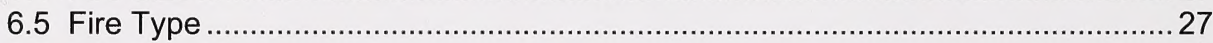

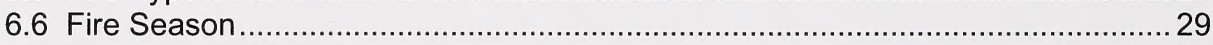

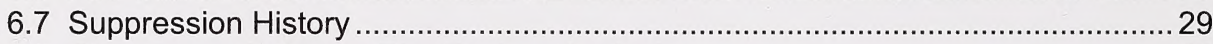

6.8. Recommendation for Fire Regime Analysis ...............................................29

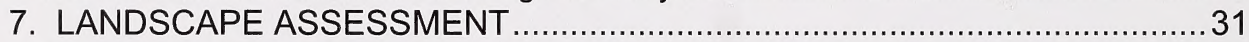

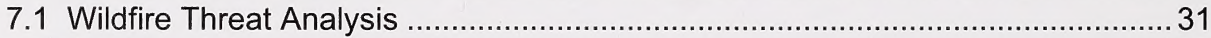

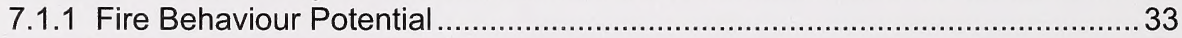

a. Head Fire Intensity ..........................................................................

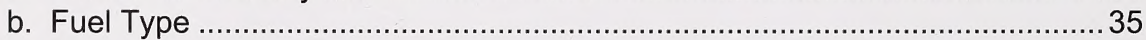

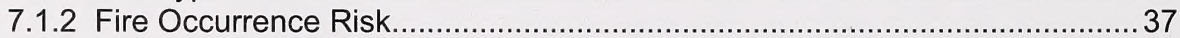

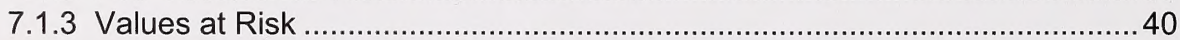

a. Ecological Values at Risk (Natural Resources, Watersheds, Soil).................40

b. Human-Related Values at Risk (Life and Infrastructure)................................42

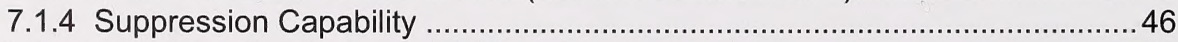

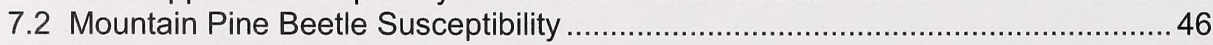

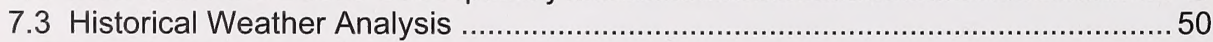

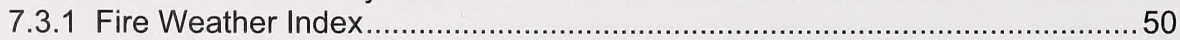

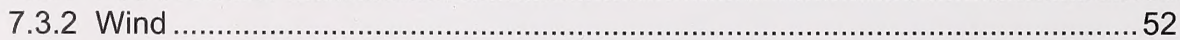

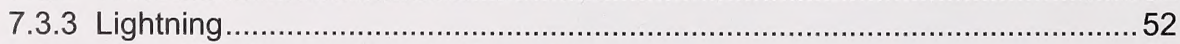

7.4 Canadian Fire Growth Model - Prometheus …………................................ 55 


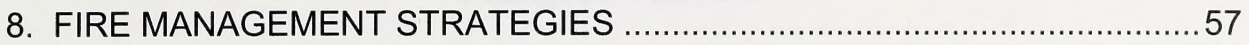

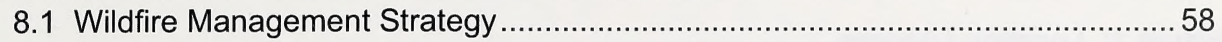

8.1.1 Managed Fire Zone ........................................................................... 58

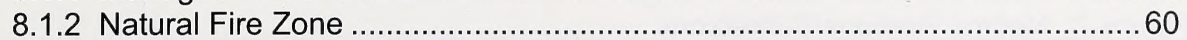

8.1.3 Wildfire Management Decision-Making ......................................................6

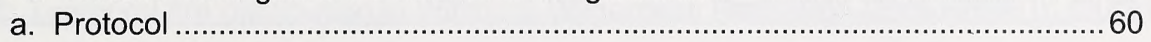

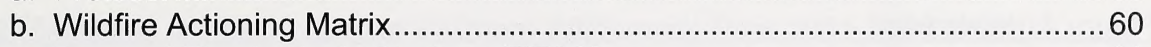

c. Escaped Fire Analysis Strategy (EFAS) .....................................................61

d. Area Closure/Fire Ban ............................................................................ 62

e. Guidelines/Criteria for Heavy Equipment Use ………..................................62

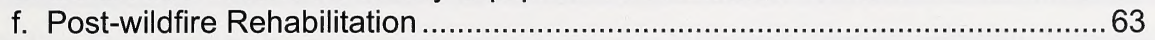

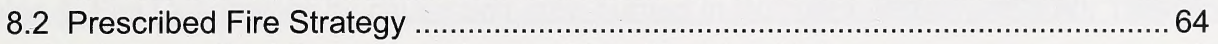

8.2.1 Prescribed Burns/Containment Lines/Capping Units .....................................65

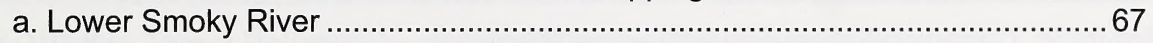

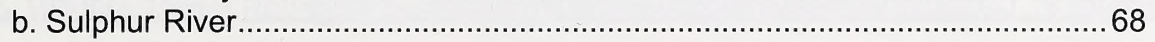

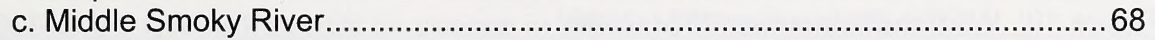

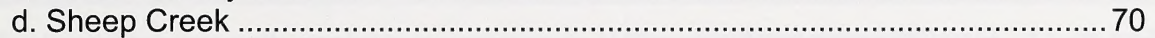

e. Meadowland Creek ............................................................................... 71

f. Upper Smoky River (Jasper National Park) ……….................................... 71

g. Rock Lake/Snake River (Jasper National Park) ......................................... 71

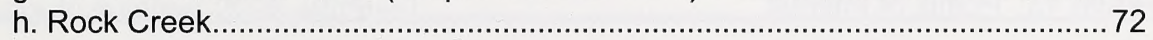

8.2.2 Prescribed Burn Implementation ........................................................ 73

9. PRE \& POST BURN RESEARCH, DATA COLLECTION AND MONITORING

10. ADJACENT FIRE MANAGEMENT

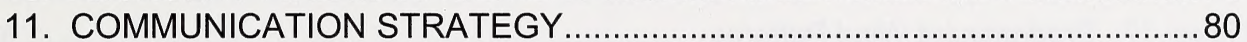

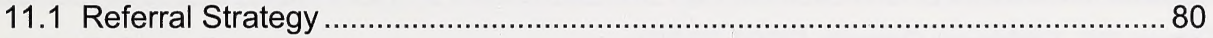

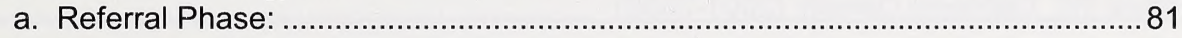

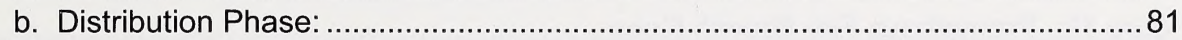

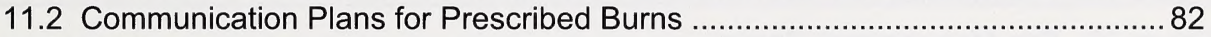

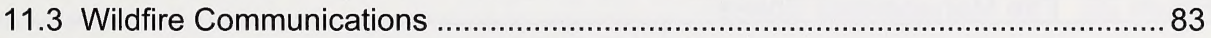

12. FIRE MANAGEMENT PLAN MONITORING......................................... 84

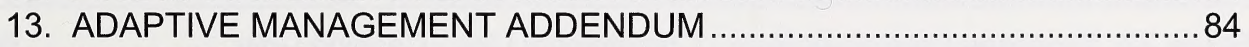

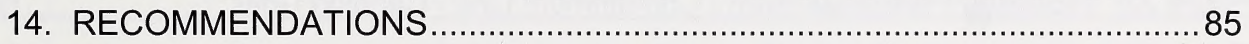

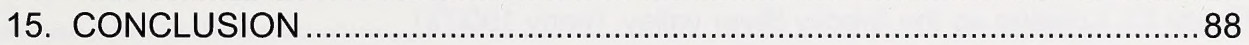

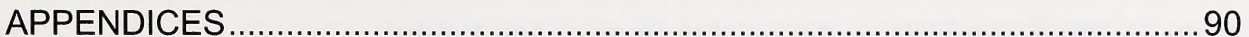

I. PROJECT PLANNING TEAM - TERMS OF REFERENCE …........................... 91

II. NOTIFICATION PROTOCOL MATRIX ……….............................................. 97

III. SRD-CD PRESCRIBED BURN/WILDFIRE COMMUNICATION FLOWCHART....98

IV. FIRE PLAN PROGRESS MONITORING REPORT ….....................................99

V. ADAPTIVE MANAGEMENT ADDENDUM ………............................................ 100

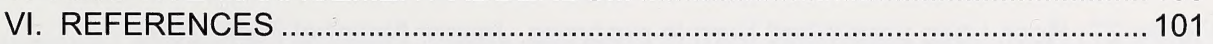




\section{Table of Figures}

Figure 1: Location / Access ………………....................................................

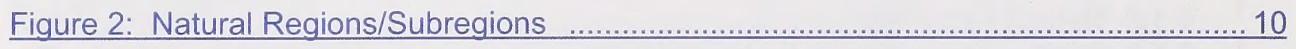

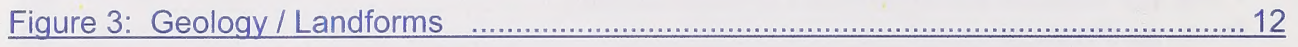

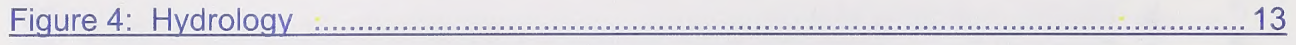

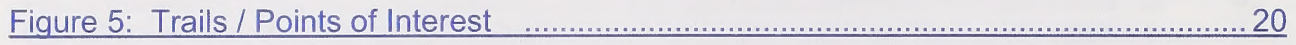

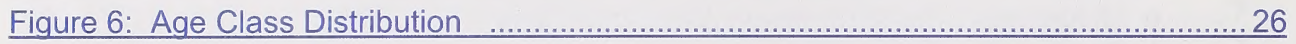

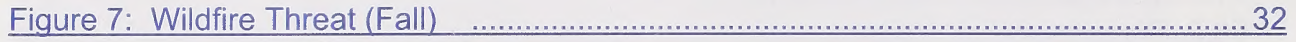

Figure 8: Fire Behaviour Potential (Fall) _...……………………............................... 34

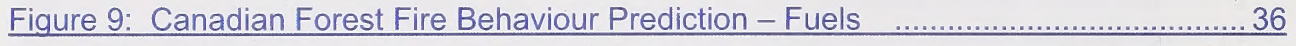

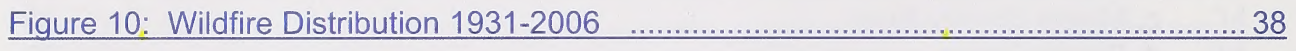

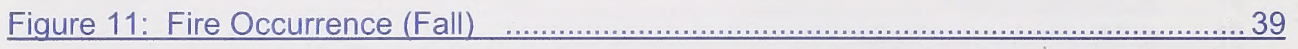

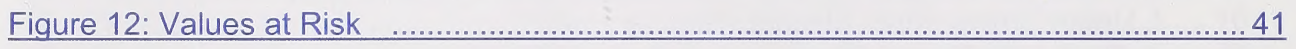

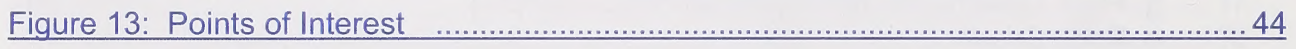

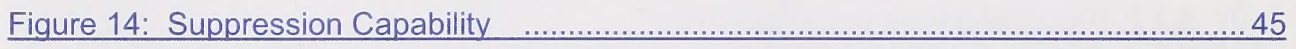

Figure 15: Mountain Pine Beetle Hazard Rating ……….......................................... 47

Figure 16: Weather Stations ………………………......................................... 51

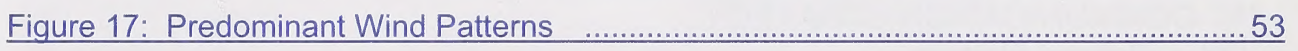

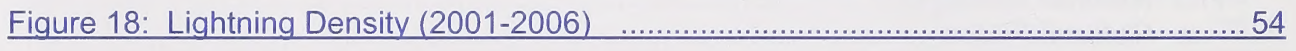

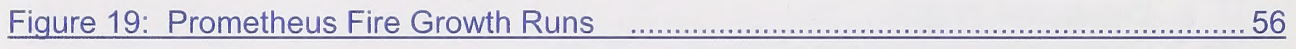

Figure 20: Fire Management Zones ………………………….............................. 59

Figure 21: Willmore Wilderness Park Wildfire Actioning Matrix _.......................................61 61

Figure 22: Proposed Prescribed Burn / Containment Line / Capping Units _...................66

Figure 23: Looking up the Smoky River valley. (early 1900's) ……...............................67

Figure 24: Big Grave Flats on the Sulphur River. (early 1900's) …………………...........6 68

Figure 25: Monoghan Creek and Sulphur River. (early 1900's) _...................................69

Figure 26: Large, stand-replacing fire burned entire valley (landscape level burn)

Looking up Smoky River towards Muddywater River. (early 1900's) …................... 70

Figure 27: Rock Lake prescribed burn in progress, Jasper National Park, $2003 \quad$............. 72

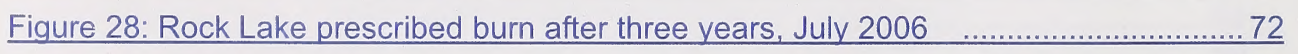




\section{List of Tables}

Table 1: Temporal fire distribution in Willmore Wilderness Park 1961-2004 (2006) .......25

Table 2: Temporal fire distribution in Willmore Wilderness Park 1961-2004 (2006) ....... 27

Table 3: Classification of fire occurrence by cause and area burned in Willmore

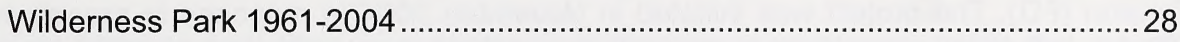

Table 4: Fire Occurrence by cause and area burned in Willmore Wilderness Park 19612004 28

Table 5: Wildfire Threat Rating by season in Willmore Wilderness Park 31

Table 6: Fire Behaviour Potential by season in Willmore Wilderness Park 33

Table 7: Head Fire Intensity ranking by season in Willmore Wilderness Park 33

Table 8: Hectares of susceptible Lodgepole Pine stands for Willmore Wilderness Park (prior to summer 2006 wildfires).

Table 9: 90th percentile weather indices for weather stations within and adjacent to Willmore Wilderness Park. 52

Table 10: Proposed conceptual units for Fire Management Plan 65 


\section{INTRODUCTION}

\section{a. Project Description}

The Willmore Wilderness Park Fire Management Plan is the product of a collaborative effort between Alberta Community Development (CD)-Parks and Protected Areas Division (PPAD) and Alberta Sustainable Resource Development (SRD)-Forestry Division (FD). The project was initiated in November 2004 in response to proposals to $C D$ for individual prescribed burns and fire management activities to meet various objectives. Development of an overall plan to guide the appropriate level and direction of fire management activities within Willmore Wilderness Park was timely. A project team with members from both departments was established to develop the Fire Management Plan, which was completed in November 2006.

Community Development, as the land manager for the Willmore Wilderness Park, sets the direction and mandates the activities permitted within the Willmore Wilderness Park. CD provided input and direction to ensure that the Fire Management Plan is compatible with the intent and objectives for the Willmore Wilderness Park. Sustainable Resource Development is responsible for wildfire management across the provincial forest protection area, including the Willmore Wilderness Park. SRD provided forest protection, fire management planning, and operational expertise in the development of the Fire Management Plan. Implementation of the Fire Management Plan is a joint effort, with CD responsible for final approval of fire management activities that proceed within Willmore Wilderness Park.

The Parks and Protected Areas Division of CD manages Alberta's parks and protected areas network to meet the main goal of preserving and protecting Alberta's natural heritage, and also to contribute to goals that support heritage appreciation and education, outdoor recreation and healthy living, as well as tourism and community. The Willmore Wilderness Park does not have a management plan, however the ecological and recreational values of the Park are well recognized and were incorporated into development of the Fire Management Plan. CD provided direction for assessing fire management options to fit the general intent and ecological objectives for Willmore. The Fire Management Plan provides pro-active fire management direction in the interim before a Park Management Plan. This Fire Management Plan was a valuable step that initiated the more detailed background preparation (e.g. biophysical data collection) that is needed to prepare a Willmore Wilderness Park Management Plan. When a Park Management Plan is completed then the Fire Management Plan will be incorporated and can be adapted, if needed, to further complement management plan direction.

The intent of this Fire Management Plan is to recommend fire management strategies to mitigate wildfire threat to landscape and species values, as well as communities; minimize threats to forest health (e.g. mountain pine beetle infestation); and allow natural fire regimes to re-establish across the landscape, while prioritizing ecological integrity. In order to meet the intent, a variety of fire management strategies will be employed. The strategies include zoning the Willmore for wildfire management between a natural fire zone where natural fires may be permitted to burn and a managed fire zone where fires will generally continue to be suppressed. Currently the entire Willmore 
Wilderness Park is a managed fire zone with full suppression. Enabling a natural fire zone as soon as possible reduces the potential to impact natural fire cycles.

Selective, conservative prescribed burns or hand cut containment lines will be used as tools within Willmore Wilderness Park to: i. provide a fireguard in order to support the Town of Grande Cache Community Protection Plan; ii. target a specific area of recurrent mountain pine beetle infestation; and iii. complement existing topography to create a contiguous fireguard to delineate the natural fire and managed fire zones. There is no intent to introduce prescribed burns on the Willmore landscape to artificially create fire patterns representing the natural range of variability.

The Fire Management Plan is a strategic, landscape level plan to guide the overall parameters of fire management within Willmore Wilderness Park. Detailed prescribed burn plans, outlining operational logistics and ecological considerations as well as communication plans (i.e. public notification and signage), will be developed for each specific burn. These detailed prescribed burn plans will be reviewed and must be approved by both departments (CD and SRD) before the burns are conducted.

The project team developed a Terms of Reference (Appendix I), which outlined the project rationale, process, team roles and responsibilities, consultation and timelines. The draft Fire Management Plan was reviewed with agencies from the surrounding jurisdictions including Jasper National Park, FMA holders, B.C. Ministry of Forests, Municipalities and local First Nations as well as primary stakeholders and interested public. A direct mail out to these agencies and key stakeholders provided the draft Fire Management Plan and invitation to a presentation for discussion of the plan and input. After the presentation, a couple weeks was allowed for further input, which was reviewed and incorporated into the final Fire Management Plan. Two large wildfires, prior to signoff of the Fire Plan, necessitated review and modification of the draft Fire Plan to adapt it to the change in scenario. The final Fire Management Plan will be available to the public online (CD and SRD websites).

This Fire Management Plan is a living document and therefore employs adaptive management. Mechanisms allow for annual review through a progress monitoring report and adaptive management addendum, which are described later in this plan. These mechanisms allow modification or refinement of the Fire Plan to occur as new knowledge and science become available or as wildfires occur. 
Figure 1: Location / Access

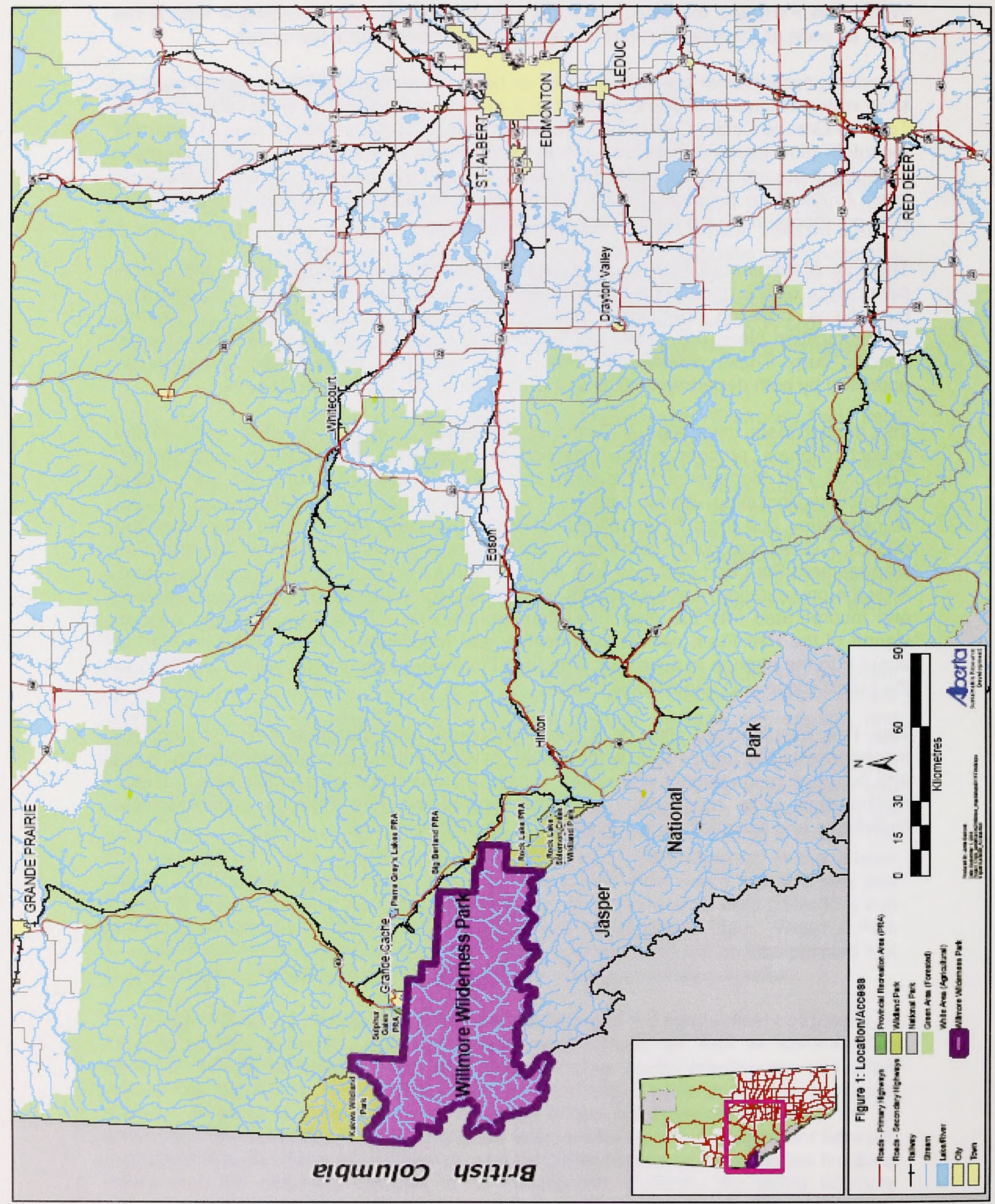

Willmore Wilderness Park Fire Management Plan - November 2006 


\section{b. Willmore Wilderness Park}

The Willmore Wilderness Park is located in Alberta approximately $400 \mathrm{~km}$ northwest of Edmonton, and adjacent to Jasper National Park (Figure 1). The planning area encompasses the 460400 ha of Willmore Wilderness Park of which approximately 245 860 ha is forested. The park was originally set aside in 1959, and in 1965 was named after the late honourable Norman A. Willmore. This unique site is governed under its own legislation, the Willmore Wilderness Park Act.

Situated in the Canadian Rocky Mountains the park has representative landscapes of the Montane, Sub-Alpine and Alpine Subregions of the Rocky Mountain Natural Region as well as the Upper Foothills Subregion of the Foothills Natural Region. The site provides rugged mountains, glaciers, alpine lakes, rivers and their tributaries, forested valley slopes, grassy meadows and wetlands.

Aboriginal people, trappers, hunters and resource prospectors have historically utilized the region. It is now used for recreational activities such as backcountry hiking, mountain biking, trail riding and hunting, as well as supporting commercial trail riding operations, commercial hunting outfitters, and trappers. Recreational motorized use is prohibited. Current development is limited to primitive facilities appropriate to a wilderness experience, such as rugged, undeveloped trails and primitive random backcountry campsites. The Willmore Wilderness Park encompasses extensive and remote natural landscapes that provide a unique wilderness experience. The level of management employed will be suited to allowing the park to retain its wilderness aspect and to enable natural processes to function with as little human interference as possible. 


\section{GOALS}

The Fire Management Plan recommends fire management strategies to mitigate wildfire threat to landscape and species values, as well as communities; minimize threats to forest health (e.g. mountain pine beetle infestation); and allow natural fire regimes to reestablish across the landscape, while prioritizing ecological integrity. These objectives can be captured in four goals: a) ecological integrity and protection of landscape values; b) community protection/FireSmart; c) forest health/mountain pine beetle control; and d) natural fire processes.

\section{a. Ecological Integrity and Protection of Landscape Values}

Willmore Wilderness Park is a significant protected area, of considerable ecological, recreational and cultural value, in Alberta's network of protected areas. Willmore provides an increasingly valuable wilderness in Alberta's rapidly developing industrial landscape. Preservation of natural heritage values is the main goal for the park, and park management objectives focus on maintaining the ecological integrity and function represented by the wilderness. The intent is that science-based management activities sustain or enhance preservation objectives, through a bias towards conserving ecological integrity, while still allowing compatible recreational wilderness opportunities. Therefore preservation of ecological integrity is the highest priority for Community Development (CD), and is the over-riding factor in assessing or conducting any fire management activities within the Willmore. The overall intent is to manage the Willmore at a landscape level for ecosystems and watersheds in order to maintain the ecological integrity supporting the wide variety of species of Willmore's biodiversity.

Ecosystems exhibit a resiliency that allows for tolerance to some disturbance in order to maintain ecological function and biodiversity similar to the pre-disturbance state. Biodiversity (i.e. characteristic species and communities) is a result of, and required for, ecosystem functions to occur with resilience and resistance to environmental change ${ }^{1}$. Ecological integrity does not infer a static state but that the ecosystem has the resiliency to allow for maintenance of biodiversity. However, it is important to manage disturbance of the ecosystem within the resiliency of current ecological states so that the disturbance does not overcome the resiliency to permanently alter the ecological state. Changes in the occurrence and distribution of species, species becoming listed as sensitive, or invasive species replacing characteristic native species, may indicate changes to the ecological states they inhabit. Ecological management within Willmore may need to compensate for the changing ecological states outside Willmore, however these ecological management considerations are consistent with, and demonstrate the valuable role of, protected areas such as Willmore.

Willmore Wilderness Park contains significant wilderness landscapes with a myriad of ecosystems supporting a variety of plant and animal species and communities. Some species are common in their subregions but others may be less common and their presence is important. In particular, Willmore's habitat may become more crucial as disturbance and development increases in the adjacent working landscape. Woodland caribou are a threatened species that include Willmore as part of their range. Minimizing impacts on caribou in Willmore supports an important provincial priority. Grizzly bears

\footnotetext{
${ }^{1}$ Walker, 1992; Baskin, 1994
} 
and the elusive wolverine also reside in Willmore. Whitebark pine, a species that is being monitored due to its decline in North America, exists in the higher ranges of the forested slopes. Provincially rare plants have been located within the park. These and other species may merit extra consideration in fire planning. However, fire planning at a landscape level, rather than micro managing for species, is anticipated to best allow sustainable ecological processes to support these species. Minimizing fire suppression may provide more protection for key species by allowing natural fire cycles to occur within the habitat.

This wilderness provides important environmental and social values through recreational opportunities as well as the knowledge that this protected wilderness exists. Natural fires are considered appropriate and beneficial within Willmore Wilderness Park. However, knowledge of the biophysical resources within Willmore, as well as the impact of fire on these various components of Willmore's wilderness resources, is largely unknown. As a result, there is some responsibility to try to avoid "catastrophic" fires in the absence of adequate knowledge. Allowing natural fires to burn within Willmore may help prevent the "catastrophic" fires that result due to extended periods of full fire suppression.

The "ecological integrity and protection of landscape values" goal permeates the Fire Management Plan which therefore attempts to minimize human intervention in natural fire cycles. A natural fire zone has been demarcated within Willmore. In this natural fire zone, natural cycles will be allowed to determine the extent and magnitude of fires that burn. Implementation of conservative, strategic prescribed burns will allow fire benefits to be realized in this natural fire zone by creating fireguards across key valleys to reduce the risk of large fires spreading throughout the contiguous valleys of the Willmore and beyond to threaten values outside Willmore.

\section{b. Community Protection/FireSmart}

Protection of people and property is a provincial priority. In particular, communities surrounded by forest may be at risk from wildfire therefore proactive measures are being developed to minimize this risk. Sustainable Resource Development has undertaken a process to develop a series of Community Protection Plans throughout Alberta in order to "FireSmart" communities that are at risk from wildfire.

The Town of Grande Cache, located adjacent to the northeast boundary of Willmore Wilderness Park, initiated development of their Community Protection Plan in November 2004. The scope of their planning area is a ten-kilometre radius around the town. This planning area includes a portion of the Smoky River valley within the Willmore Wilderness Park. Prevailing winds from the west and extensive contiguous forests pose the risk of wildfire escaping Willmore and threatening Grande Cache.

The Willmore Fire Management Plan project team identified community protection as one of their main goals for the Fire Management Plan. The Grande Cache Community Protection Plan was developed in conjunction with the Willmore Fire Management Plan in order to meet the fire management objectives for Grande Cache as well as the objectives of the Willmore Fire Management Plan. The actions of both plans were developed to be complementary in order to meet the overall FireSmart objective. 


\section{c. Forest Health/Mountain Pine Beetle Control}

Forest health includes management of the pests and disease that attack the forest. Currently the biggest threat is Mountain Pine Beetle (MPB). MPB is an insect pest that can have a serious impact on pine forests. The MPB are normally found as small endemic populations in Alberta, however a current epidemic in neighbouring British Columbia, as well as warmer winters and high volumes of susceptible pine forests in Alberta, is increasing the occurrence of MPB and likelihood of an infestation in Alberta.

Since 1999, SRD has been actively monitoring MPB in Willmore Wilderness Park through aerial and ground surveys, as well as pheromone baits. Small pockets of mountain pine beetle have been identified and controlled each year through falling and burning of the individual infected trees. With this "fall and burn" method, individual infected trees, identified through ground surveys, are cut down, and then cut into pieces and burned at a high intensity to kill the inhabiting MPB. An increase in the MPB infestation in the summer of 2005 resulted in the mobilization of an intensive operation to selectively fall and burn over 5000 individual infested trees, with over 10000 trees removed over the following fall until early summer. Control activities, such as surveying and selective fall and burn, will continue to be implemented as the most effective and appropriate MPB control tactic for Willmore Wilderness Park.

Reducing the spread and impact of MPB on pine forests is a high priority in Alberta. The project team identified MPB in the fire management plan objectives in order to consider fire management activities that may help impact MPB. Strategies include direct control through applying a prescribed burn in the Meadowland Creek area. The intent of that prescribed burn is to eliminate a recurrent MPB population, remove the pine habitat that supports their reoccurrence, and create a barrier to hinder MPB spread from B.C. eastward. Further prescribed burns to control MPB are not proposed in this fire plan. However, indirect control is potentially provided by creating a natural fire zone where natural fires may be allowed to burn including MPB infected areas or pine forests that provide beetle habitat. This indirect control was demonstrated when two large wildfires in the summer of 2006 burned MPB infested areas and removed significant tracts of MPB habitat. Indirect control may also be provided by the fireguard prescribed burns, which remove some pine habitat and may create barriers to MPB movement.

\section{d. Natural Fire Processes}

Fire plays an important ecological role in the forest regime and across other landscapes. Fire is a natural disturbance that influences the ecological state across a continuum of scales such as at minute scales within the forest stands to a landscape level such as the Willmore Wilderness Park land base. Many ecosystems depend on fire for their periodic regeneration, and their plant and animal species are adapted to the conditions created by fire. Some impacts of fire include ${ }^{2}$ : nutrient cycling, carbon recycling and energy flow; conversion of forest litter into a nutrient-rich soil conditioner; increased soil temperature to stimulate plant growth; release of seeds and root sprouting; changes in plant competition, succession and diversity; impacts on forest pests; and changes in habitat that may be beneficial or negative for different species. Fire recycles in order to regenerate. It determines the mosaic of landscape patterns, and shifts the vegetation and wildlife biodiversity mix.

\footnotetext{
${ }^{2}$ Based on Wright and Heinselman (1973) from Pyne 1996; Jasper National Park brochures.
} 
Willmore is a large land base with historic evidence of fire disturbance through records (since 1931), photos, anecdotal information as well as visual scars on the landscape. In some areas, fire cycles may be 180-200 years, while other areas have relatively short fire cycles of 100-120 years, with the last stand-replacing fires in the late 1800's or early 1900 's. Due to the length of the fire cycles, as well as some impacts of fire suppression efforts over the last 40 years, the majority of the extensive forests throughout Willmore contain relatively old, even-aged trees. These old, contiguous stands of large trees are viewed by some as "un-natural" for the forest and at risk of a large, catastrophic wildfire. However, these forests can be considered representative of old growth forests that are expected to occur in areas with long fire cycles. Photos of burned areas (pg 61-63) indicate that large areas of mature forests, such as currently present, preceded those burns. Therefore the size and timing of the resulting natural fires that eventually occur will be appropriate for Willmore's particular fire regime.

Traditional fire management approaches involve suppression, and then later planning prescribed burns across the landscape to reintroduce disturbance patterns to mimic the natural range of variation. However defining the natural range of variation is a coarse filter approach with general ranges. If the fire cycle is a couple hundred years, then it is natural for the forests to get to an old state and then undergo a large stand-replacing fire. There are no human records of the state of Willmore's forest a couple hundred years ago so we do not know the natural pattern or type of fires that occurred in these older stands. Historically, there has been human influence through burning by Aboriginal peoples. Also, the climate has varied over the last hundreds of years. A comparison of the forest patterns adjacent to Willmore is not representative since those forests are located in a different natural region and climate, and are part of a working landscape influenced by timber harvesting and other human activities. Finally, how does one define the appropriate point in time to use for emulating the natural disturbance pattern? Applying the traditional fire management approach entails intensive data collection, analysis, and human manipulation that are not appropriate to management within this protected area.

Therefore the project team chose to embark on a significant deviation from traditional fire management thinking. This deviated approach uses prescribed fire to delineate a natural fire zone where natural fires may be allowed to re-establish on the landscape if, where, and when they occur. In this way, nature maintains natural fire patterns on the landscape instead of the process being human-driven. The philosophical shift, towards minimizing fire suppression and human manipulation so that nature can run its course, requires a policy shift within SRD. SRD's current mandate to manage fires means that suppression has been the policy direction in the Willmore. However, allowing natural fires enables the benefits of fire and reduces the demand for fire suppression resources, which is beneficial for both departments as well as the ecology of Willmore Wilderness Park. 


\section{BIOPHYSICAL DESCRIPTION}

Capturing portions of four natural subregions, Willmore contains a wide variety of landscapes and landforms, geology, hydrology, elevations, climate, soils, flora, fauna and historical/cultural resources.

\section{a. Location/Access}

Willmore Wilderness Park is located on the western border of Alberta near the top of the range of Canadian Rocky Mountains (Figure 1). Willmore is bordered by British Columbia to the west, Jasper National Park to the south, Kakwa Wildland Provincial Park to the north, forested provincial crown land along the east and Rock Lake-Solomon Creek Wildland Provincial Park in the bottom southeast corner. It is located within the Eastern Slopes area, referring to the eastern slopes of the mountain ranges running down the southwest border of Alberta. Willmore is approximately $400 \mathrm{~km}$ northwest of the capital city of Edmonton. The Town of Grande Cache is adjacent to the Park in the northeast. Willmore is accessed from Highway 40 (to Grande Cache), which intersects Highway 16 (from Edmonton to Jasper) west of Hinton.

There are 4 main access points: Rock Lake Provincial Recreation Area (PRA); Berland staging area near the Big Berland PRA; Cowlick staging area; and Sulphur Gates PRA. These access points may contain basic parking, camping and equestrian facilities. Other informal access points likely exist. Backcountry trails enter from Rock LakeSolomon Creek Wildland Park, Kakwa Wildland Park, Jasper National Park and British Columbia.

\section{b. Natural Regions/Subregions}

Alberta is divided into six natural regions, each with a subset of subregions. The majority of Willmore Wilderness Park is located in the Rocky Mountain Natural Region, providing representation of the Montane, Sub-Alpine and Alpine Subregions; as well as capturing a portion of Upper Foothills Subregion in the Foothills Natural Region (Figure 2). The spectrum of subregions captured within this extensive park as well as the transitions between subregions results in a diversity of landscapes and species.

The Alpine Subregion includes all areas above treelike including vegetated areas, rockland, snowfield and glaciers. The Sub-Alpine Subregion is the most extensive in Willmore and is found below the Alpine Subregion at $1500-2000 \mathrm{~m}$. The Upper Foothills Subregion is at lower elevations below $1500 \mathrm{~m}$. A long, narrow strip of Upper Foothills Subregion transects the Willmore from Grande Cache along the Smoky River south to Jasper National Park. A small piece of Montane Subregion also extends into Willmore from Grande Cache along the Lower Smoky River. 
Figure 2: Natural Regions/Subregions

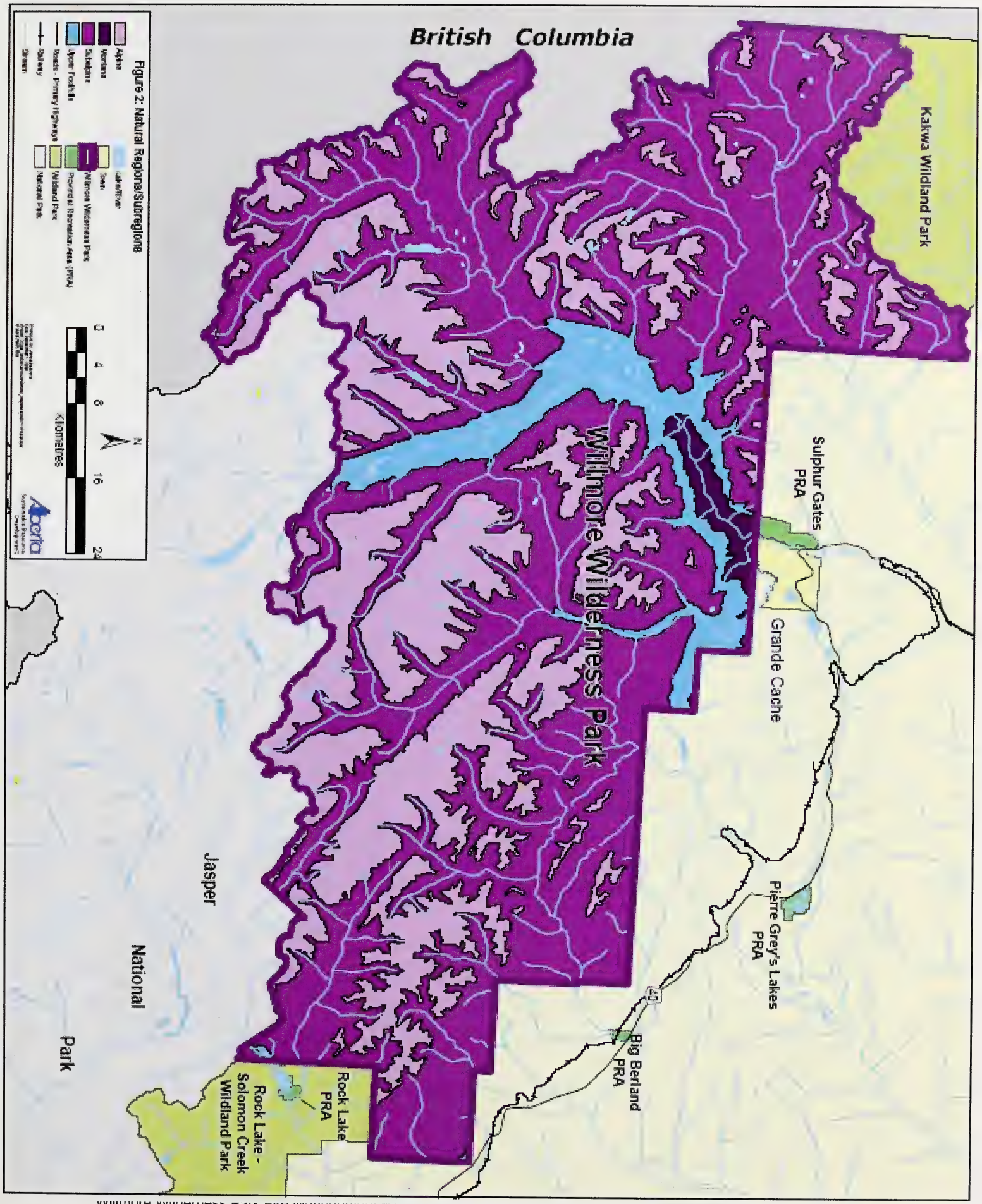

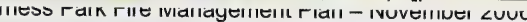




\section{c. Geology/Landforms ${ }^{3}$}

Willmore Wilderness Park contains two physiographic units: the Rocky Mountains and the Foothills units (Figure 3), which are different than the Rocky Mountain and Foothills Natural Regions. The geologic Foothills unit underlies the Upper Foothills, Sub-Alpine and Alpine Subregions, while only the Sub-Alpine and Alpine Subregions overlay the geologic Rocky Mountains unit. Elevation within Willmore increases from $300 \mathrm{~m}$ in the northeast to over $3000 \mathrm{~m}$ in the south.

The Rocky Mountain Unit is divided into the Front Ranges to the east and the Main Range along the Continental divide (defining the Alberta-BC border) as well as part of the Hart Range in the northwestern portion of Willmore. The structure of the Rocky Mountains unit ranges from fairly subdued mountains with rounded summits in the more northerly and easterly sections to high craggy summits with evidence of glaciations in the more westerly and southerly areas. Glacial features include cols, arêtes, cirques, hanging valleys, horns, tarns and U-shaped valleys. Glaciers are more common in the Main Ranges and morainal, colluvial glaciofluvial and bedrock deposits dominate the landscape. The Main Ranges are generally non-linear with individual or clustered peaks of increasing elevation from east to west. Main Range bedrock consists of intensely folded Mesozoic and Proterzoic strata. The Front Ranges are characterized by a northwest-southeast trend of the ranges with parallel valleys. Bedrock shows a general southwest dip with long, smooth slopes and steep, precipitous slopes to the northwest.

The Foothills unit is of moderate to high relief and separates the Rocky Mountain unit from the subdued topography of the unit outside Willmore. The Foothills consist of a series of nearly parallel razorback ridges aligned northwest to southeast. Bedrock is a folded Cretaceous and Tertiary stratum blanketed by regional and local Cordilleran and Mountain till. Colluvial material is present as aprons, blankets and veneers with fluvial deposits from the numerous watercourses. Glaciofluvial material is present in melt water channels and terraced along major watercourses with eolian veneers in some areas.

Surface deposits affect the development of soils and plant communities and are a major determinant of ecosystem structure and productivity. The variety of surface deposits found in Willmore includes residual material, colluvial material, morainal material, glaciofluvial deposits, fluvial deposits, fluviolacustrine deposits, glaciolacustrine deposits, eolian deposits, and organic deposits.

Materials in the Alpine Subregion are generally residual bedrock and colluvium and often found on steep slopes with extensive areas of unvegetated bedrock. Morainal materials occupy much of the Sub-Alpine Subregion with colluvial and residual bedrock materials frequently at higher elevations. Fluvial and glaciofluvial deposits are common along stream valleys, with lesser amounts of glaciolacustrine and aeolian materials. In the montaine, the landforms of the major valleys are primarily fluvial and glaciofluvial terraces and fans with smaller areas of glaciolacustrine, aeolian and morainal deposits. The Upper Foothills Subregion has frequent bedrock outcrops of marine shale and nonmarine sandstone, and morainal deposits are common over bedrock throughout much of the area, although colluvium and residuum occur on steeper terrain.

\footnotetext{
${ }^{3}$ Dumanski et al 1997; Twardy and Corns 1980; Taylor 1982; Walker et al 1982
} 
Figure 3: Geology / Landforms

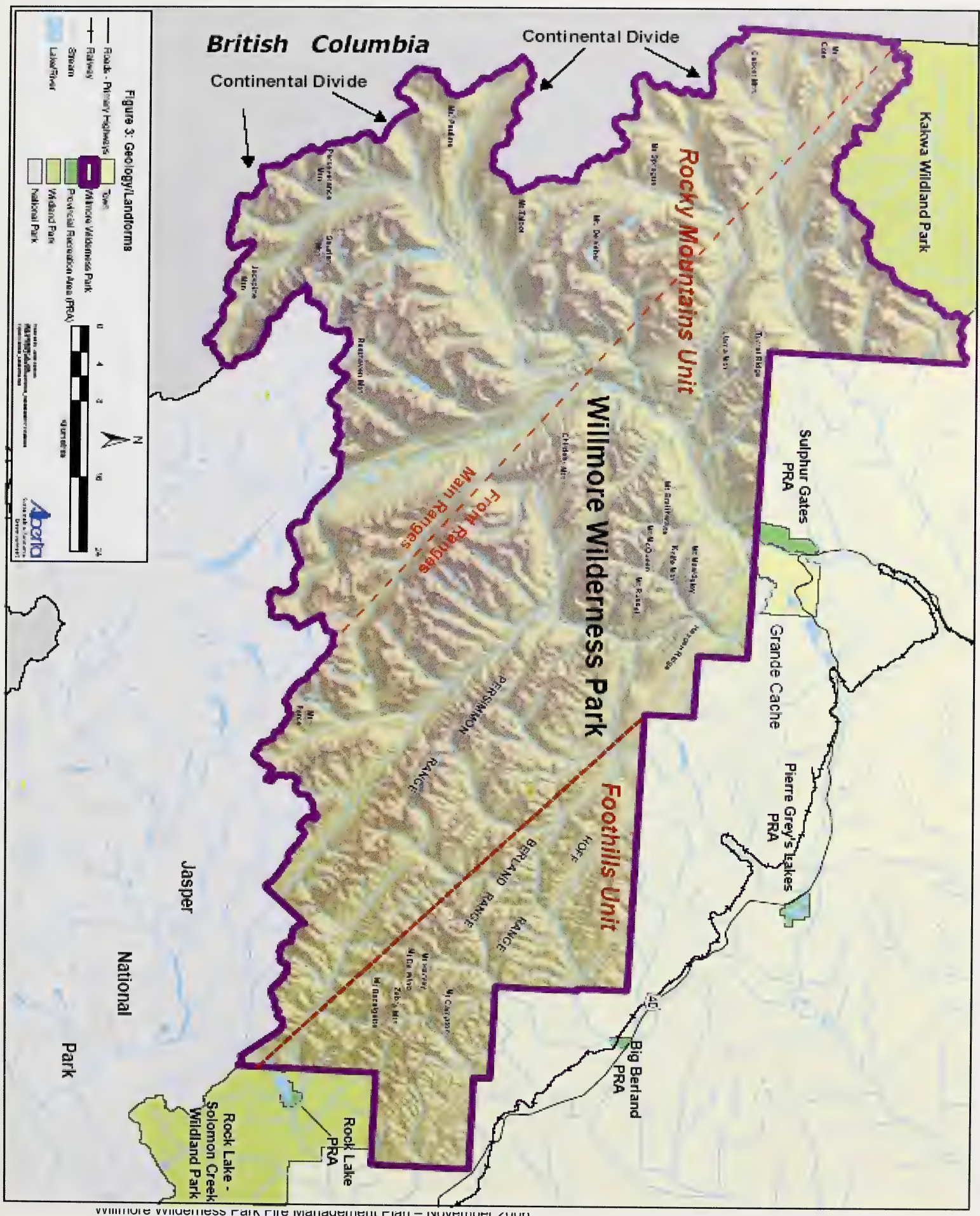

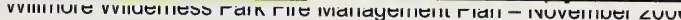


Figure 4: Hydrology

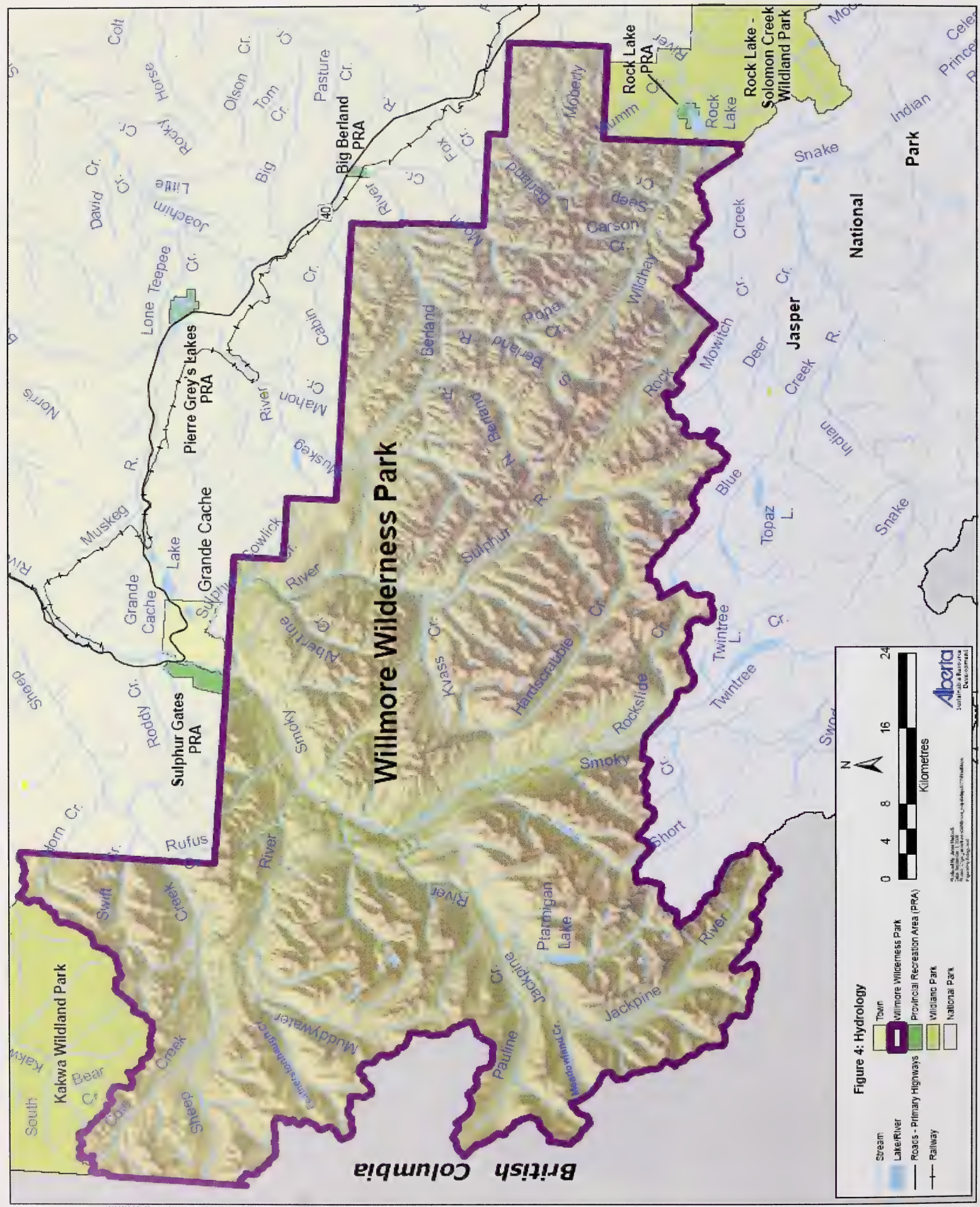




\section{d. Hydrology 4}

The headwaters of Willmore's major rivers, along the southern and western boundaries have broad grassy flats across valley bottoms with sub-alpine forests dominating the slopes and growing down to the river banks in lower, well-drained valleys. Major rivers within Willmore include the Smoky, Berland, Wildhay, Sulphur, Jackpine and Muddywater with all but the Smoky originating within Willmore (Figure 4). Several tributaries feed into the rivers. The forested slopes are often increasingly wet towards the bottom where the forests open into wetlands. High volumes of water are trapped in permanent snowpack and within glaciers that are present on some of the high mountains, such as the formidable Resthaven Glacier spanning the boundary between Willmore and Jasper.

\section{e. Soils ${ }^{5}$}

Willmore Wilderness Park contains a variety of soils, which vary across the subregions (Figure 2). Much of the Alpine Subregion has no soil because the amount of weathered material is too thin to qualify as a soil. Whereas, in the sub-alpine, soils vary widely reflecting the great diversity in parent materials and ecological conditions. Brunisolics and Luvisolics occur commonly under a wide variety of conditions. Regosolics occur on colluvial slopes and active fluvial landforms. Podzolics are mainly in upper elevation, moist sites under spruce-fir forests. Cryosolics are in the Front Ranges. Gleysolics and Organics occur on wet sites on a variety of materials. Soils also vary greatly in the montane due to the complex topographic and climatic conditions in this subregion. Soils under grasslands are mostly Chernozemics, Brunisolics and Regosolics. Forest soils include Brunisolics and Luvisolics. In the Upper Foothills Subregion, soils of upland sites are typically Luvisolics and Brunisolics with Gleysolics and Organics in wet sites.

The Brunisols, including the Dystric, Sombric, Melanic and Eutric Great Groups, are found in Willmore. They are generally associated with non-forest vegetation especially alpine vegetation and grasslands. They vary widely in their characteristics and therefore in their response to burning. Repeated burning on these soils, particularly under grass and shrub cover, may reduce site fertility, plant growth and plant community structure.

Only Gray Luvisols are found in Willmore and are common on morainal and colluvial deposits under coniferous forest vegetation, particularly lodgepole pine. Generally, Luvisols may be more resilient to the impacts of burning than Brunisols, although repeated burning may have the same impact as with the Brunisols.

Podzolic soils are only found in moist and cool environments of the Sub-Alpine and Alpine Subregions. Orthic Humo-Ferric Podzols are most common at medium elevations under sub-alpine fir-Englemann spruce forest cover. At increasing elevations Orthic Ferro-Humic Podzols occur under moderately drained higher elevation forests. Orthic Humo-Ferric and Sombric Ferro-Humic Podzols are occasionally found in tree line and alpine areas. Burning of Ferro-Humic Podzols may temporarily elevate soil nutrients resulting in translocation of phosphorous deeper where it is less available for plants ${ }^{6}$.

\footnotetext{
${ }^{4} \mathrm{CD}, 2001$

${ }^{5}$ Negrave 2005

${ }^{6}$ Cade-Munum et al 2000
} 
Cryosol soils are frozen within $2 \mathrm{~m}$ or even within $50 \mathrm{~cm}$ of the surface and found in the coldest areas of the upper sub-alpine and alpine areas, typically on morainal deposits. Turbic Cryosols are common in alpine areas. Static Cryosols are the most abundant and support forest growth. Organic Cryosols typically form under sphagnum moss or heath at high elevations. Cryosols are often poorly drained and unlikely to support deep-burning fires except when fire weather indices are extreme. Intense fires on northerly forested slopes with Static Cryosols may induce temporary thawing and slope failure.

Regosols are common in mountain environments such as in Willmore. These soils are often associated with Brunisols and typically found in riparian areas or near larger watercourses, in alpine areas, and on active slopes and toe-slopes. Humic Regosols are characteristic of alpine and upper sub-alpine grasslands. Cumulic variants of Regosols are found near watercourses with flood events, or the base of slopes with landslides. Regosolic soils should be considered sensitive to burning due to limited development and low nutrient capital associated with low organic matter content. Upslope areas with tree island and krummholtz vegetation between closed forests and non-vegetated ridges are likely the most sensitive. The combination of Regosolic soils and upslope position, which would be exposed to intense pre-heating from the advancing fire, may lead to near-complete loss of vegetation cover and soil humus and a return to near primary succession conditions. This occurrence has been observed on flights over Willmore.

Organic soils in Willmore are derived from wetland vegetation with Organic fen soils derived from sedges and brown mosses, and Organic bog soils from sphagnum mosses. In Willmore, most fens succeed to open or closed forest while bogs remain open. Most Organic soils in Willmore are Terric Mesisols. Although Organic soils are typically saturated, surface layers do dry out and can support surface fires with a high potential for holdovers at greater Drought Code values. Post-fire succession may be quite slow on sites with Organic soils.

In general, soils in the Foothills geologic unit are dominated by Orthic Gray Luvisols as well as Brunisolic and Podzolic Gray Luvisols on modest slopes with medium to fine textured material. Podzols are found on cool, northerly slopes and areas with an eolian veneer. In the Rocky Mountain geologic unit Eluviated Dystric and Eluviated Eutric Brunisols developed on till and colluvial landscapes predominate on areas supporting forests. Podzols are found on cool, northerly slopes, areas with an eolian veneer and some alpine areas. Cryosols and Regosols dominate the soil landscape above tree line.

\section{f. Climate ${ }^{7}$}

Information on the climate of Willmore is sparse. Due to the size of the Park, diversity of landscapes and changes in altitude, the weather can be expected to vary considerable throughout the Park. Temperatures vary throughout the subregions (Figure 2). The Alpine Subregion is generally the coldest subregion year round with no frost-free period. Greater windspeed redistributes the snow and increases the cooling rates. In the SubAlpine, temperatures are usually moderate, below freezing temperatures occur in all months and winter precipitation is higher than in the other subregions. Temperatures are a bit warmer in the montane and chinooks are characteristic so it may be intermittently snow-free in the winter. The Upper Foothills Subregion generally experiences the highest summer precipitation with July being the wettest month, and there is likely a

\footnotetext{
${ }^{7}$ Holland et al 1982; Achuff 1994, CD 2001
} 
moisture surplus during the growing season. Changes in Willmore's climate are expected due to climate change trends.

In general, the weather is characterized by long, cold winters and short cool, wet summers. Mean temperature in January is approximately $-11 \mathrm{C}$, and approximately $10 \mathrm{C}$ in July, however summer temperatures can be quite hot and winter temperatures much colder. Average precipitation (rain/snow) is $450 \mathrm{~mm}$ (10 year average of $246-635 \mathrm{~mm}$ for April 1-October 31) with more precipitation on the westerly or northwesterly windward slopes compared to the east leeward slopes. The frost-free period is about 30 days, but frost is possible in every month. A lightning shadow along the west ranges limits lightning occurrence but lightning occurrence increases towards the eastern boundary.

Topography modifies the prevailing weather patterns which trend from the west. The general northwest to southeast orientation of valleys and drainages tends to channel lower altitude winds along these features. Valleys oriented parallel to the prevailing wind direction tend to experience high wind speeds while perpendicular valleys tend to reduce wind speeds resulting in a complex pattern and layering of wind flows in the Willmore.

\section{g. Vegetation/Flora ${ }^{8}$}

A diversity of plant communities is supported due to the various Rocky Mountain and Foothills Subregions (Figure 2), and the range of elevations, slope, temperature, and precipitation.

\section{Alpine}

The Alpine Subregion lies above tree line over $2000 \mathrm{~m}$ in elevation. Alpine vegetation typically forms a complex, fine-scale mosaic in which microclimatic variations are reflected by marked changes in dominant species. Significant environmental factors include aspect, wind exposures, time of snow melt, soil moisture and snow depth. Poorly developed soil, cool temperatures, very short growing season and temperature extremes limit vegetation productivity. The non-forested alpine area consists primarily of upland sedges, alpine grasses, moss, lichen, and dwarf shrubs and may include species such as heathers, mountain avens, and moss campion. Diverse, colourful herb meadows occur in moist sites below melting snow banks or along streams. Highest elevation communities are composed mainly of lichens on rocks and shallow soil.

\section{Sub-Alpine}

The various microclimates of the mountain slopes, valleys and ridges influence the vegetation in the Sub-Alpine Subregion (1500-2000m). This subregion is often divided into the lower subalpine characterized by closed forests of lodgepole pine, Engelmann spruce (or introgressive hybrid with white spruce) and sub-alpine fir, and an upper subalpine with spruce (mainly Engelmann)/fir closed forests and open forests near tree line. Forests dominated by Lodgepole pine occur on the south, east and west facing aspects, particularly where disturbance (e.g. fire) is high. Engelmann spruce, hybrid spruce and sub-alpine fir dominate north aspects and moist west and east slopes with low fire frequency. The understory consists of a diverse variety of vegetation. Some typical understory species in the Engelmann spruce/sub-alpine fir forests include false azalea, white-flowered rhododendron, huckleberry, dwarf bramble and partridgefoot. High elevation grasslands are found mostly on steep, southerly and westerly aspects in the Front Ranges. Depressional areas with poor drainage are dominated by black spruce

\footnotetext{
${ }^{8} \mathrm{CD}, 2001$; personal communication-Ksenija Vujnovic (PPA/CD); Negrave, 2005
} 
bogs, fens and shrub lands. Snow avalanche paths also create a diverse mix of shrubby and herbaceous communities.

\section{Montane}

The montane landscape is characterized by a pattern of open forests and grasslands. Characteristics tree species include Douglas fir and white spruce. Understory vegetation includes, grasses, sedges, shrubs as well as other plants. Grassland may also occur.

\section{Upper Foothills}

Upland forests of the Upper Foothills Subregion are mainly coniferous and dominated by lodgepole pine, with some white spruce in moister areas lacking fire such as coulees, north aspects and depressional areas. Deciduous tree cover and understory species cover are higher than in the Sub-Alpine Subregion due to the warmer climate. Understory contains various bushes and other plants, and a well developed moss layer dominated by either feathermosses, or peat and brown mosses, depending on if the site is dry or wet.

\section{Rare Plant Species and Communities}

Willmore Wilderness Park contains numerous vascular and non-vascular plants that are rare in a provincial context, and over sixty have been documented so far. These include various vascular plants (e.g. whitebark pine, mountain currant, one-headed everlasting, trifid-leaved fleabane, alpine harebell, northern rough fescue, two-parted sedge), moss species (e.g. alpine broom moss, Blytt's fork moss, neat bog moss, Lindberg's bog moss, Porsild's bryum), and lichen species (e.g. Cladonia bellidiflora, C. bacilliformis, C. squamosa). Two provincially rare rough fescue communities (tufted hair grass, and hairy rye grass) are found within Willmore. Many more plant species and communities are likely to be discovered and inventorying will be an ongoing process.

Mosses are an important component of the Rocky Mountain ecosystems. More than $70 \%$ of Alberta's moss flora is found in the northern Rockies, including Willmore Wilderness Park. Haller's applemoss, listed under the federal Species at Risk Act (SARA), is found in Jasper National Park and several valleys within Willmore have high potential for supporting this species. Porsild's bryum, listed as threatened by the Committee on the Status of Endangered Wildlife in Canada (COSEWIC) and awaiting designation under SARA, has recently been discovered within Willmore Wilderness Park and additional sites likely exist. Unique landscapes, such as lower subalpine treed cliffs found hidden in the forests, support various rare moss and vascular plant species.

Significant populations of whitebark pine, a species of concern, have been found in Willmore. Unfortunately these pine are also been attacked by MPB. An inventory of the whitebark pine needs to be completed, along with ground checks to determine their health and to collect cones. The potential impacts of fire need to be considered.

\section{h. Wildlife/Fauna ${ }^{9}$}

A variety of species occur within and across the subregions in Willmore (Figure 2). Diversity varies across Willmore depending on the subregion and habitat makeup. Species found in Willmore include grizzly bear, black bear, cougar, wolves, wolverines, lynx, and coyote as well as numerous small fur-bearers such as marten and squirrel.

\footnotetext{
${ }^{9} \mathrm{CD}, 2001$; personal communication-Jeff Kneteman \& Rudy Hawryluk (F\&W/SRD), Ksenija Vujnovic (PPA/CD)
} 
Wolverines are a species of special concern (COSEWIC) and potentially threatened. Willmore may protect some of the best wolverine habitat in Alberta.

Scattered grasslands on exposed south-facing slopes in the sub-alpine, alpine and montane provide ungulate habitat. Large ungulate species include the woodland caribou, moose, elk, bighorn sheep, mountain goats, mule deer and white-tailed deer. The threatened woodland caribou are of particular concern in Alberta due to habitat threats outside Willmore and declining numbers. Due to impacts on habitat outside Willmore, the A la Peche herd relies on the Willmore for its year round habitat and survival. They range south and east of the Smoky River, and south of the Jackpine River. The Red Rock - Prairie Creek herd range is north of the Jackpine River, north and west of the Smoky River, and in the winter are along the Kakwa River drainage in the adjacent Kakwa Wildland Park. Further understanding of how the caribou use the Willmore and react to fire will be important in determining how to manage caribou within the Fire Management Plan objectives. Fire suppression in caribou habitat affects the natural fire cycle for forest regeneration and set the stage for a catastrophic fire that could have a significant impact on their habitat and lichen, which is one of their food sources.

Many boreal, foothill and mountain bird species populate Willmore. The Clark's nutcracker plays an important role in propagation of the threatened whitebark pine by burying/eating the pinecones. Past and current monitoring in Willmore of the sensitive Harlequin duck has identified several provincially important streams as well as the locations of pairs in the spring. This information provides a benchmark for assessing response to fire, as well as trends due to industrial disturbance outside Willmore and regional weather patterns.

Fish species in Willmore include: arctic grayling, mountain whitefish, brook trout cutthroat trout, burbot, long-nose and white suckers, several cyprinids, and the threatened bull trout. Fish populations in Willmore are relatively low. Most rivers, streams and lakes have low productivity due to cold temperatures, low nutrient levels and a meagre food supply. Stream channels are often extensively braided with limited bank cover and few deep pools. Fast flowing mountain streams with shallow headwaters are unsuitable winter habitat. The growth rates of fish are relatively slow due to the cold water, limited nutrients and short growing season.

The wildlife of Willmore provides opportunities for wildlife viewing and photography, as well as hunting, fishing and trapping in remote but accessible wilderness. There are also valuable opportunities through inventorying and research to observe wildlife species and behaviour in a large wilderness landscape.

\section{i. Historical/Cultural Resources ${ }^{10}$}

The region was historically utilized by the Aboriginal people, trappers, hunters and resource prospectors. Archaeological finds have provided evidence that Willmore was inhabited by Aboriginal people as early as 10000 years ago. Following the annual migration of big game herds of Buffalo and Rocky Mountain Bighorn Sheep they travelled between the high mountain meadows in the summer to the protected lower slopes and valleys in the winter.

${ }^{10}$ CD, 2001; Willmore Wilderness Park map, ISBN 0-7785-0003-9. Pub No. I/670, May 2003. 
Europeans arrived with the fur trade and established Grande Cache. A network of trails created in Willmore to support the trading activities amongst the trading posts forms the basis for the existing trail system (Figure 5). Approximately 750 kilometres of trails in Willmore provide access along all of the major eastern valleys and connect the valleys via high mountain passes. The western portion of the park is rugged and access is difficult, therefore trails in this area require several days of travel and are less used.

Historical remnants of the trapping and defunct mining days still exist as old cabins or rotting timber frames, and pieces of equipment. Curly Phillips, a famous Jasper outfitter once had a cabin near Ptarmigan Lake. The Pope Thoreau site belonged to the Blue Diamond Coal Company and contains three old mining cabins and a forestry cabin. Additional mining cabins and an old steam tractor are located nearby at Carson Creek. Historic forestry patrol cabins are still maintained for patrols or in case of emergency.

Locations are named after different people who played a role in the Willmore area. Clark's crossing on the Smoky River is named after Stan Clark who worked for the Canadian Forestry Service and became superintendent of the Rocky Mountain Reserve in 1912. Washy Creek was named after Washy Joe, a member of the Alexis band, trapper and rancher, who saved Vincent Wanyandie's life. Adams Creek is named after Washy's son Adam who was a trapper at Muskeg. Adam's lookout (constructed in 1941) was named after Adam Agnes, an early Aboriginal pioneer.

Gravesites also capture some of Willmore's human history. Kvass Flats is named after Norwegian trapper Fred Kvass who lived and is buried there. Pierre Delorme is buried at Big Graves at the base of Sheep Mountain. Pierre's granddaughter (younger sister to Louis Delorme, one of the most prominent Aboriginal leaders in the region) is buried at Kvass Flats at Little Graves. Other known gravesites include Dolphus Agnes (daughter of Washy Joe) and Madelaine Fraser (mother of Adam Joachim, a local trapper, prospector, guide and spiritual leader who was respected for his honesty and integrity) along the Berland River, baby Delorme and Thappe (member of Beaver tribe from northwest of Grande Cache) on the Sulphur River, and George Hargreaves (outfitter) by Casket Creek.

\section{j. Recreation}

The area was historically utilized for extraction of its natural resources and now these resources sustain a variety of recreational activities. Current development is limited to primitive facilities appropriate to a wilderness experience, such as rugged, undeveloped trails and primitive random backcountry campsites. The current network of trails, originally developed to provide travel routes for trading, is now used for recreational access into the backcountry of Willmore (Figure 5). These wilderness trails vary in difficult, and are sometimes obscure and not easily identifiable on the ground.

Willmore is used for recreational activities such as backcountry hiking, mountain biking, trail riding and hunting. It also supports commercial trail riding operations, commercial outfitters, and trappers. There are no roads within Wilmore and recreational motorized use is prohibited. The Willmore Wilderness Park encompasses extensive and remote natural landscapes that provide a unique wilderness experience. These recreational activities are challenging in this remote, backcountry wilderness. Ecological management of the park to retain its wilderness aspect will enable the wilderness experience of these recreational activities to continue. 
Figure 5: Trails / Points of Interest

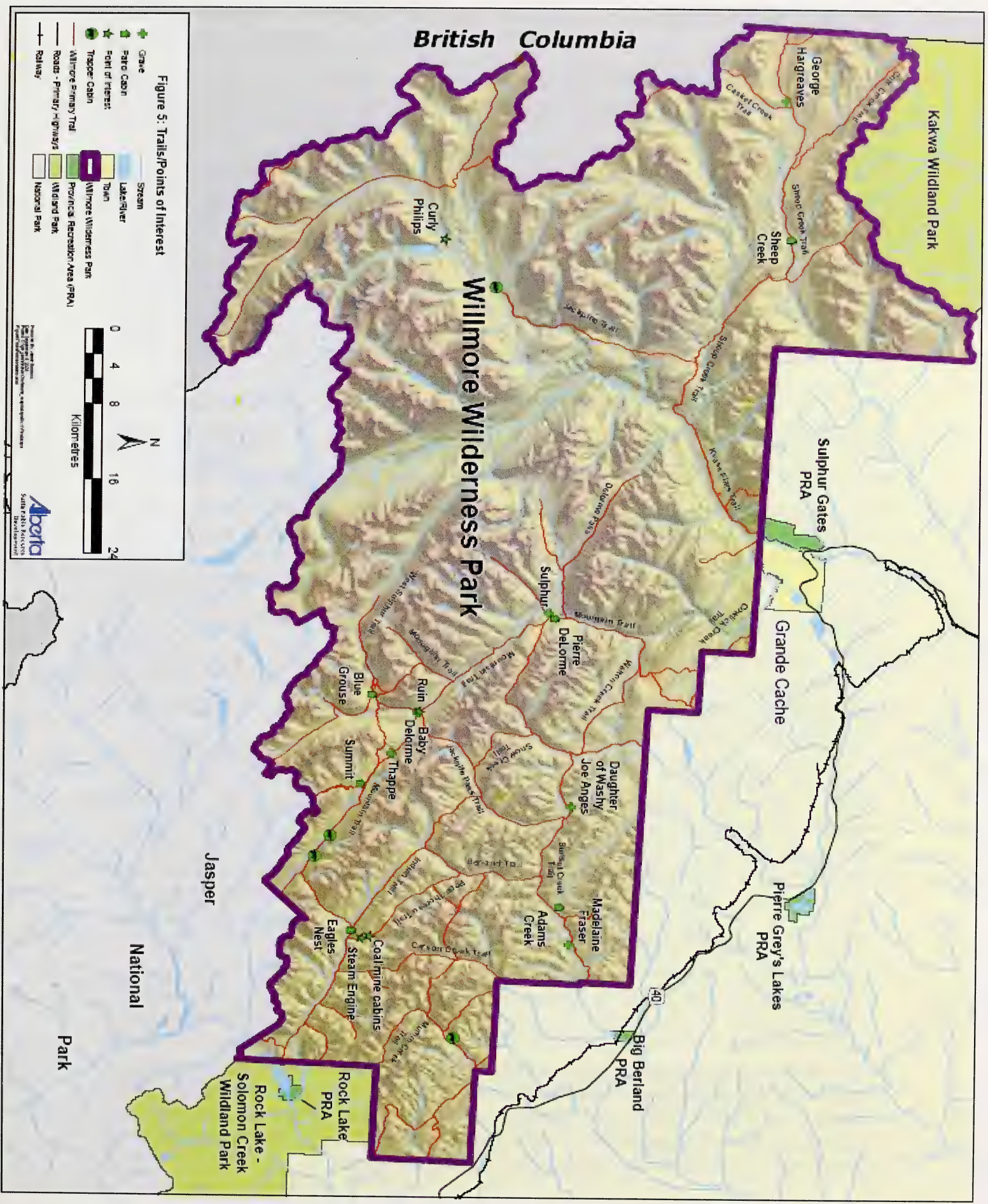

Willmore Wilderness Park Fire Management Plan - November 2006 


\section{VALUES}

The large, relatively undisturbed wilderness landscape of Willmore Wilderness Park holds a high preservation value that provides substantial ecological, social and economic benefits. The Willmore is particularly valuable due to its size, which encompasses complete ecosystems and supports undisturbed ecological functions. This preservation value will only increase as pressures on the surrounding landscape escalate and protected areas within Alberta become more important in providing balance with the development on the working landscape.

The Willmore provides both tangible and non-tangible personal, commercial and societal benefits that are gained through direct use, indirect use or even non-use. Although the value of benefits derived from the Willmore Wilderness Park have not yet been quantified it is expected that the value would be substantial, especially in terms of the preservation value due to provision of ecological benefits.

The preservation value of Willmore captures the actual ecological benefits as well as the intrinsic value of knowing that these ecological benefits are protected. A large protected area, such as Willmore provides substantial ecological benefits through its ecosystem services for water, air, soil and biodiversity:

- The Willmore contributes to provincial water quality and quantity. Watersheds are protected and the headwaters of several important rivers originate in the mountains of Willmore and flow out into the province. The water reservoir function provided by the snow and glaciers, or held by the sponge-like forests, wetlands, and lakes is important. The value of the water that is captured and cleaned within Willmore will increase, as water becomes an increasingly valuable commodity.

- The vast forests also provide carbon sequestration as well as oxygen production therefore cleansing the air and playing a role in mitigating global warming. In fact, the microclimate of Willmore likely influences and mitigates the external climatic patterns that characterize the adjacent environments.

- The soils enriched by nutrient cycling support the vegetation and habitat that in turn supports the wildlife, insects and microorganisms that constitute the biodiversity of the Willmore. This biodiversity encompasses the more common as well as the rare or endangered plants, animals, insects and microorganisms. This biodiversity provides gene sources, potential medicinal sources, educational and scientific opportunities, as well as the existence value from knowing that species are protected. Biodiversity also provides long-term resiliency for the ecosystem to cope with disturbance. Protection of habitat and species within Willmore supports national and provincial biodiversity and endangered species initiatives.

- Representation of subregions of the Rocky Mountain and Foothills Natural Regions supports provincial goals for representation within the protected areas network. Representation of these subregions also captures environmentally sensitive areas within them such as wetlands, critical wildlife habitat and unique features or species.

- The Willmore represents a significant ecological benchmark. The relatively unaltered nature of the Willmore provides research opportunities that may result in important ecological lessons that are transferable to management of the adjacent working landscape. As a benchmark it can also provide a comparison for monitoring development on the rapidly transforming working landscape. 
Social benefits includes the physical and mental health benefits, as well as historic, cultural, spiritual, intrinsic and creative benefits:

- The Willmore supports recreational backcountry activities such as hiking, horseback riding, biking, camping and hunting. These activities provide exercise, socializing and stress relief to recharge a person's well being. The opportunity for a self-supported adventure provides a sense of accomplishment, connection with nature, and the chance to escape civilization.

- The Willmore also provides people with spiritual and cultural benefits either related to specific locations that have personal significance, or through providing an overall sense of place.

- Historical locations such as coal and trappers cabins, gravesites and artifacts archive the characters and activities supported by the Willmore in a past era. This history provides educational and interpretive opportunities to enrich the experience of visitors and nearby residents.

- Willmore is significant in terms of providing intrinsic or existence value just because it exists as such a large wilderness with biodiversity and ecological integrity.

- The landscape has generated much creative value in terms of inspiring writing, drawing, painting, photography and other artistic endeavours either for income or personal exploration.

- The quality of life of adjacent communities and residents is influenced by their proximity to the Willmore. The Willmore influences the aesthetics and viewscapes, recreational opportunities, commercial opportunities and even the climate and environment of their location.

Finally, the Willmore provides direct and indirect economic benefits in terms of supporting commercial recreation and tourism operations, as well as community businesses and livelihoods both within and outside:

- Commercial trail riding operators and commercial hunting outfitters provide the expertise and resources for trips into the Willmore. It is however the wilderness values of the Willmore that entice their clients into investing in the trip.

- Tourism services and other service industries in the adjacent communities, as well as further away, also benefit from the purchases of visitors. Visitors to the Willmore must purchase food, accommodations, equipment, petrol and other supplies in order to complete their trip. The cost and time invested in traveling, preparing and participating on a trip into the Willmore is likely substantial.

- Non-recreational commercial incomes such as trapping are also supported by the Willmore.

- Writers, artists or photographers may earn income by selling the products that are inspired by a trip into the Willmore.

The economic, social and ecological benefits derived from the preservation value of the Willmore Wilderness Park are substantial and merit careful management of this unique wilderness area to maintain that value in perpetuity. The Willmore Wilderness Park is not only a valuable protected area in Alberta's network, but an important piece of natural capital in Alberta. 


\section{LEGISLATION \& POLICY FRAMEWORK}

Willmore is administered by the Alberta Government under provisions of the Willmore Wilderness Park Act. The Act defines park boundaries, sets management goals and provides the Lieutenant Governor in Council with the authority to change park boundaries and implement regulations relating to use of the Park. The Willmore Wilderness Park Act allows for regulations that may draw on or make inapplicable any of the provisions and regulations of the Public Lands Act, Forests Act, Wildlife Act or any Act or regulations relating to prevention or suppression of fire, removal or destruction of forest growth, prevention of soil erosion or conservation of water.

The Willmore Wilderness Act was amended in October 1995 to preclude issuing of dispositions under the Public Lands and Mines and Minerals Act as well as preclude issuing of timber dispositions under the Forests Act. Therefore, all mineral exploration, industrial activity and commercial timber harvesting is prohibited within the Park. The Policy for Resource Management of the Eastern Slopes (revised 1984) delineates most of the park as Prime Protection Zone therefore also deeming mineral exploration incompatible. The Forest Land Use and Management Regulations (1976) under the Forests Act provide authority to restrict motorized vehicle use, provide protection for natural resources and prohibit erecting structures (other than tents). Motorized vehicle may be permitted for rescue, fire or management purposes. Under the Federal Aeronautics Act, a 1966 order prohibits the taking off or landing of aircraft in the Park without permission. Water bodies within the Willmore are subject to Federal Legislation. All motorized boat use on the Smoky and Berland Rivers was prohibited through a 1978 order of the Canada Shipping Act that amended the boating restriction regulations.

Commercial trail riding, guiding and outfitting operations as well as trapping continue to be permitted in Willmore. Community Development issues permits for the commercial trail riding. Fish and Wildlife Division (SRD) issue trapper licences, set fur quotas and regulations. $C D$ issues authorization for trapline access and trappers cabins. Permits are not currently required for the commercial hunting outfitters, although their clients are required to have hunting licences and permits. Recreational hiking, biking and equestrian use is allowed and no permitting system for these activities currently exists. Relevant provincial policies relating to various management activities and issues will apply.

The Forest and Prairie Protection Act states that Sustainable Resource Development (SRD) is responsible for fire suppression and prevention in the Forest Protection Area, which includes the Willmore Wilderness Park. Provincial SRD policy currently mandates that all fires be suppressed within the Willmore Wilderness Park. Modification of the policy will be needed to fully realize the recommendations of this Fire Management Plan. 


\section{FIRE HISTORY}

Fire regime and fire history information is an essential component in describing the role that fire plays in forested ecosystems. This information contributes to an understanding of disturbance patterns and processes. A fire regime is defined as "the kind of fire activity or pattern of fires that generally characterize a given area"11. It is derived from the fire history including: fire frequency, fire cycle, fire type, fire size, fire season, fire severity and fire intensity, of fires that occur in a given area (e.g. natural region or subregion). Evaluating these given characteristics provides necessary information to support various aspects of forest protection and fire management strategies.

Data on Willmore's fire history is relatively recent however fire on the landscape is evident in the fire patterns seen on the ground, as well as through historic photos and anecdotal information. Historically there was also aboriginal influence on the landscape. Fire history data collection in the Rocky Mountains (including Willmore) comes mainly from wildfire records collected over the relatively short period of time since 1961 . Relevant information from these studies may be applied to guide short term fire management planning. The provincial database consists of point source locations of all reported fires in Alberta from 1961 to 2004 and includes a large number of attributes related to the burning period. The database also contains historical spatial wildfire information for large fires (Class E>200 ha) from 1930. This database was used primarily to describe the spatial and temporal patterns of fire occurrence in Willmore. A number of fire regime parameters were evaluated including: fire frequency, cycle, type, size, season and intensity. The following analysis of the database from 1961-2004 was completed prior to two large wildfires, which occurred in the summer of 2006 . Therefore the two wildfires are noted but not included in the detailed analysis that follows.

\subsection{Fire Frequency}

Fire frequency is the number of fires that occur over a period of time. In the 43 year period prior to 2006, a total of 40 fires had occurred in the Willmore Wilderness Park, burning 4354.59 hectares of forested land (Table 1). In the summer of 2006 two wildfires in the west part of the park burned an additional 6300 and 14554 hectares. Geographic differences in wildfire occurrence and burned area are related to regional differences in climate, topography, and fuel type. In the Rocky Mountain Natural Region, wildfires are uncommon and limited in size due to these factors. Fire frequency has been variable over each year from 1960 to 2004, ranging from zero to five fires per year. Relatively few fires have been recorded, which may be attributed to less rigorous fire tracking. Since the provincial database was initiated in 1961, fire records and tracking have improved. The yearly fire statistics demonstrate the wide variation in number of fires and area burned each year. The most fires on record occurred in 1992 (5 of the 6 fires for that decade), but accounted for only $0.01 \%$ of the total area burned during the 43-year period. In Table 1, the total area burned in each time period is mainly attributed to a few large fires.

\footnotetext{
${ }^{11}$ Merrill and Alexander, 1987
} 
Table 1: Temporal fire distribution in Willmore Wilderness Park 1961-2004 (2006)

\begin{tabular}{lll}
\hline Period & Count & Area Burned (ha) \\
\hline $2000-2004$ & 4 & 1797.03 \\
$1990-1999$ & 6 & 0.7 \\
$1980-1989$ & 10 & 1881.04 \\
$1970-1979$ & 14 & 600.12 \\
$1961-1969$ & 6 & 75.7 \\
Total & 40 & 4354.59 \\
\hline 2006 & 2 & 20854 \\
TOTAL & $\mathbf{4 2}$ & $\mathbf{2 5 2 0 8 . 5 9}$ \\
\hline
\end{tabular}

\subsection{Fire Cycle}

Fire cycle is the number of years required to burn over an area equal to the whole area of the forest. Detailed fire cycle information is not available for the Willmore Wilderness Park and one has to look to fire cycle information from similar areas such as along the northern portion of the eastern slopes of Alberta including Banff and Jasper National Parks. Comparisons can only be made to areas in these Parks with similar subregions, forests, environments and topography. Studies have shown that each natural subregion appears to have a unique fire cycle, suggesting that fire activity is influenced at this scale. These differences can be attributed to fuels (i.e. vegetation), weather and topography. The Willmore Wilderness Park is situated in the Rocky Mountain Natural Region with representative samples of Montane, Sub-Alpine and Alpine Subregions and a small extension of Upper Foothills Subregion of the Foothills Natural Region. Willmore will have a fire cycle unique to its own combination of subregions and their associated topography, vegetation and weather.

In general, the forest fire cycle is the highest in the Montane Subregion and, as result of historical ignition probabilities and fire weather indices, it burns fairly often. Willmore only contains a small pocket of montane in the northeast around Grande Cache. The Alpine Subregion, characterized by scattered, low-growing vegetation and lack of fuels, experiences very few wildfires. The majority of Willmore is in the Sub-Alpine Subregion. The Sub-Alpine Subregion can be characterized by infrequent small wildfires and very infrequent large, high intensity wildfires. This can be attributed to cool and rainy summers, elevation, and complex topography resulting in poor burning conditions. Subregions with longer fire cycles generally have cooler, wetter climates, and less lightning activity. In the Upper Foothills Subregion, wildfires are frequent medium, or infrequent large-sized, and predominantly lightning-caused. A portion of this subregion is found along the Smoky River valley from Grande Cache to Jasper National Park.

An Alberta Vegetation Inventory (AVI), including age class data, was completed for eight representative townships throughout Willmore in 1998. The age class distribution (Figure 6) shows large areas of forest in the 80-140 and 180-200 year age ranges. These age clumpings suggest that large stand-replacing fires occur approximately every 100 years. The 180-200 year old trees, found mainly along riparian areas and north facing slopes, consist of sub-alpine fir and Engelmann spruce. The 80-140 year old trees include mostly even-aged lodgepole pine stands on south and west facing slopes that resulted 
from wildfire events in the late 1800s and early 1900s. Older trees are likely remnant islands missed by the fire. The age class distribution shows relatively little forest area in the younger age classes suggesting that there have been few recent disturbances.

A preliminary fire history study ${ }^{12}$ of the Willmore Wilderness Park was undertaken by the Foothills Model Forest program to sample valleys within the back Main (Continental) Ranges, Front Ranges and Foothills ${ }^{13}$ Ranges (Figure 3 ). It was observed that areas of high vegetation complexity occur throughout most main valleys suggesting fairly frequent wildfires. The forests of the Foothills Ranges were affected by large, recent (within past 100 years) fires, which left very few patches of residual trees. Forests of the Main Ranges are mainly of low vegetation complexity and are generally much older inferring less frequent fires (greater than 100 years) than in most of the main valleys of the Foothills and Front Ranges.

Figure 6: Age Class Distribution

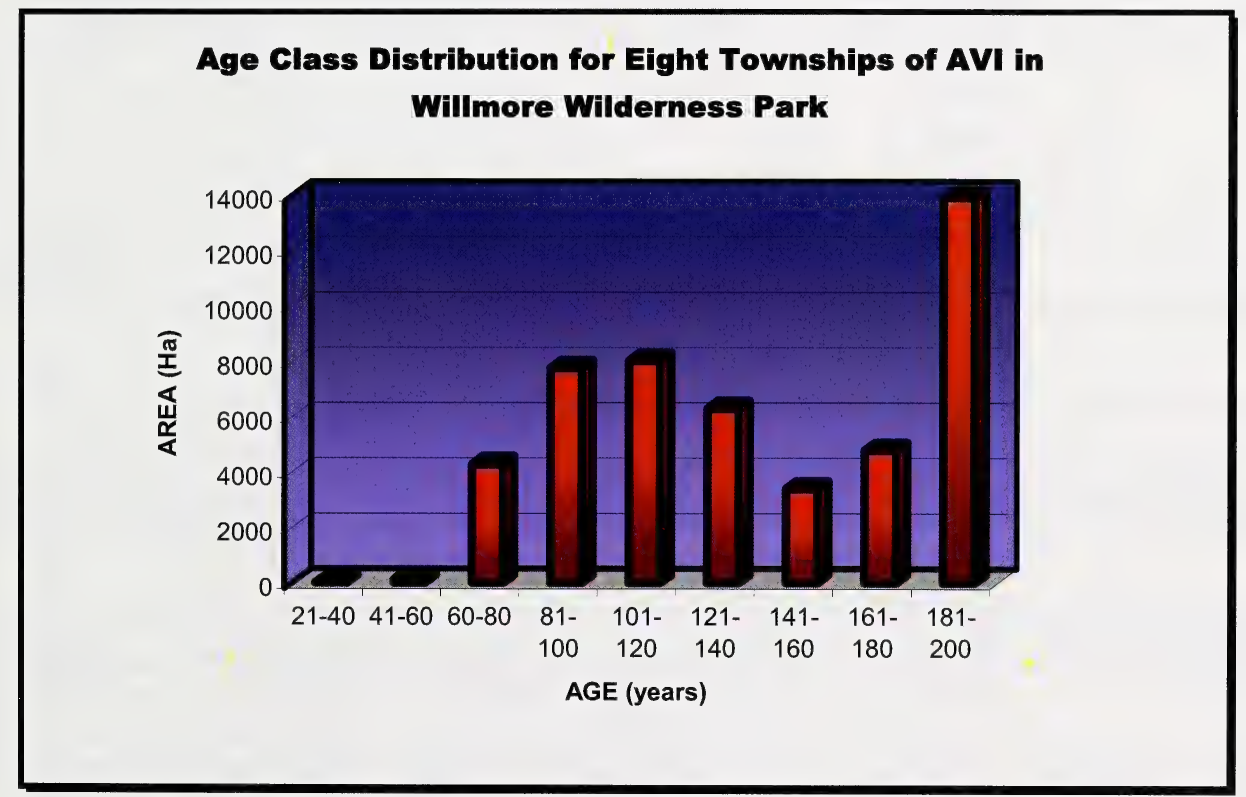

\subsection{Fire Intensity}

Fire intensity is a measurement of the rate and amount of heat released per length of flame front $(\mathrm{kW} / \mathrm{m})$. In the eastern slopes, where Willmore is located, the fire regime can be described by infrequent but high intensity fires that usually occur in August and September. Historically, large, high intensity wildfires have been wind-driven events occurring in the fall. The majority of the Willmore Wilderness Park lies within the SubAlpine Subregion and is subject to a cooler wetter climate. Longer fire cycles allow increased fuel build-up so that when warmer weather conditions occur, larger and more

\footnotetext{
${ }^{12}$ Rogeau 1999.

${ }^{13}$ Referring to geological unit, not natural region
} 
intense fires result. In areas where more frequent fires occur the intensity is reduced given the more moderate availability of fuel.

\subsection{Fire Size}

Fire history studies suggest that forest fires burned large areas of the eastern slopes during the 1889 to 1891 period $^{14}$. In the Willmore Wilderness Park, prior to 2006 there had been 40 wildfires since 1961, burning a total of 4354.59 ha. The largest fire occurred in 1987 burning 1803.61 ha, which accounted for over $40 \%$ of the total area burned from 1961-2004 (Table 2). Over $60 \%$ of the fires from 1961-2004 were small (Aclass $<0.1 \mathrm{ha})$. According to the provincial database (1930-2004) for Class $E$ ( $>200 \mathrm{ha})$ fires, there were three Class $E$ fires on record since 1961 contributing to over $92 \%$ of the total area burned and no recorded Class $E$ fires from 1931 to 1961. In the summer of 2006 two class E wildfires burned an additional 6300 and 14554 hectares.

Table 2: Temporal fire distribution in Willmore Wilderness Park 1961-2004 (2006)

\begin{tabular}{lclll}
\hline Size Class (ha) & Count \% Occurrence & Area Burned (ha) & \% Total Burned \\
\hline A $(0.01$ to 0.1$)$ & 24 & $60.00 \%$ & 0.87 & $0.02 \%$ \\
B $(0.11$ to 4.0$)$ & 7 & $17.50 \%$ & 6.15 & $0.14 \%$ \\
C $(4.1$ to 40.0$)$ & 3 & $7.50 \%$ & 27.92 & $0.64 \%$ \\
D $(40.1$ to 200.0$)$ & 3 & $7.50 \%$ & 307.16 & $7.05 \%$ \\
E $(200.1+)$ & 3 & $7.50 \%$ & 4012.49 & $92.14 \%$ \\
Total (1961-2004) & $\mathbf{4 0}$ & $\mathbf{1 0 0 . 0 0 \%}$ & $\mathbf{4 3 5 4 . 5 9}$ & $\mathbf{1 0 0 . 0 0 \%}$ \\
2006 Wildfires: E & 2 & & 20854 & \\
& & & & \\
TOTAL (1961-2006) & $\mathbf{4 2}$ & & $\mathbf{2 5 2 0 8 . 5 9}$ & \\
\hline
\end{tabular}

\subsection{Fire Type}

Fire type refers to the cause of the fire, either human-caused (anthropogenic) or ignited by lightning. The total leading cause of fire for the Willmore Wilderness Park from 19612004 was lightning, accounting for $55 \%$ of total fire occurrences and about $54 \%$ of area burned (Table 3 ). Human caused fires accounted for $45 \%$ of the total fires occurrences and about $46 \%$ of area burned. Willmore does not permit industrial activity therefore the primary source of these anthropogenic fires was recreational users who were responsible for almost $38 \%$ of total fires and over $40 \%$ of area burned. In less accessible areas of Willmore the fire occurrences are likely due to lightning.

\footnotetext{
${ }^{14}$ Tymstra et al. 2004
} 
Table 3: Classification of fire occurrence by cause and area burned in Willmore Wilderness Park 1961-2004

\begin{tabular}{lllll} 
General Causes & Count $\%$ Occurrence & Area Burned (ha) & \% Area Burned \\
\hline Lightning & 22 & $55.00 \%$ & 2367.48 & $54.37 \%$ \\
Anthropogenic & 18 & $45.00 \%$ & 1987.11 & $45.63 \%$ \\
Total & & & & \\
Detailed Causes & & $100.00 \%$ & 4354.59 & $100.00 \%$ \\
Lightning & 22 & $55.00 \%$ & 2367.48 & $54.37 \%$ \\
Recreation & 15 & $37.50 \%$ & 1806.22 & $41.48 \%$ \\
Other & 2 & $5.00 \%$ & 178.87 & $4.11 \%$ \\
Misc. Known & 1 & $2.50 \%$ & 2.02 & $0.05 \%$ \\
Resident & 0 & $0.00 \%$ & 0 & $0.00 \%$ \\
Forest Industry & 0 & $0.00 \%$ & 0 & $0.00 \%$ \\
Railroad & 0 & $0.00 \%$ & 0 & $0.00 \%$ \\
Not Used & 0 & $0.00 \%$ & 0 & $0.00 \%$ \\
Incendiary & 0 & $0.00 \%$ & 0 & $0.00 \%$ \\
Unknown & 0 & $0.00 \%$ & 0 & $0.00 \%$ \\
Total & & & & $100.00 \%$ \\
\hline
\end{tabular}

The cause of the fire also differs throughout the year (Table 4). Lightning-fires occurred from June to September, with the majority in August. Human caused fires occurred from May to November with the majority during October.

Table 4: Fire Occurrence by cause and area burned in Willmore Wilderness Park 1961-2004

\begin{tabular}{|c|c|c|c|c|c|c|}
\hline Month & Coun & $\%$ Total & $\%$ Lightning & $\%$ Anthropogenic & Area Burned (ha) & $\%$ Burned \\
\hline January & 0 & $0.00 \%$ & $0.00 \%$ & $0.00 \%$ & 0.00 & $0.00 \%$ \\
\hline February & 0 & $0.00 \%$ & $0.00 \%$ & $0.00 \%$ & 0.00 & $0.00 \%$ \\
\hline March & 0 & $0.00 \%$ & $0.00 \%$ & $0.00 \%$ & 0.00 & $0.00 \%$ \\
\hline April & 0 & $0.00 \%$ & $0.00 \%$ & $0.00 \%$ & 0.00 & $0.00 \%$ \\
\hline May & 1 & $2.50 \%$ & $0.00 \%$ & $5.56 \%$ & 0.01 & $0.00 \%$ \\
\hline June & 6 & $15.00 \%$ & $18.18 \%$ & $11.11 \%$ & 1812.49 & $41.62 \%$ \\
\hline July & 5 & $12.50 \%$ & $18.18 \%$ & $5.56 \%$ & 0.23 & $0.01 \%$ \\
\hline August & 16 & $40.00 \%$ & $59.09 \%$ & $16.67 \%$ & 566.12 & $13.00 \%$ \\
\hline September & 4 & $10.00 \%$ & $4.55 \%$ & $16.67 \%$ & 169.59 & $3.89 \%$ \\
\hline October & 7 & $17.50 \%$ & $0.00 \%$ & $38.89 \%$ & 1805.85 & $41.47 \%$ \\
\hline November & 1 & $2.50 \%$ & $0.00 \%$ & $5.56 \%$ & 0.30 & $0.01 \%$ \\
\hline December & 0 & $0.00 \%$ & $0.00 \%$ & $0.00 \%$ & 0.00 & $0.00 \%$ \\
\hline Total & 40 & $100.00 \%$ & $100.00 \%$ & $100.00 \%$ & 4354.59 & $100.00 \%$ \\
\hline
\end{tabular}




\subsection{Fire Season}

Fire season is the period of the year during which fires are most likely. The fire season varies with geographic location and helps delineate the boundaries of areas with different fire regimes. Monthly variation in wildfire distribution can be explained by land use patterns and weather. The majority of wildfires in the Willmore Wilderness Park occurred during the summer months (Table 4). The largest amount of area burned between June and October, accounting for over $80 \%$ of the total area burned from 1961 to 2004 . The assessment of fire distribution on a monthly basis revealed that $40 \%$ of the fires occurred in August. Due to lack of large fire sizes that occurred during the 1961 to 2004 period, it is difficult to ascertain the peak burning season, but June to October generally provides fire weather conditions favourable to large fires. The two large wildfires in 2006 started in late June and early July during a period of intense, hot, dry weather exacerbated by high winds.

\subsection{Suppression History}

The Alberta Forest Service assumed responsibility for suppressing wildfires in 1930 after the transfer of resources from the Federal Government. The first fire season under provincial jurisdiction began in 1931. Fire suppression would have likely been relatively ineffective during these early forest protection periods in remote areas such as the Willmore Wilderness Park. As a result natural fire regimes would not have been significantly altered.

In 1954 the Government of Alberta strengthened its fire prevention and fire suppression programs. Forest Protection became its own Branch with additional fire fighting equipment and new lookout towers to enhance the overall forest protection program. In 1969, the Forest Service re-organized, which significantly advanced Forest Protection programs providing greater efficiencies for the coordinated initial attack of fires. Since the 1960's there have been relatively few fires in Willmore. Given the current age classes of the forest, which indicate a general fire cycle greater than 100 years, it can be argued that fire suppression has not been a significant factor in shaping the current forested landscape of Willmore Wilderness Park. However, continuation of suppression with highly effective suppression resources will start to lengthen fire cycles beyond their natural range and therefore alter natural fire regimes. Large areas of forest in the park may be approaching the end of their natural fire cycles and, when weather conditions are favourable, will likely burn over the next few decades.

The two wildfires in 2006 were only suppressed on their eastern boundaries where they threatened to continue along the Sheep Creek valley out of Willmore, or along the Smoky River valley towards Grande Cache. The remainder of the perimeters on the two wildfires was monitored but not suppressed, and instead allowed to burn out naturally under the influence of topography, ecology and weather.

\subsection{Recommendation for Fire Regime Analysis}

Wildfire regime analysis contributes to the understanding of fire as an important ecological process in the forest ecosystems in Alberta. The regime analysis defines the activity and patterns of fire in a particular area by analyzing the historical data for: fire frequency, cycle, intensity, size, severity, type and season. A fire regime analysis attempts to capture common fire effects and spatial patterns to gain a sense of the variability within natural fire regimes. Traditionally it provides useful information to: improve fire and fuels management planning; identify spatial and temporal variability in 
fire occurrence across the landscape particularly to identify areas with a high probability of burning that require wildfire threat mitigation; identify opportunities for enhancement of ecological integrity; define relative levels of fire hazard across the landscape; and define long term targets for prescribed fire programs to maintain disturbance levels within the natural range of variability. Sustaining forest landscapes at historical disturbance rates, are more likely to maintain ecosystems in the long run and conserve ecological integrity. Ideally, this ecological integrity is best achieved by minimizing the human interference due to suppression that, through removing natural fire, then requires prescribed fire to reintroduce the fire onto the landscape.

Fire history information in the Willmore Wilderness Park is currently limited to the last 43 years of recent provincial fire history data. Age class information and vegetation information exists for only eight townships throughout the park. A wildfire regime analysis would fill current knowledge gaps. For Willmore, the fire regime analysis would not be applied as traditionally done in fire management planning, since the traditional application is suited to areas that are driven by human interference. Instead development of the fire regime analysis could be used to support research. The Willmore provides a unique opportunity to analyse the fire regime in an area that is relatively unaltered by humans in order to gain insight into how fire dependent ecosystems function and are maintained naturally.

The fire regime information would provide a very important benchmark that could be used for different purposes. Future natural fire occurrences in the natural fire zone of Willmore could be monitored to see if they occur within the estimated natural range of variation predicted by the fire regime analysis. In this way, monitoring in Willmore can validate or refine components of the fire regime analysis, such as the fire cycle. The fire regime information would also provide a benchmark for measuring the results of implementing the fire management plan and help ensure that fire management strategies are not altering historical disturbance rates and impacting ecosystems. It could also provide a benchmark in order to observe the impacts of climate change in the future. The fire regime analysis for Willmore may be applicable to other areas that are expected to have a similar fire regime and could serve as a preliminary predictor of the fire regime in that area. However, Willmore may prove to be relatively unique in its fire regime. 


\section{LANDSCAPE ASSESSMENT}

\subsection{Wildfire Threat Analysis}

Provincial FireSmart landscapes initiatives focus on mitigating the likelihood of large, high intensity, high severity fires across the landscape. Designing FireSmart Landscapes involves the use of wildfire threat assessment and fire regime analysis to evaluate the negative ecological, social, and economic impacts of wildfire. In the Willmore, a wildfire threat analysis was used to provide some preliminary context for starting the fire management planning. The Wildfire Threat Assessment Model incorporates four components: (1) Fire behaviour potential, (2) Fire occurrence risk, (3) Values at risk, and (4) Suppression capability. Assessing each of these components is key in determining the component that is driving the wildfire threat. Wildfire threat can be used to identify areas on the landscape most at risk to wildfire. Wildfire threat analysis information can be incorporated into fire management planning and risk mitigation.

In the Willmore, the primary driver of the overall wildfire threat is fire behaviour and is attributed mainly to continuous forest fuels. The fire occurrence risk and presently known values at risk components are low which decreases fire threat, however the suppression capability component is poor which increases fire threat. The highest wildfire threat in Willmore and adjacent area occurs in the spring months of May through June and in the fall from September through October (Table 5). This increased wildlife threat, during the spring and fall seasons, can be attributed primarily to favourable fire weather conditions increasing the risk of fire ignition and spread. Most of the rating (approximately $39 \%$ ) is high across all three seasons and over $60 \%$ of each season's rating is in the high to extreme range. The ratings are fairly similar across the three seasons with a slight shift from the higher to lower ranges in the summer. Fall is generally considered the season with the highest wildfire threat and this season was used to analyze each of the four components for Willmore.

Table 5: Wildfire Threat Rating by season in Willmore Wilderness Park

\begin{tabular}{llll} 
& \multicolumn{2}{c}{ Season } & \\
\cline { 2 - 4 } Rating & Spring & Summer & Fall \\
\hline Low & $15.01 \%$ & $16.04 \%$ & $14.80 \%$ \\
Moderate & $17.93 \%$ & $23.14 \%$ & $20.49 \%$ \\
High & $39.03 \%$ & $38.45 \%$ & $39.28 \%$ \\
Very High & $11.58 \%$ & $7.79 \%$ & $11.45 \%$ \\
Extreme & $16.45 \%$ & $14.58 \%$ & $13.98 \%$ \\
\hline
\end{tabular}

Figure 7 illustrates the wildfire threat for the fall. The highest ratings occur in the valley bottoms and main travel corridors. The red (extreme) conditions indicate areas of forest with fuel types, which typically exhibit more extreme fire behaviour. 
Figure 7: Wildfire Threat (Fall)

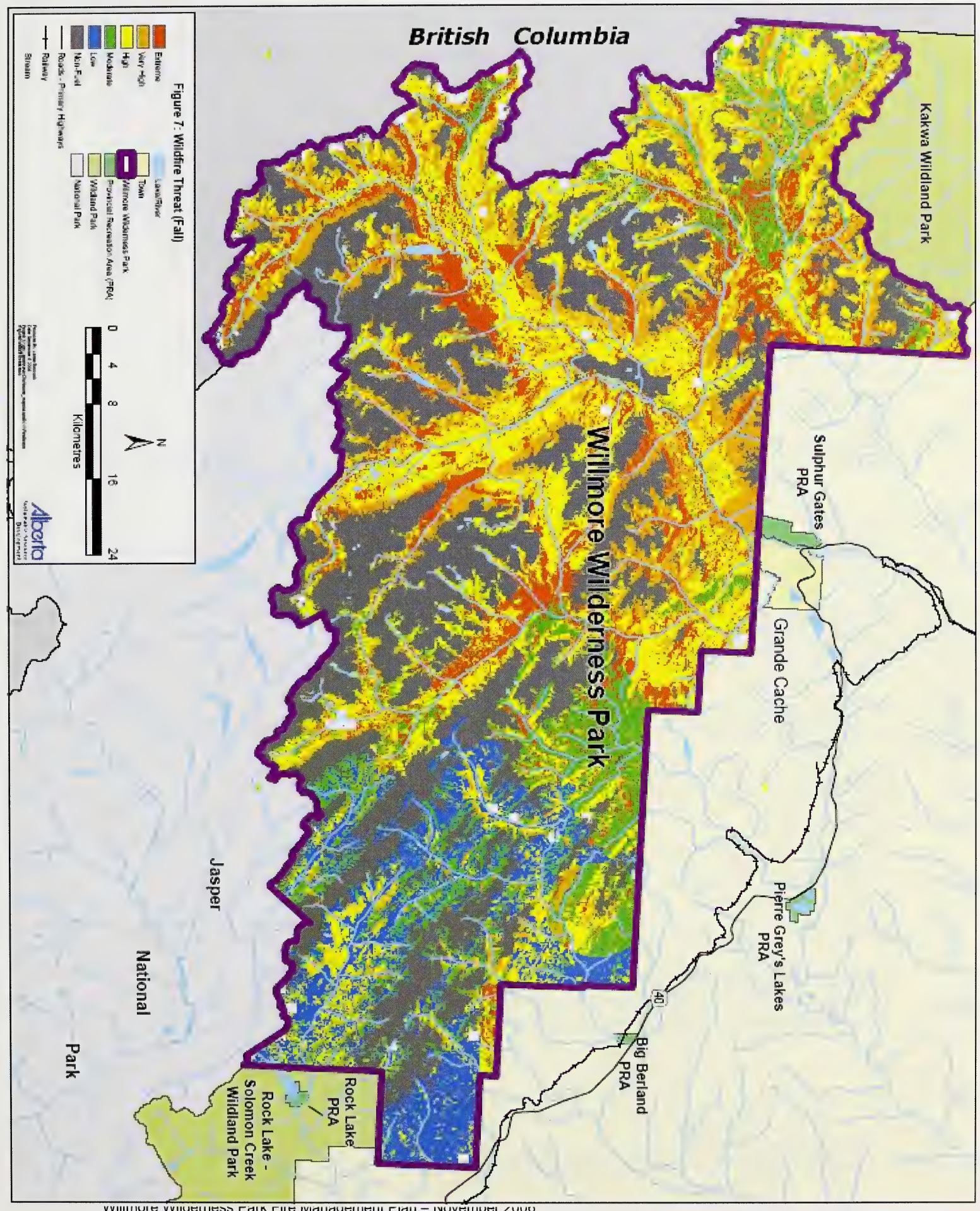




\subsubsection{Fire Behaviour Potential}

Fire behaviour is the driver of fire. It is the manner in which fuel ignites, flame develops, and the fire spreads to exhibit other fire phenomenon due to the interaction between fuels, weather and topography ${ }^{15}$. Fuel, topography and weather are the three primary variables that influence wildfire behaviour. There is the potential for extreme fire behaviour in the Willmore Wilderness Park due to continuous coniferous fuels, moderately steep slopes, and a funnelling effect due to the topography in the valleys producing strong southwest winds during periods of high fire hazard. The fire behaviour potential is similar throughout the fire season, with slightly higher values occurring in the spring and fall (Table 6).

Table 6: Fire Behaviour Potential by season in Willmore Wilderness Park

\begin{tabular}{llll} 
& Season & & \\
\cline { 2 - 4 } Rating & Spring & Summer & Fall \\
\hline Low & $7.21 \%$ & $41.77 \%$ & $14.17 \%$ \\
Moderate & $63.88 \%$ & $31.06 \%$ & $57.79 \%$ \\
High & $2.07 \%$ & $2.98 \%$ & $3.13 \%$ \\
Extreme & $26.84 \%$ & $24.18 \%$ & $24.92 \%$ \\
\hline
\end{tabular}

\section{a. Head Fire Intensity}

Head Fire Intensity (HFI) is the rate of energy released per unit of length of fire front. It is primarily driven by fuels and gives an indication as to the type of fire behaviour to expect. It is a function of the Fine Fuel Moisture Code (FFMC), Build-Up Index (BUI) and Initial Spread Index (ISI) as well as fuel complex ${ }^{16}$. HFI is a major determinant of certain fire effects and influences the ability to control the fire. In the Willmore, HFI is similar throughout the fire season, although slightly higher in the spring and fall (Table 7).

Table 7: Head Fire Intensity ranking by season in Willmore Wilderness Park

\begin{tabular}{llll} 
& Season & \\
\cline { 2 - 4 } Rank & Spring & Summer & Fall \\
\hline $1(<10 \mathrm{~kW} / \mathrm{m})$ & $0.00 \%$ & $21.05 \%$ & $0.00 \%$ \\
$2(10-500 \mathrm{~kW} / \mathrm{m})$ & $7.21 \%$ & $20.72 \%$ & $14.17 \%$ \\
$3(500-2000 \mathrm{~kW} / \mathrm{m})$ & $63.88 \%$ & $31.06 \%$ & $57.79 \%$ \\
$4(2000-4000 \mathrm{~kW} / \mathrm{m})$ & $2.07 \%$ & $2.98 \%$ & $3.13 \%$ \\
$5(4000-10000 \mathrm{~kW} / \mathrm{m})$ & $26.84 \%$ & $24.18 \%$ & $24.92 \%$ \\
$6(>10000 \mathrm{~kW} / \mathrm{m})$ & $0.00 \%$ & $0.00 \%$ & $0.00 \%$ \\
\hline
\end{tabular}

Figure 8 illustrates the fire behaviour potential for the fall season in the Willmore Wilderness Park. Significant components of non-fuel (i.e. rock) provide a barrier to fire spread, and the steep, rough topography also influences the wildfire spread.

\footnotetext{
${ }^{15}$ Merrill \& Alexander, 1987

${ }^{16}$ These indices (FFMC, BUI, ISI) are explained in section 7.3.1
} 
Figure 8: Fire Behaviour Potential (Fall)

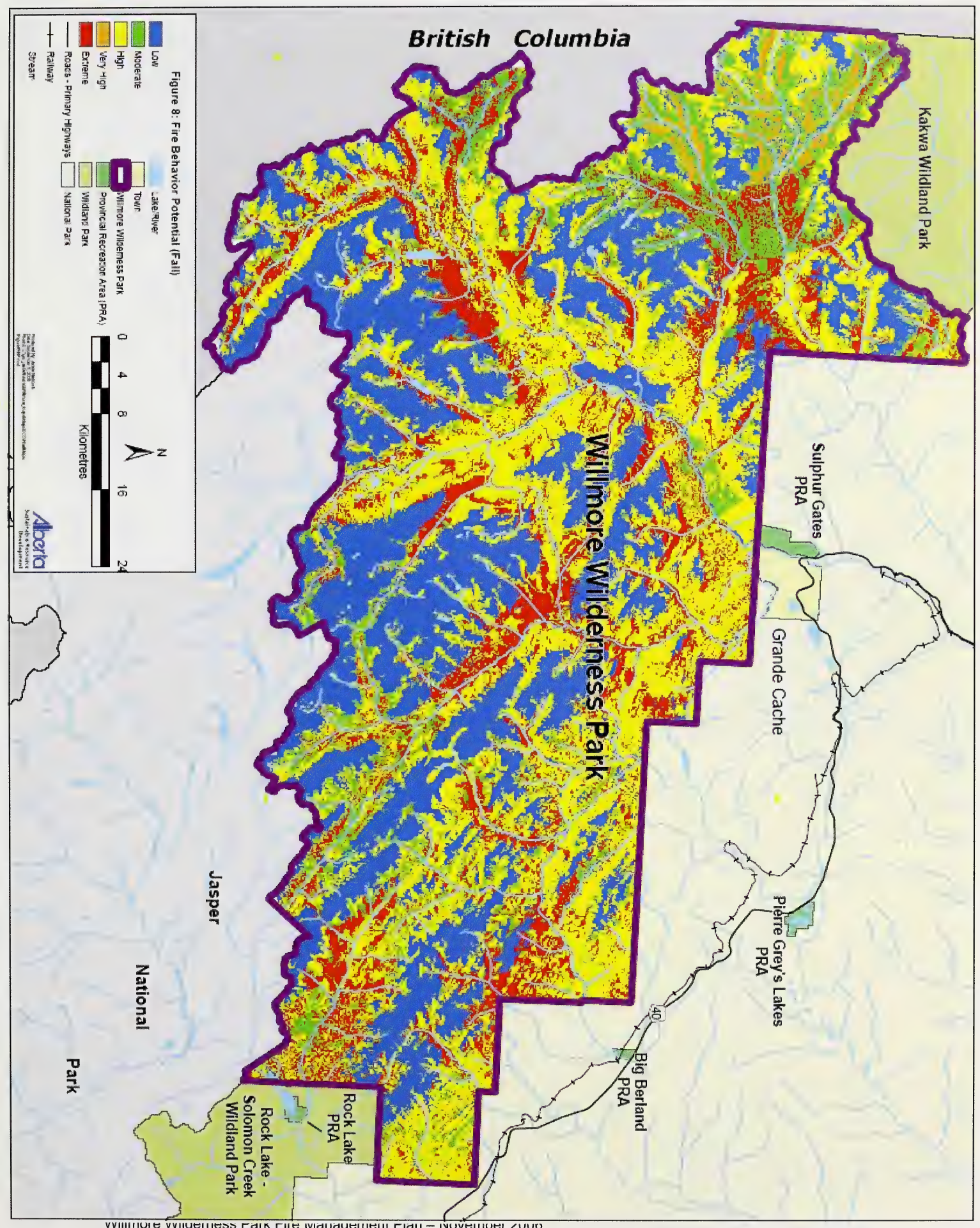




\section{b. Fuel Type}

The fire behaviour potential fuel type is one of the three primary variables that influence wildfire behaviour. Fuels influence the ignition, rate of spread, build-up, intensity and overall behaviour of fire. Wildland fuels vary widely in their distribution, physical characteristics and effect on fire behaviour. A fuel type is an identifiable association of fuel elements of distinctive species, form, size, arrangement, and continuity that will exhibit characteristic fire behaviour under defined burning conditions ${ }^{17}$. Fuel types are described qualitatively using stand structure and composition, surface and ladder fuels, and forest floor cover and organic layer. Using the Canadian Forest Fire Behaviour Prediction system, the fuel types in the Willmore Wilderness Park are primarily classified as C-2 (Boreal Spruce) and C-3 (Mature Lodgepole Pine) (Figure 9).

In general the $\mathrm{C}-2$ forest structure is composed of moderately stocked spruce stands. Surface fuels are continuous and contain primarily Labrador tea shrub. Ladder fuels are present with tree crowns extending nearly to the ground and surface fuels. The forest floor is a composed of continuous feather moss and Cladonia sp (reindeer lichen), with low to moderate amounts of down woody debris. The typical crown base height of a C-2 fuel type is 3 meters and is a critical factor in crown fire potential. The fuel type is likely to involve crown fuels at low intensities due to crowns extending near the ground and reaching surface fuels. With the horizontal and vertical fuel arrangement, there is the potential for fast spreading high intensity fires with the possibility of long range spotting.

The C-3 forest structure is generally a fully stocked mature lodgepole pine stand. The surface fuels are light with a small amount of spruce understory and down woody debris. There are sparse ladder fuels with the tree crowns well above and separated from the surface fuels. The site is primarily upland and well drained with continuous feather moss on the forest floor and a moderately deep compacted organic layer. The typical crown base height of 8 meters is a critical factor in crown fire potential. The fuel type is less likely to involve crown fuels at low intensities because the crowns are well above surface fuels and the ladder fuels are sparse. Therefore more intense surface fire is required to initiate crown involvement. If sufficient spruce understory exists to create ladder fuel between the surface and crown fuels, then crown fire will occur at lower intensities.

\footnotetext{
${ }^{17}$ Merril and Alexander 1987
} 
Figure 9: Canadian Forest Fire Behaviour Prediction - Fuels

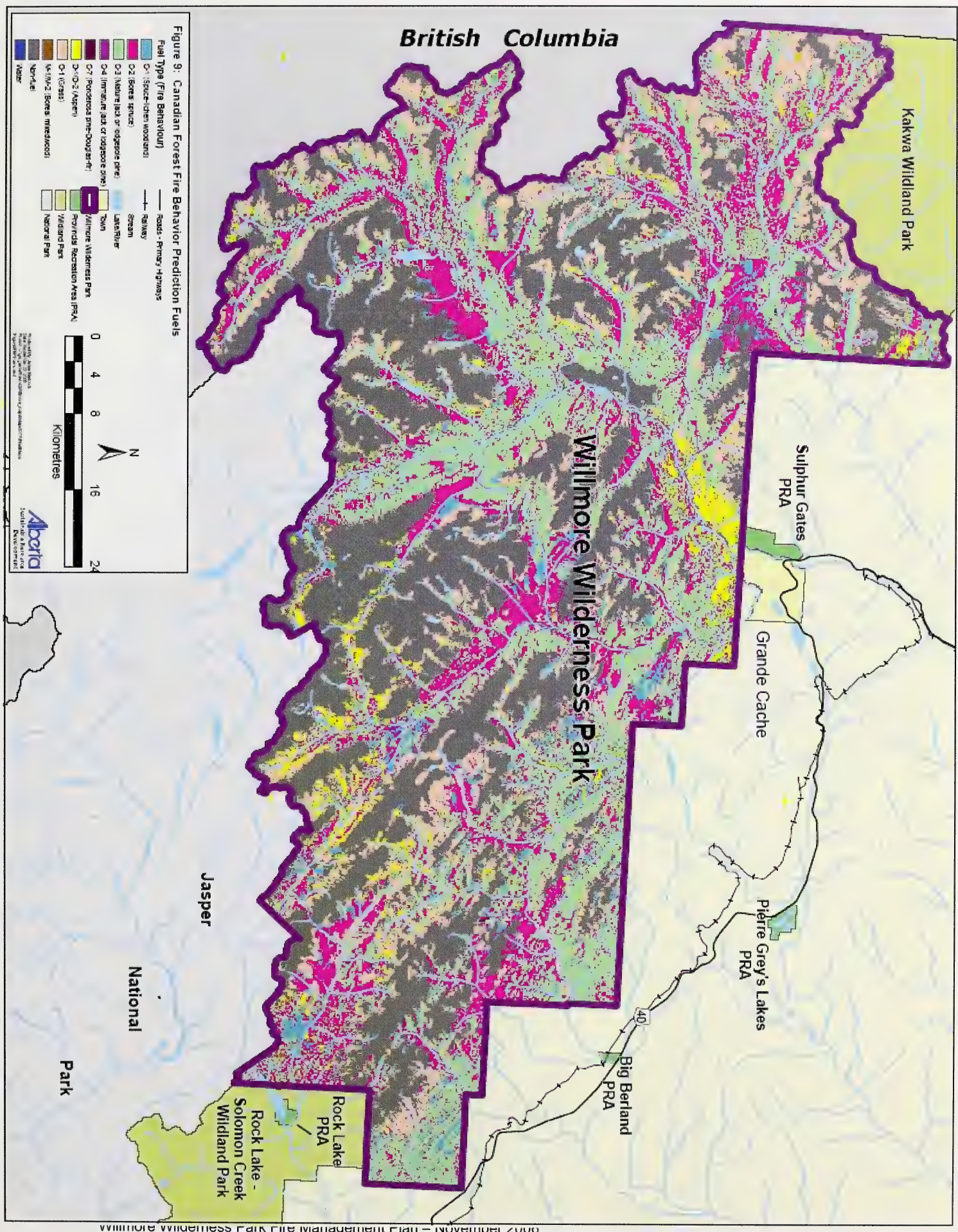




\subsubsection{Fire Occurrence Risk}

Fire occurrence risk is determined by the presence of causative agents, such as human and lightning. Topography is a major factor that can affect the distribution of lightning, particularly along the east slopes. The effect of slope, aspect and elevation result in a lightning shadow on the east slopes of the continental divide which runs along the west side of Willmore. This shadow results in a low incidence of lightning in this area. Lightning also tends to strike on ridge tops where there is little or no fuel to ignite. Willmore has several non-forested ridge and mountaintops providing potential lightning targets however weather conditions and lack of fuels at these higher elevations preclude most ignitions. It is not known if climate change will have an impact on fire occurrence risk, such as affecting the frequency or location of lightning, or resulting in warmer temperatures and vegetation at higher elevations to provide fuel if lightning strikes.

The other main cause of fires is human-related ignition. Motorized vehicle use and industrial development is prohibited in the Willmore Wilderness Park. Therefore the main human use of the park is for non-motorized recreation such as hunting, fishing, horse riding, hiking and camping. Smouldering campfires, or careless disposal of a match or cigarette, provide sources of these human ignitions.

The wildfire distribution history indicates relatively few recorded wildfires (only 42) in the planning area since 1931 (Figure 10). Most of these fires have been less than 200 ha and frequently are only 0.01-4.0 ha. The majority have been lightning-caused and occurred in the main valley corridors. Risk of lightning-caused fires occurs mainly during the summer and into the fall. Several fires have been human-caused, with the risk of human-related fires occurring in the spring, summer, and fall.

The greatest fire occurrence risk lies just east of Willmore in the Grande Cache area during the fall fire season (Figure 11). This high risk can be attributed to human presence (e.g. fall hunting season) and development providing increased chances of ignition. 
Figure 10: Wildfire Distribution 1931-2006

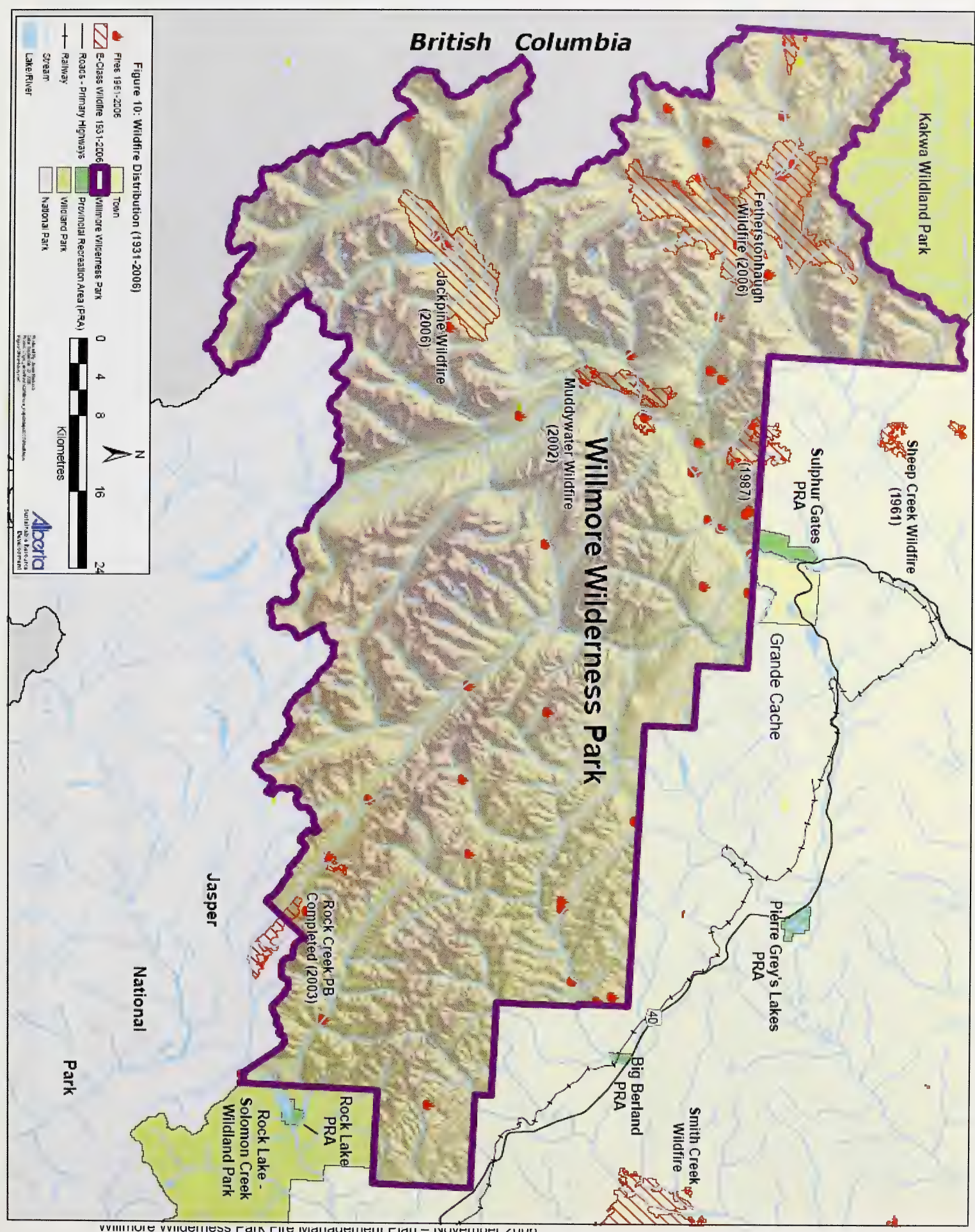


Figure 11: Fire Occurrence (Fall)

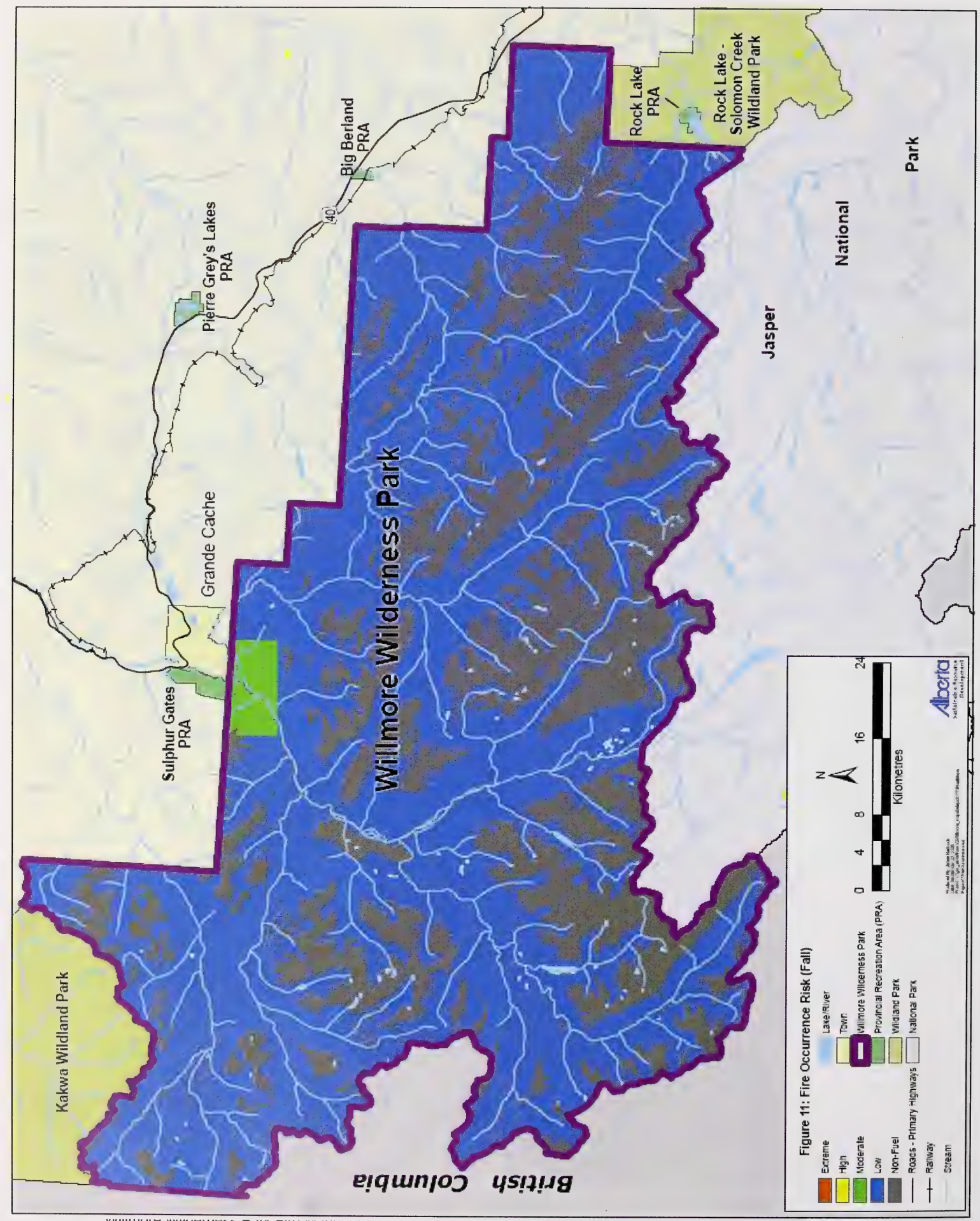




\subsubsection{Values at Risk}

Values at Risk are human or natural resource values that may be destroyed or altered by fire. An area will have a higher rating if it includes, or is in close proximity to, priority values at risk or several values at risk. The provincial priorities for fire suppression to protect values at risk are: (1) Life, (2) Communities, (3) Watershed and Soils, (4) Natural Resources (e.g. Timber, Protected Areas, Fish and Wildlife Habitat, Threatened and Endangered Species), and (5) Infrastructure.

Within the Willmore Wilderness Park, the predominant values at risk are ecological: natural resources, watersheds and soils. The human-related values at risk, life and infrastructure, are important where they occur but are not extensive within the park (Figure 12). On the east side of Willmore, life, community, infrastructure and timber resources are the main values at risk adjacent to the park and are concentrated mostly within the community of Grande Cache and surrounding Forest Management Area. Kakwa Wildland Park to the north and Jasper National Park to the south are significant protected areas that likely have a similar prevalence of ecological values at risk in the areas adjacent to Willmore. The Rock Lake-Solomon Creek Wildland Park to the southeast would have the same focus on ecological values at risk. However, the embedded Rock Lake Provincial Recreational Area (PRA) would have a stronger emphasis on human life and infrastructure. In British Columbia, foremost values at risk would probably be the commercial timber adjacent to the Willmore boundary, with the more distal priorities being life, community and infrastructure.

\section{a. Ecological Values at Risk (Natural Resources, Watersheds, Soil)}

Willmore Wilderness Park is significant in the extent and value of natural resources, ecosystems and ecological processes that it contains and protects. Therefore, these ecological values at risk are a priority. Ecological values at risk, as defined in fire management, include watersheds, soil, timber (in parks timber is non-commercial and therefore refer to forests, particularly old growth), protected areas, fish and wildlife habitat, threatened and endangered species. In general, for Willmore Wilderness Park, this list could be broadened to include landscapes, ecosystems and ecological processes.

Protection of these ecological values must recognize the role of natural fire and that exclusion of natural fire does not ensure protection of these values but may even cause their loss. Any fire management activities should contribute to protecting these values at risk from potentially destructive or "catastrophic" fire but should not preclude the ability of natural fire to restore and therefore "protect" these ecological values. Because ecological processes are complex and interactive, it is hard to determine how to protect them from fire or how to utilize fire. Minimal interference in natural fire processes is likely the best management approach.

Forest or landscapes in general, as well as fish and wildlife habitat should be considered a priority that is best captured at a landscape level. Specific consideration may be important when known values at risk include endangered, threatened or of concern species. Woodland caribou are a threatened species in Alberta and portions of the Willmore Wilderness Park are identified as calving, summer, winter and rutting range for the A la Peche herd as well as calving and summer range for the Red Rock-Prairie Creek caribou herd. It is important that wildfire management planning in Willmore incorporates current information to best preserve and protect caribou habitat. Other animal species that require consideration because of development pressures outside 
Figure 12: Values at Risk

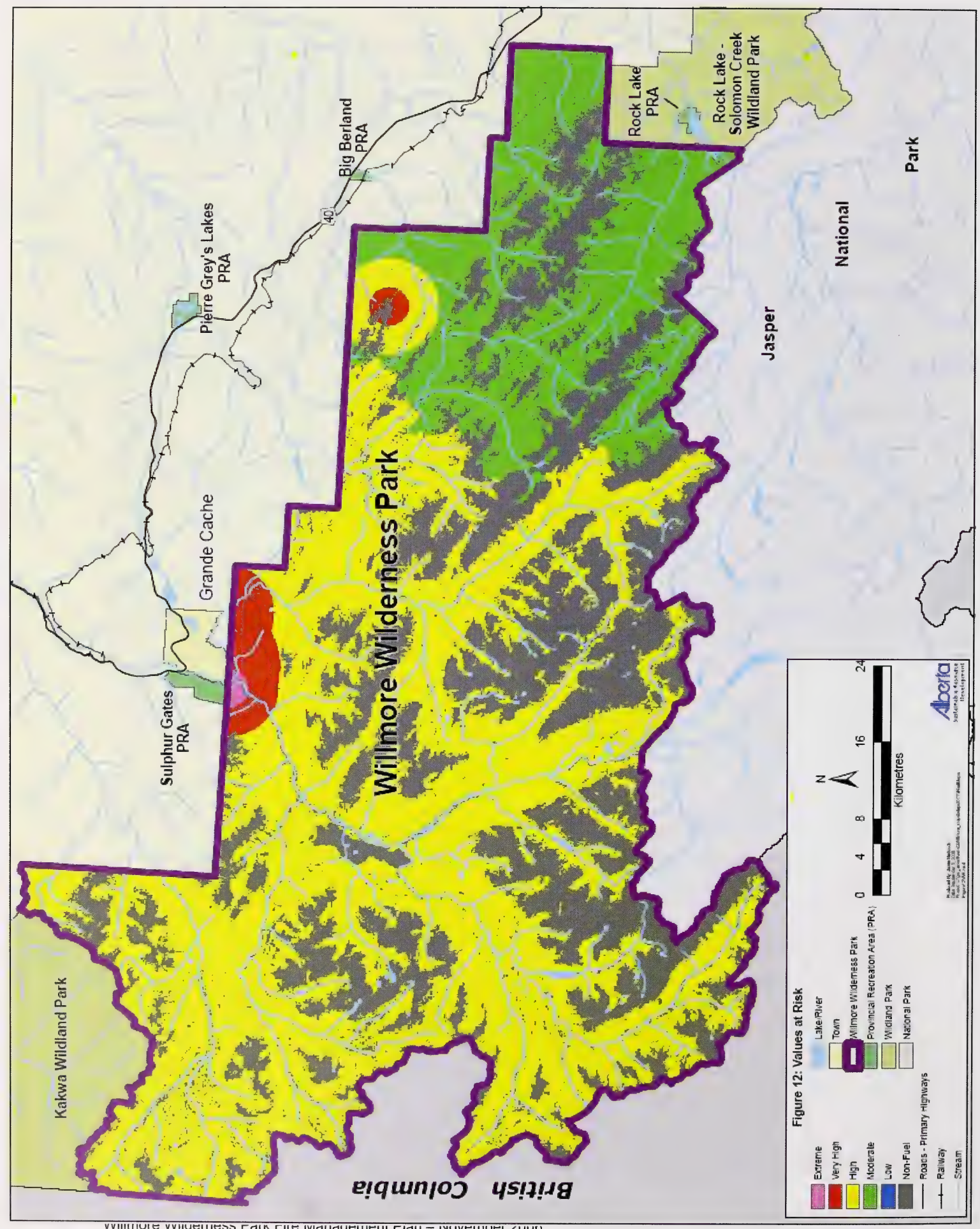


Willmore include: grizzly bears, wolverine, harlequin ducks, and bull trout. There are also many important known and yet to be discovered vascular and non-vascular plants. Significant plant species or communities such as whitebark pine, rare northern rough fescue and mosses occur within Willmore.

Wildlife and plant inventories, as well as research into the appropriate application of fire for some species needs to be completed. Specialists for specific species of concern will be consulted for their recommendations regarding the general fire management strategy as well as for specific prescribed burn planning. Detailed biophysical information has not been collected within Willmore therefore presence and locations of species may be vague or unknown. The impacts of fire on the species may not be known. Collecting biophysical information will better help identify and prioritize values at risk. However, fire management at a landscape level is intended to allow natural processes to provide the balance that is most suitable for the species within Willmore.

The Willmore Wilderness Park includes many important watersheds and valley drainages (Figure 4). The headwaters for rivers such as the Smoky, Berland, Sulphur, Jackpine, Muddywater and Wildhay occur in the continental divide. These rivers and their tributaries extend throughout Willmore. These watersheds provide critical habitat for species such as the Bull trout and Harlequin ducks. These waterways have naturally low productivity due to low temperature and nutrient content and therefore may be sensitive to disturbance. The main concern is erosion resulting in siltation, increased water temperature, and debris entering the watercourse. Impacts on riparian areas or on the drainage of forests adjacent to riparian areas should also be considered.

Willmore contains a variety of soils related to its various subregions and geology. Some of these soils are impacted more by fires than others. Intensity of the fire may determine the soil damage. It is important to define the locations and fragility of the soils in order to assess areas of concern when developing the detailed prescribed burn plans.

Collection of biophysical information will be a long and gradual process but will help to refine and validate fire management direction in the future. In addition, pre and post burn research will provide information on the effects of fire. In light of knowledge gaps, and recognizing that management for specific species is difficult, it is best to approach the fire management at a landscape level and let nature take its course with minimal human intervention. Protecting ecological values at risk implies caution, but actually involves the risk of letting natural fires burn so that ecological processes can occur.

\section{b. Human-Related Values at Risk (Life and Infrastructure)}

The human-related values at risk in Willmore are important but manageable, due to their minimal extent in the Willmore. The Willmore Wilderness Park is a remote area that prohibits industrial development. It is only used for non-motorized recreational activities such as backcountry hiking, mountain biking, trail riding and hunting, as well as supporting commercial trail riding operations, commercial hunting outfitters, and trappers. As a result, there has been relatively little human development within the park and there are few infrastructure values at risk. The infrastructure values at risk include points of interest such as historical gravesites, old trapper and resource prospector cabins, as well as the active patrol and trapper's cabins throughout the park (Figure 13). Vegetation management mitigation measures around these sites and structures may have to be employed to protect them from wildfire. 
The human life component relates to the recreational use of Willmore, which is extensive but not intensive. Willmore Wilderness Park is truly a wilderness area characterized by large remote, rugged areas with difficult access. Therefore human use relative to size is relatively low. Most of the recreational human use is along existing trails and uses the informal campsites. This use is likely highest in the front country areas in closer proximity to the staging areas, with the number and extent of use diminishing towards the west and in the rugged and remote areas. Trapping activity is related to access to trap lines and cabins. Park patrols, by CD Conservation Officers, generally utilize existing trails and the patrol cabins. Generally, knowledge of the timing and location of people within Willmore will be unknown, therefore there is always the human factor to consider related to fire in the Willmore. Sufficient communications and safeguards will always be employed during wildfires or prescribed fire operations. 
Figure 13: Points of Interest

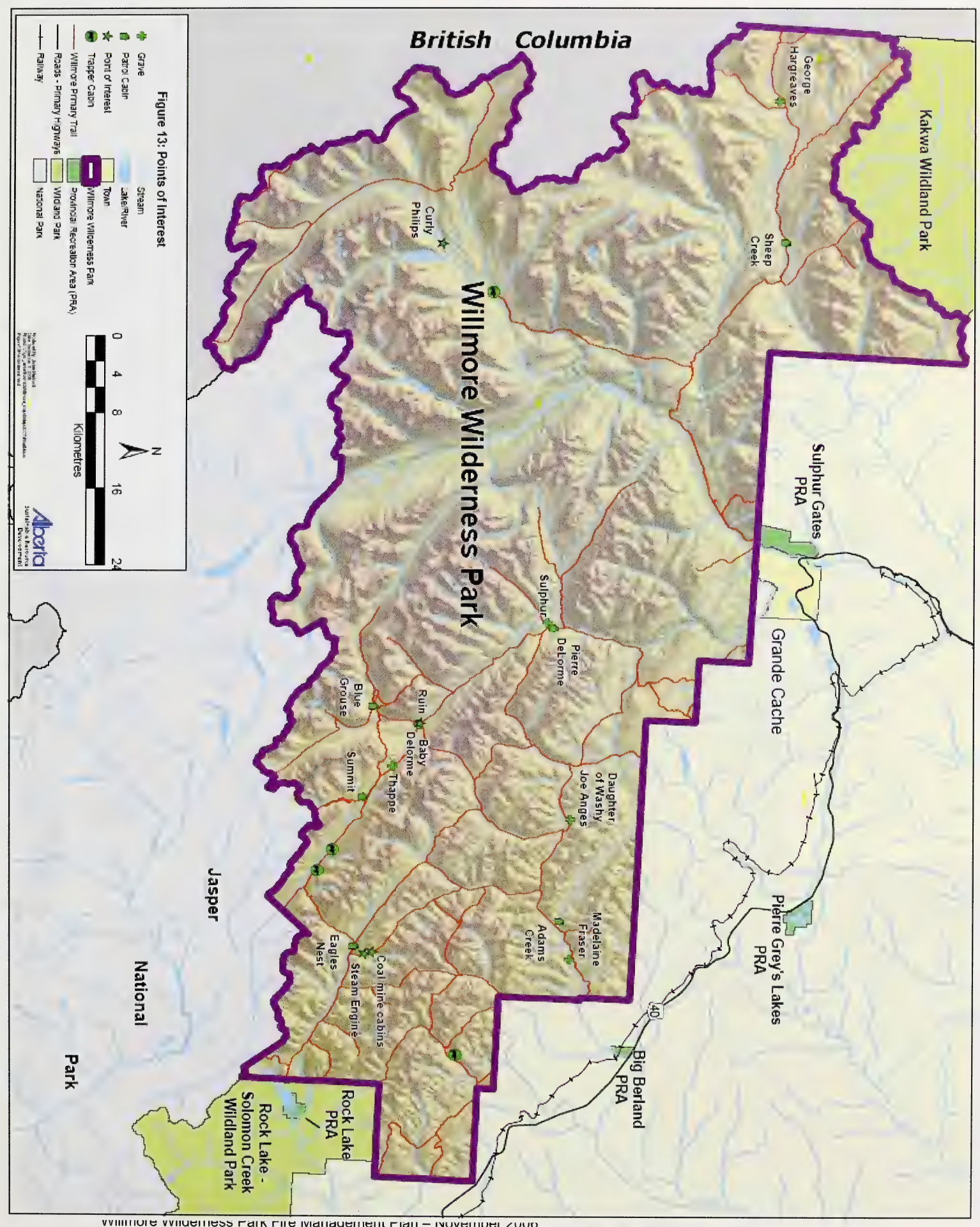

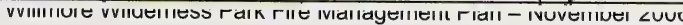


Figure 14: Suppression Capability

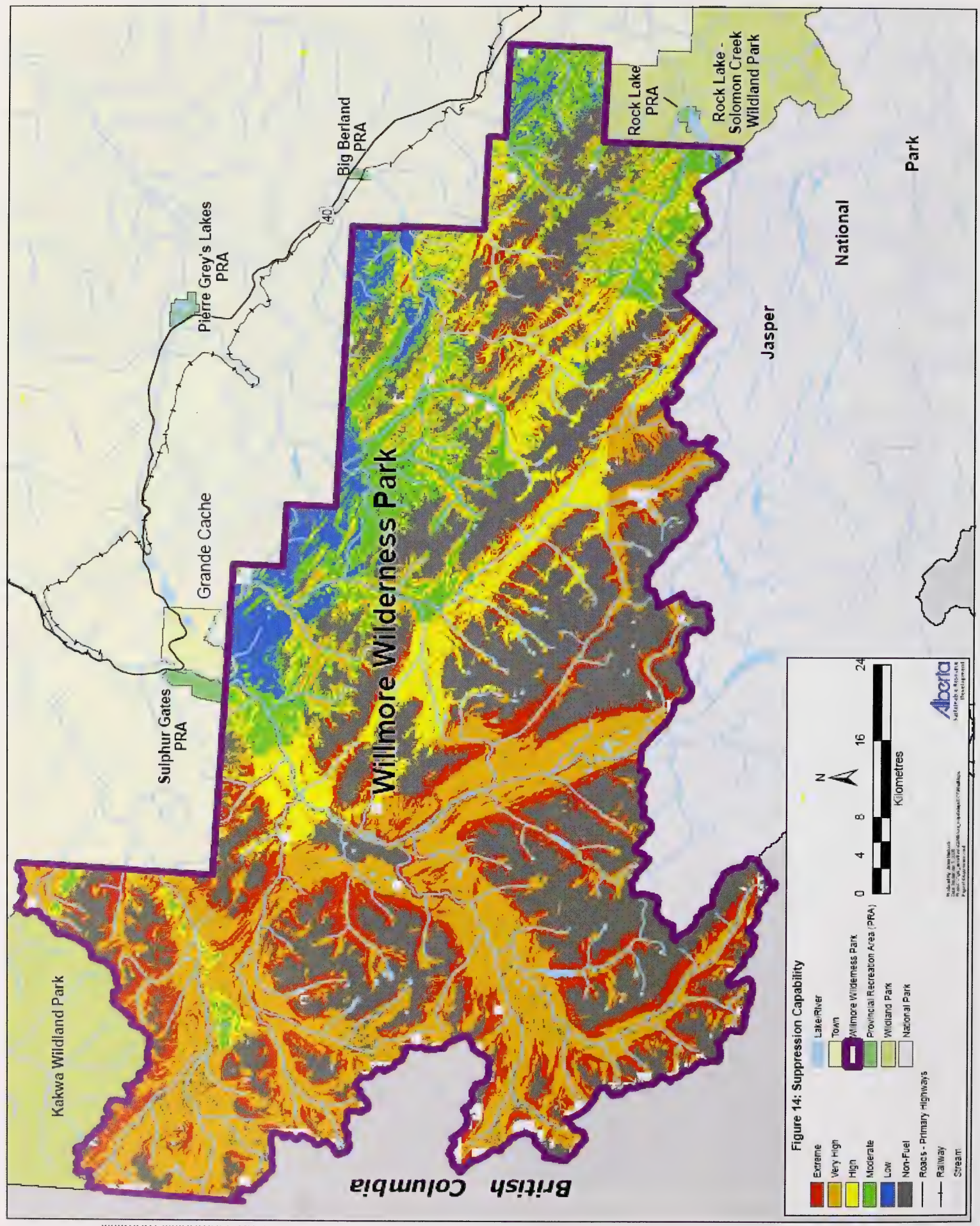




\subsubsection{Suppression Capability}

Suppression capability includes factors and limitations that are related to the ability to contain a wildfire upon detection. Fixed detection (lookout towers), air attack (time for aircraft to reach fire), steepness of slope, and presence of skimmer lakes (suitable for aircraft to collect water) are factors that influence suppression capability. Suppression capability is poor, and therefore risk is higher, for much of the Willmore area due to the remoteness, and steepness of slope (Figure 14). Most of Willmore is shown as high to extreme risk for suppression capability with the moderate to low risk areas being located along the eastern front country area and particularly near Grande Cache.

Fixed detection consists of one lookout tower located in the north east corner of the park (Adams Creek) and one lookout tower located adjacent to the park near the community of Grande Cache (Mt. Hamel). The ability to detect fires for the majority of the Willmore Wilderness Park from these two locations is limited due to the topography. Air attack would be dispatched out of the secondary air tanker base located just outside Grande Cache, however air tankers are infrequently based in this location. Steepness of slope limits the ability for aircraft to operate in the park. The few small lakes within Willmore are not generally suitable skimmer lakes to provide the water for fighting wildfire.

\subsection{Mountain Pine Beetle Susceptibility}

The mountain pine beetle (MPB) is currently the most destructive native insect pest of mature lodgepole pine forests of western North America. Its range extends from the Pacific Coast east to the Black Hills of South Dakota, and from northern British Columbia (B.C.) and western Alberta south into northwestern Mexico.

In late summer, adult MPB's emerge from their infested trees and fly to new trees where they burrow in to lay their eggs and in the process introduce a blue stain fungus that kills the trees. Over the next 1-2 years the eggs hatch into larva and pupa and new adults emerge at the end of summer (late July - early August) to fly to new trees and continue the cycle. Extreme temperatures colder than $-40 \mathrm{C}$ in the winter, sustained temperatures of $-25 \mathrm{C}$ in the early fall or late spring, or intense burning of infected trees, is needed to kill the MPB. Climate change is potentially increasing the MPB range. Areas are becoming more hospitable to the MPB as occurrences of extreme cold temperatures are decreasing, and trees are becoming more susceptible to infection if stressed by climatic conditions (e.g. drought).

Mature, MPB-prone lodgepole pine content on Alberta's Eastern Slopes, including Willmore Wilderness Park, is currently at a historically high level. Due to the influx of MPB from B.C., and recent weather patterns of milder winters and warm, dry summers which are favourable to MPB, Alberta is facing a high risk of a major MPB outbreak. There are MPB infestations in areas where they have not historically occurred. Currently, active infestations are found in the Crowsnest Pass, Canmore, Banff National Park, Jasper National Park, Willmore Wilderness Park, and Kakwa Wildland Park. With a large in-flight from B.C. this summer, MPB has been detected in high numbers in the Smoky region around Grande Prairie and in low numbers as far east as Fox Creek. These MPB populations pose a potential threat to Alberta's forests. 
Figure 15: Mountain Pine Beetle Hazard Rating

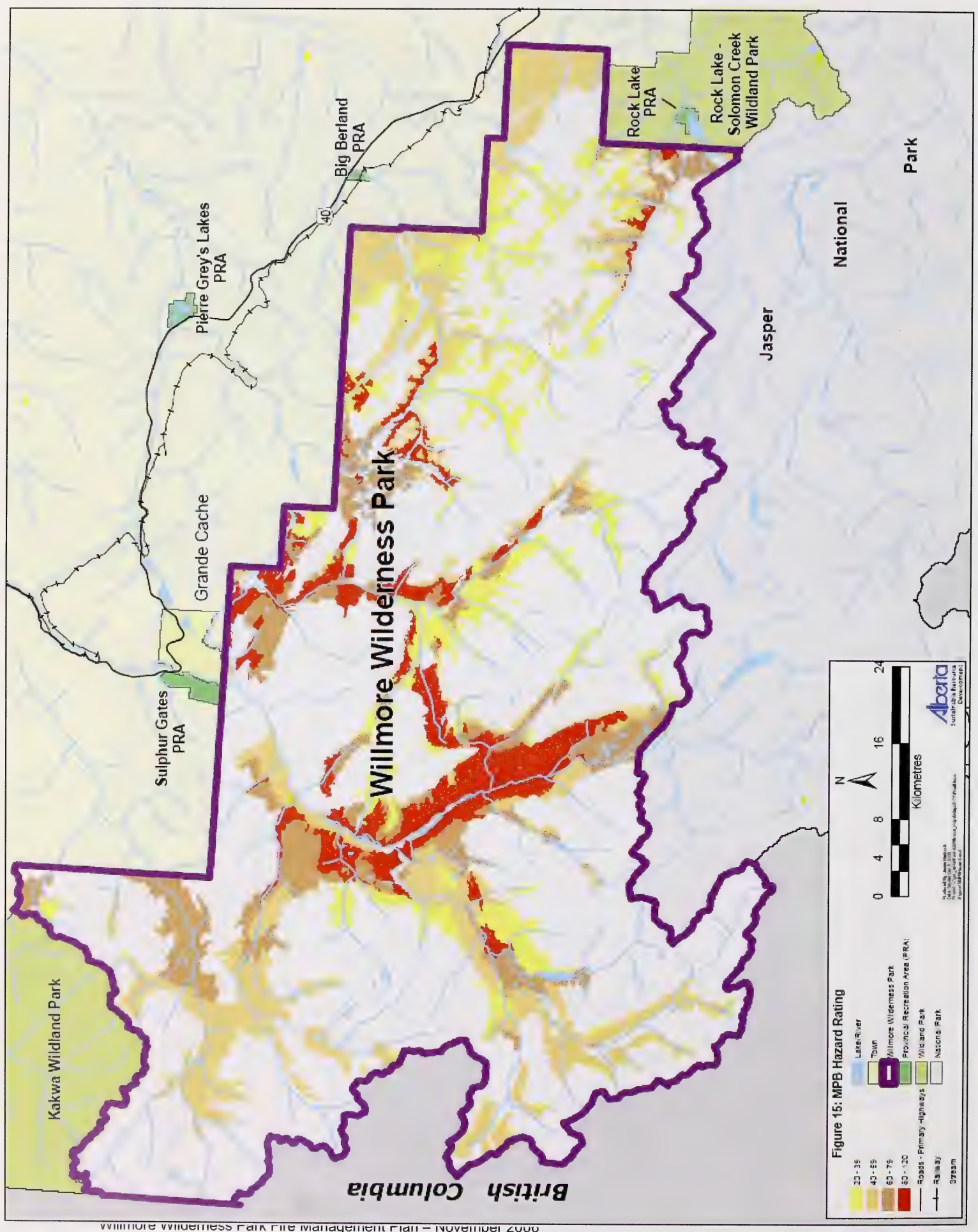


Monitoring in Willmore since 1999 indicates that the MPB activity has been increasing with a sharp increase in 2005 attributed to a mass MPB flight a couple years earlier. Previously, three active infestations had been identified and were being controlled by fall and burn to selectively destroy individual infected trees. These three sites, at Casket Lake, Beaverdam Creek and Meadowland Creek, are all located along the western boundary of Willmore close to B.C. In the summer of 2005, infestation was found throughout the Fetherstonhaugh, Muddywater, Casket, Sheep, Pauline, and Jackpine drainages. This infestation was controlled with an extensive fall and burn operation to remove over 5000 individual infected trees, followed by baiting (pheromone traps) to curtail the spread of beetles where timely fall and burn was not feasible. This operation had a significant impact on the infestation. Surveying, with fall and burn, was continued from the fall of 2005 until early summer of 2006 with removal of over 10000 trees. In the summer of 2006, two wildfires in the Fetherstonhaugh-Sheep Creek-Muddywater drainages and the Jackpine drainage burned a significant amount of MPB infestation as well as MPB habitat. The two wildfires provided unanticipated MPB control benefits.

MPB preferentially attack pine trees that are 80 years old and older, have a diameter at breast height of $20 \mathrm{~cm}$ and greater, and are found in stands of a density ranging from $750-1400$ trees per hectare ${ }^{18}$. Based on these criteria and factors such as latitude and elevation, a MPB Hazard Rating can be estimated. Hazard ratings are for individual stands and identify stands that will be most affected (trees killed) by MPB attack based on the percentage of pine, tree size, age, etc. However, the rating does not indicate where the MPB is likely to attack.

The MPB hazard rating for the Willmore Wilderness Park is highest in the Smoky River and Sulphur River valleys (Figure 15) however currently the MPB infestation has been mainly west of the Smoky River. Prior to the wildfires of 2006, over 100,000 hectares of the approximately 152,000 hectares of lodgepole pine ${ }^{19}$ in the Willmore Wilderness Park were in the high to extreme susceptibility class (Table 8). The two large wildfires in 2006 included significant amounts of pine forest, which would previously have been classified as moderate to extreme susceptibility in a similar distribution as in Table 8. The wildfires therefore shifted the susceptibility rating for the burned pine from the moderate or extreme susceptibility to low susceptibility. A small amount of scorched trees on the perimeter of the wildfires may be classified as extreme susceptibility in the short term but by the following year these dead trees will be in the low susceptibility class.

Table 8: Hectares of susceptible Lodgepole Pine stands for Willmore Wilderness Park (prior to summer 2006 wildfires).

\begin{tabular}{ll}
\hline Susceptibility Class & Area $(\mathrm{Ha})$ \\
\hline Low & 0 \\
Moderate & 36,357 \\
High & 57,108 \\
Very High & 32,311 \\
Extreme & 26,099 \\
TOTAL & 151,875 \\
\hline
\end{tabular}

\footnotetext{
${ }^{18}$ In Willmore, MPB are even attacking thinner trees. Whitebark pine is preferred to lodgepole pine.

${ }^{19}$ Willmore contains 245680 ha of forest.
} 
Falling and burning of individual trees is the control method currently used. Fall and burn is a reactive approach used to control identified infested trees, but has little impact on the amount of MPB habitat in the area and therefore does not decrease MPB susceptibility that is based on suitable MPB habitat. Prescribed burning or wildfire can reduce the beetle population if the fire is intense enough to kill them while they are in the trees. The use of prescribed burning for MPB management can be used to decrease beetle habitat in the area by removing the pine to reduce MPB susceptibility. It is not feasible or ecologically responsible to pro-actively burn vast areas of pine habitat in Willmore in anticipation of MPB infestation. Therefore, the intent is to continue to use fall and burn of individual trees as the main control method within the Willmore. However, strategic prescribed burns intended as fireguards in key valleys will also remove MPB habitat, provide potential blockage of MPB movement through those valleys and enable opportunities for future natural fires to burn MPB populations and habitat, create MPB blockages and decrease MPB susceptibility. 


\subsection{Historical Weather Analysis}

\subsubsection{Fire Weather Index}

Weather is one of the key variables influencing fire behaviour. Fire weather observations across the province have been recorded and entered into a database since 1973 . Willmore is lacking detailed weather records and in the current weather database only the period from 1984 to 2003 includes Fire Weather Index (FWI) codes (Canadian Forest Fire Weather Index) for Willmore. Data within the park is only available from one permanent weather station (Casket Mountain/E3) and one lookout tower (Adams Creek/AC), with some short term records from one temporary weather station (Willmore/WW) (Figure 16). A permanent weather station located adjacent to the park in Grande Cache (Grande Cache/GC) provides weather data representative of the front country area of Willmore in its vicinity.

The permanent weather station at Casket Creek was installed in 1995 in the Casket valley by the headwaters of the Jackpine River near the western boundary. The Adams Creek lookout tower, located on a ridge in the east end of the park, has been collecting weather data since 1974. A temporary weather station has been located in the Meadowland creek valley on the west side of the park for the summers of 2004-2006.

The climate and weather patterns in the Willmore Wilderness Park are driven primarily by topography and the influence of the Rocky Mountains. The continental divide along the west boundary influences the amount of summer rain and depth of winter snow pack, with decreasing precipitation further from the divide. Topographic features such as aspect and elevation exert strong controls over moisture content of forest fuels.

The Canadian Forest Fire Weather Index (FWI) System provides a uniform method of rating fire danger across Canada. The FWI System rates fire potential in a particular fuel type (e.g. mature pine) based on observations of air temperature, relative humidity, windspeed and precipitation. There are six components of the FWI.

Three fuel moisture codes follow daily changes in the moisture content of three classes of forest fuels:

1. Fine Fuel Moisture Code (FFMC) - surface litter and fine fuels, which influence ignition and flammability of fine fuels;

2. Duff Moisture Code (DMC) - moderate depth duff which indicates fuel consumption in the duff and medium woody material; and

3. Drought Code (DC) - deep duff layers, which indicates seasonal drought effects and smouldering in deep layers and large logs.

The fuel moisture codes are used to develop the three fire behaviour indexes:

4. Initial Spread Index (ISI) - rate of spread from wind and FFMC;

5. Build-up Index (BUI) - available fuel from DMC and DC; and finally the

6. Fire Weather Index (FWI) - fire intensity derived from ISI and BUI to give the general index of fire danger.

The $90^{\text {th }}$ percentile $\mathrm{FWI}$ indicates the FWI that is equal to or greater than $90 \%$ of all $\mathrm{FWI}$ measurements for the entire year over all years they have been recorded. On average the $90^{\text {th }}$ percentile Fire Weather Indices, based on the weather stations within and adjacent to Willmore Wilderness Park, would generate fairly moderate fire behaviour conditions (Table 9). 
Figure 16: Weather Stations

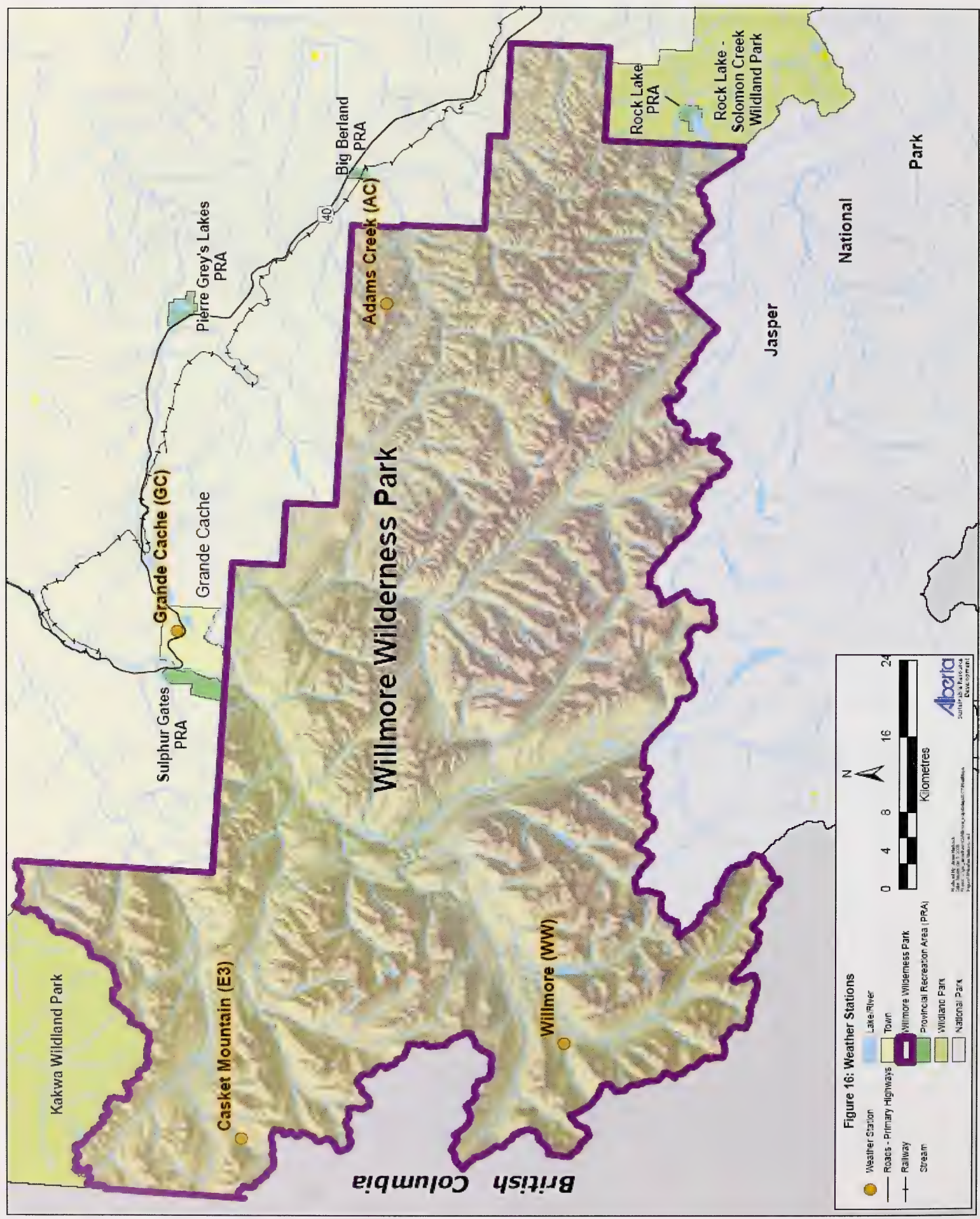


Table 9: 90th percentile weather indices for weather stations within and adjacent to Willmore Wilderness Park ${ }^{20}$.

\begin{tabular}{lllllll}
\hline Weather Station & FFMC & DMC & DC & ISI & BUI & FWI \\
\hline Casket Mtn (E3) & 88.6 & 20 & 275.4 & 7.7 & 31.1 & 13 \\
Grande Cache (GC) & 90 & 41 & 410.01 & 9 & 60 & 19 \\
Willmore Wilderness (WW) & 91.3 & 42.9 & 318.34 & 8.3 & 59.32 & 18.38 \\
\hline
\end{tabular}

However, extreme fire weather conditions do occur in the Willmore Wilderness Park creating extreme fire behaviour conditions. The climate has been trending towards warmer and drier conditions reminiscent of historic weather conditions that preceded large stand replacing fires of the east slopes 80 to 120 years ago. This trend has a direct impact on increasing the number of critical burning days (i.e. days of extreme fire behaviour). Climate change may influence weather conditions and result in increased extreme fire behaviour conditions in the future.

\subsubsection{Wind}

One of the most important weather elements affecting wildfire behaviour and wildfire spread is wind direction. It is the one of the most variable and unpredictable weather elements. Wind patterns are strongly influenced by the orientation of major and minor valleys to the prevailing wind, as well as heating and cooling. The weather data and valley orientation give a general sense of the predominant wind patterns in the Willmore Wilderness Park (Figure 17). In general the wind patterns flow in many directions along the major valleys throughout Willmore and then flow to the northeast once they exit the park. The valleys with a south to west orientation, such as the Smoky River, are more likely to be under the influence of higher and more sustained wind speeds. Changes in wind direction, such as before precipitation, can cause a change in the direction of fire spread, such as happened with the Jackpine wildfire of 2006.

\subsubsection{Lightning}

Lightning is an important causal agent of wildfires in Alberta and impacts the Fire Occurrence Risk. A lightning shadow (i.e. less lightning) occurs on the east slopes of the continental divide influenced mainly by topography. As a result of the effects of slope, aspect, and elevation there are fewer lightning caused fires. The lightning distribution and weather conditions in the higher elevations lowers the ignition potential resulting in fewer fires. The 2001-2006 lightning density map (Figure 18) illustrates a gradient in lightning distribution across the park. With increasing distance from the continental divide, lightning density increases. The relationship between lightning density and the number of lightning strikes can be used to indicate fire ignition potential. The ignition potential from lightning for most of the Willmore is relatively low.

\footnotetext{
${ }^{20}$ The Adams Creek weather station records daily not hourly weather data and therefore was not included in the analysis
} 
Figure 17: Predominant Wind Patterns

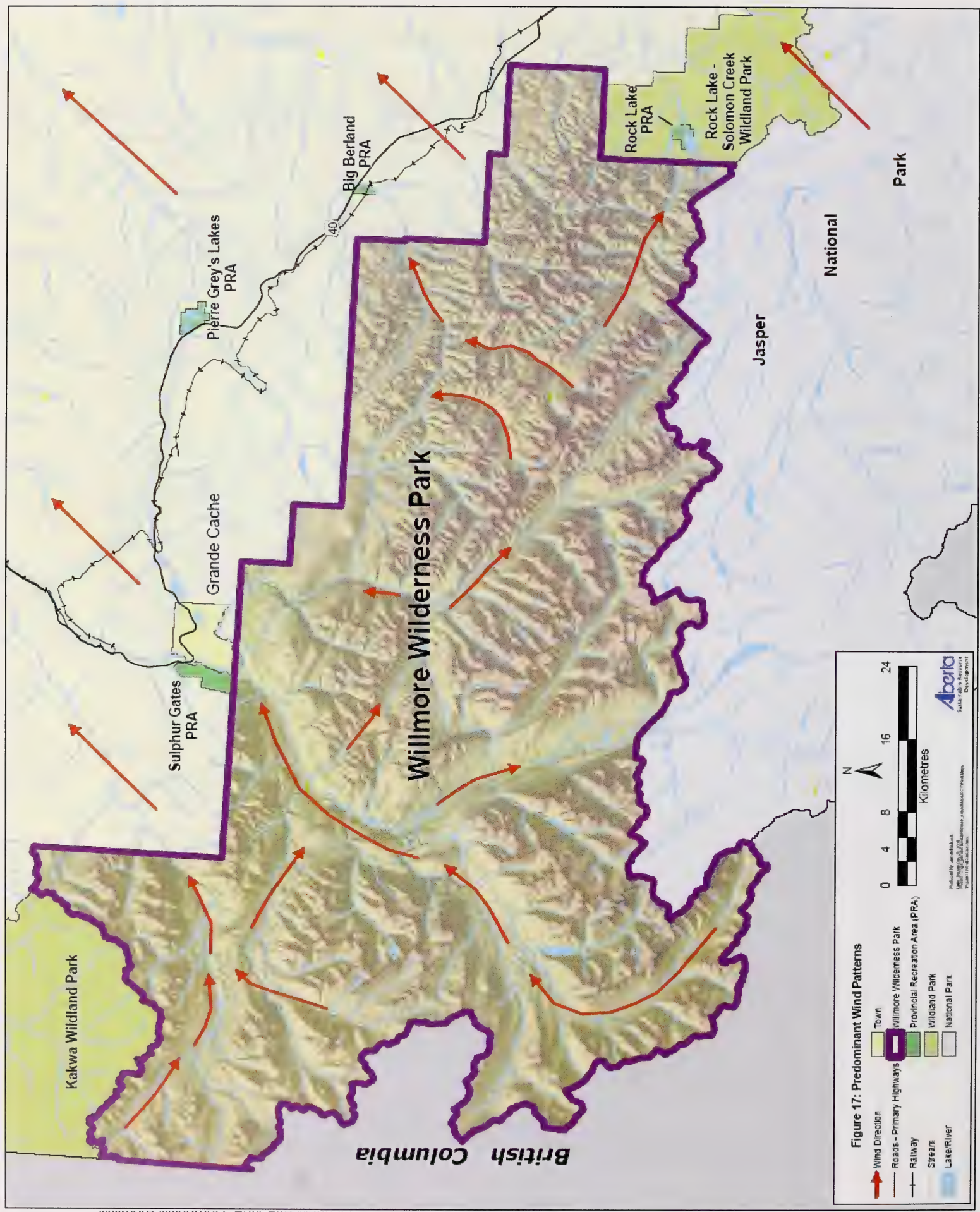


Figure 18: Lightning Density (2001-2006)

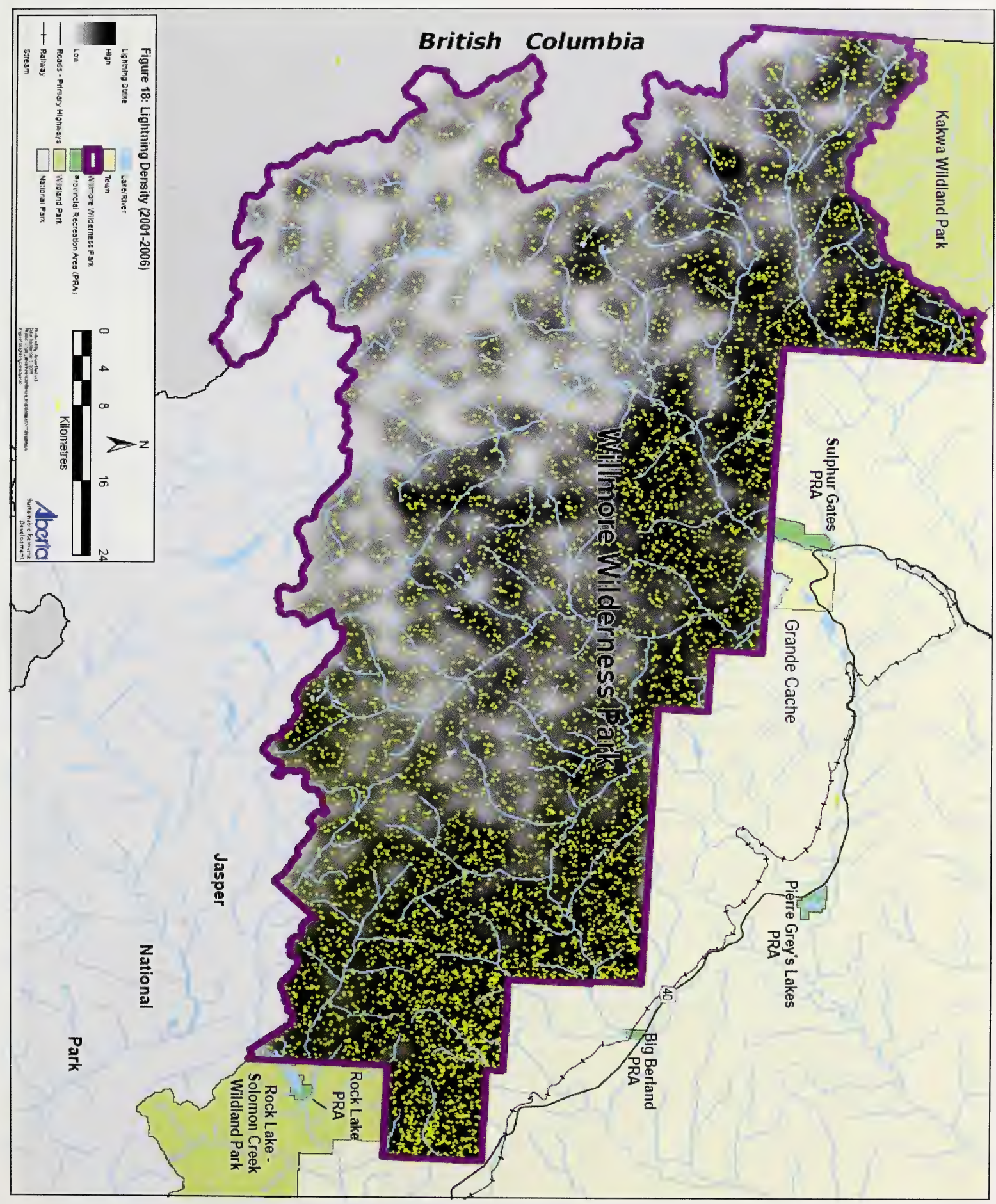

Willmore Wilderness Park Fire Management Plan - November 2006 


\subsection{Canadian Fire Growth Model - Prometheus}

Prometheus is a Canadian Wildland Fire Growth model developed as a fire management decision support tool. It is a deterministic fire growth simulation model that uses spatial fire behaviour input data on topography (slope, aspect and elevation) and Fire Behaviour Potential (FBP) fuel types, along with weather stream information to model how a fire might occur on the landscape. Prometheus modeling was one tool used to identify and assess the potential placement of prescribed fire for this Fire Management Plan.

Fire growth runs were simulated using $90^{\text {th }}$ percentile weather values from the Grande Cache weather station and a series of historic ignitions placed across the landscape. Scenarios were modeled over one burning period with no fire suppression to provide a general sense of potential fire growth runs under these circumstances (Figure 19)

Fire Weather Indices used for the simulation were as follows:

- Fine Fuels Moisture Code: FFMC-90

- Duff Moisture Code: DMC-41

- Drought Code: DC-410

- Temperature Minimum- $10^{\circ} \mathrm{C}$

- Temperature Maximum-24 ${ }^{\circ} \mathrm{C}$

- Wind speed Minimum-7 km/hr

- Wind speed Maximum-23 km/hr

- Wind Direction-Southwest

- Relative Humidity $31 \%$

Simulating a one-day fire run using historic ignitions demonstrates three main valleys of concern where fire could potentially escape beyond the park: Smoky River, Sheep Creek and Sulphur River. This simulation identifies opportunities to strategically place prescribed burns in these three main valleys to close off the north and west portions of the park from escaping fire. Large fire potential is also evident in the Smoky River and Jackpine River valleys under moderate conditions and could potentially burn major valleys under more extreme fire burning conditions. The large deciduous component adjacent to the Town of Grande Cache limits the fire growth potential, however the coniferous fuel wicks indicate that there is an inherent risk.

The Prometheus modeling illustrated potential areas of fire growth and helped supplement other information as well as field visit observations to identify locations where fireguards should be considered when developing the natural fire and managed fire zones, as well as considering community protection for Grande Cache and protection of adjacent values at risk. The 2006 wildfires (which occurred prior to implementation of the fireguards Pubs proposed in this Fire Plan) proved that fireguard Pubs for the Sheep Creek valley and the Middle Smoky River locations are well justified. One wildfire proceeded east along the Sheep Creek valley towards the initial proposed Sheep Creek PB location, as well as down the Muddywater valley towards the proposed Middle Smoky River PB location. The other wildfire followed the Jackpine River east towards the Smoky River and the proposed Middle Smoky River PB location. 
Figure 19: Prometheus Fire Growth Runs

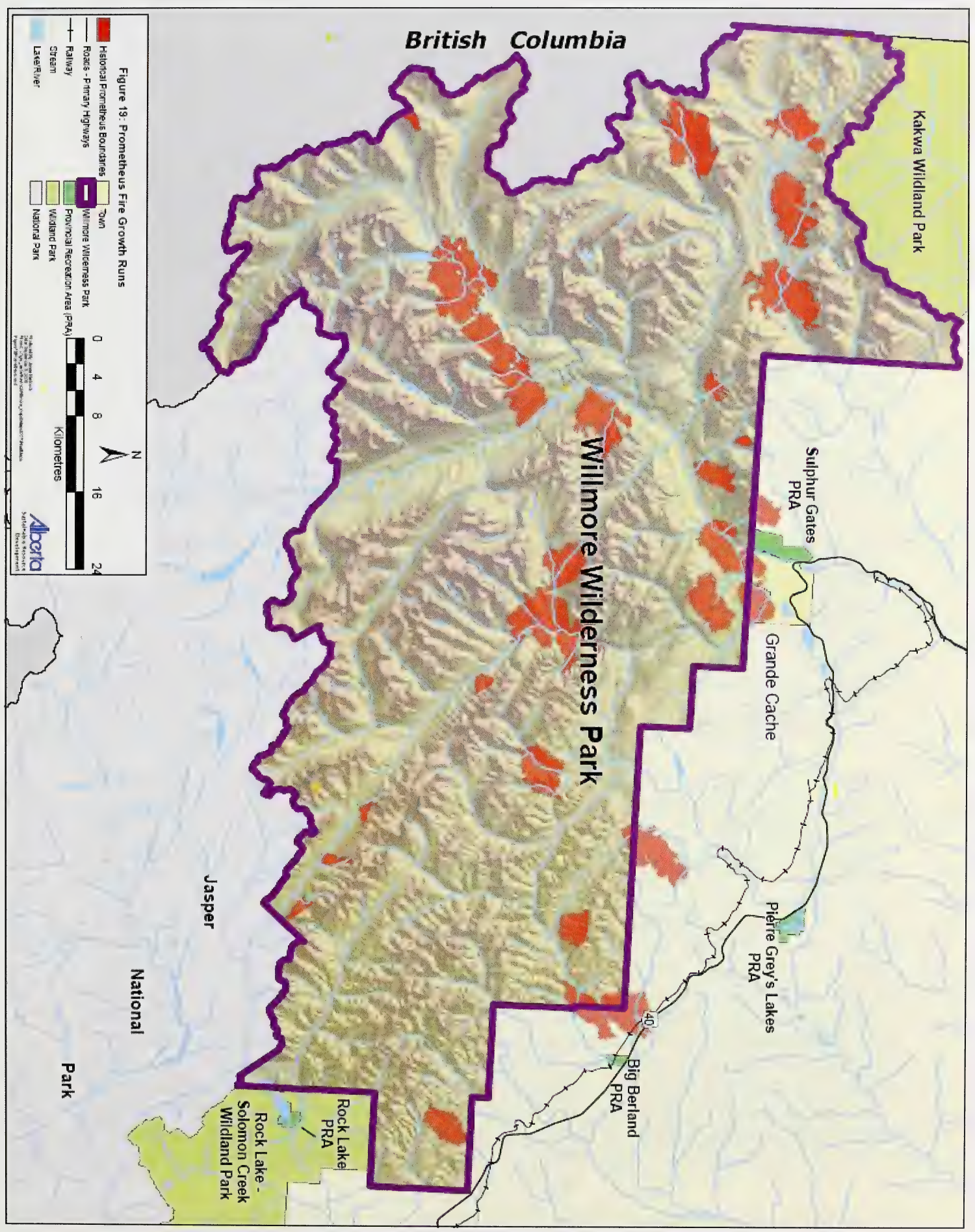




\section{FIRE MANAGEMENT STRATEGIES}

The primary focus of wildfire management provincially has been on suppression of all wildfires. Current wildfire management must shift to embrace the need to consider both the positive and negative impacts of wildfire, as well as the consequences of fire exclusion. Wildfires actually provide fire management by removing accumulations of old and dead material from the forest, therefore resulting in less intense and severe wildfire. The natural fire cycles will differ in their frequency and resulting fire intensity depending on their location. Interrupting the natural cycle, whether long or short, results in fuel accumulation and the potential for larger, higher intensity fire than may occur in the natural cycle. Integrated and adaptive approaches to fire management must recognize the need to allow natural fire regimes to resume on the landscape where feasible.

The Willmore Wilderness Park presented an opportunity to deviate from current fire management approaches in order to develop a landscape level Fire Management strategy that minimizes human manipulation and suppression while achieving key goals. The intent of this overall Fire Management Plan is to recommend strategies to:

- Mitigate wildfire threat to landscape and species values, as well as communities;

- Minimize the threat to forest health (e.g. MPB);

- Allow natural fire regimes to re-establish across the landscape; while

- Prioritizing ecological integrity.

In order to meet the intent, a variety of fire management strategies will be employed.

Fire management in the Willmore Wilderness Park will follow a two-pronged approach:

First, there is the Wildfire Management Strategy for dealing with wildfires through the natural fire and managed fire zoning, which includes a process for assessing and actioning the fires in each zone.

Second is the Prescribed Fire component with the conservative introduction of selective prescribed burns, a capping unit and containment lines to meet fire management goals. The prescribed burns and capping unit allow delineation of the natural fire and managed fire zoning for the Wildfire Management Strategy.

Alberta Community Development (CD), Parks and Protected Areas Division, provides land management direction for the Willmore Wilderness Park. The Forestry Division of Alberta Sustainable Resource Development (SRD) is responsible for wildfire management in the Forest Protection Area of Alberta. Current provincial fire management policy promotes suppression of wildfires within Willmore Wilderness Park.

The Fire Management Plan is a strategic, landscape level plan to guide the overall parameters of fire management within Willmore Wilderness Park. All Fire Management Plan decisions will be based on discussion between the two departments (CD and SRD) to determine what is appropriate within the legislative and policy (including fire management policy) framework for Willmore. A notification protocol matrix (Appendix II) will ensure notification of appropriate $C D$ and SRD staff for wildfire management decisions. Detailed prescribed burn plans will be developed specific to each prescribed burn (PB). These PB plans, outline operational guidelines and ecological considerations to be employed in conducting the PB. Each PB plan also includes a communication plan that outlines the mechanisms of public notification and signage. Both departments must sign off these individual PB plans before the burns are conducted. 


\subsection{Wildfire Management Strategy}

The Willmore Wilderness Park is divided into two fire management zones: a natural fire (backcountry) zone where natural fire processes may be allowed to occur, and a managed fire (front country) zone with active suppression of most fires (Figure 20). The general division into these zones is based on a natural barrier located diagonally across Willmore Wilderness Park. This diagonal barrier is provided by the Persimmon mountain range extending from the south boundary of Willmore Wilderness Park northwest to the Sulphur River, and then the series of mountain ranges that continue northwest to Kakwa Wildland Park with breaks at the Smoky River and Sheep Creek. Strategic prescribed burn locations were selected to create fireguards across the Sulphur River, Smoky River and Sheep Creek valleys where these breaks in the ranges could potentially allow fire to escape into the managed fire zone and along the valleys. The fireguards secure the natural fire zone in order to allow the opportunity for natural fires to burn in that zone with minimal risk to values outside Willmore.

Fires that start in the natural fire zone will be assessed in order to determine if it is reasonable to let them burn. Fires in the managed fire zone will continue to be suppressed to prevent escape into the adjacent working landscape and accompanying communities and industry. However, just as there may be cases in the natural fire zone that warrant full suppression, there may also be fires in the managed fire zone where minimal or no suppression is required. The actioning of fires in the natural fire and managed fire zones of Wilderness Park is outlined in section 8.1.3 and Figure 21.

The entire Willmore Wilderness Park will be considered a managed fire zone until strategic prescribed burn fireguards are completed to allow the natural fire zone to occur. Therefore, in the interim, wildfires in the proposed natural fire zone will be assessed and acted on based on the threat of escape through the valleys where the fireguards are proposed. When the strategic fireguards have been completed then wildfire suppression operations will be conducted according to the natural fire and managed fire zones. In the future, complementary fire management in the adjacent land base may allow expansion of the natural fire zone.

\subsubsection{Managed Fire Zone}

The managed fire zone includes the front country region of Willmore Wilderness Park east of the diagonal mountain barrier extending from Jasper National Park to Kakwa Wildland Park. This diagonal barrier is provided by the Persimmon Range and a series of contiguous ranges. In this front country area, as the Rocky Mountains transition into the upper foothills, the topographic features, continuous forest fuels, and therefore lack of natural barriers, make it difficult to control fire spread outside of Willmore.

In light of the provincial mandate, the managed fire zone implies full suppression of all fires and maximum use of suppression resources. Suppression strategies and tactics will follow SRD, Forestry Division Standard Operating Procedures and may involve single or multiple fire resource (crews, equipment, aircraft) dispatch depending on fire hazard, fire behaviour and values being threatened. However, these suppression strategies and tactics will be modified to ensure that they are appropriate within this protected area. Because this managed fire approach (i.e. suppression) has certain ecological implications, the natural fire zone was developed for the other $2 / 3$ of Willmore to provide the opportunity for natural fire processes to occur and allow the ecological benefits. 
Figure 20: Fire Management Zones

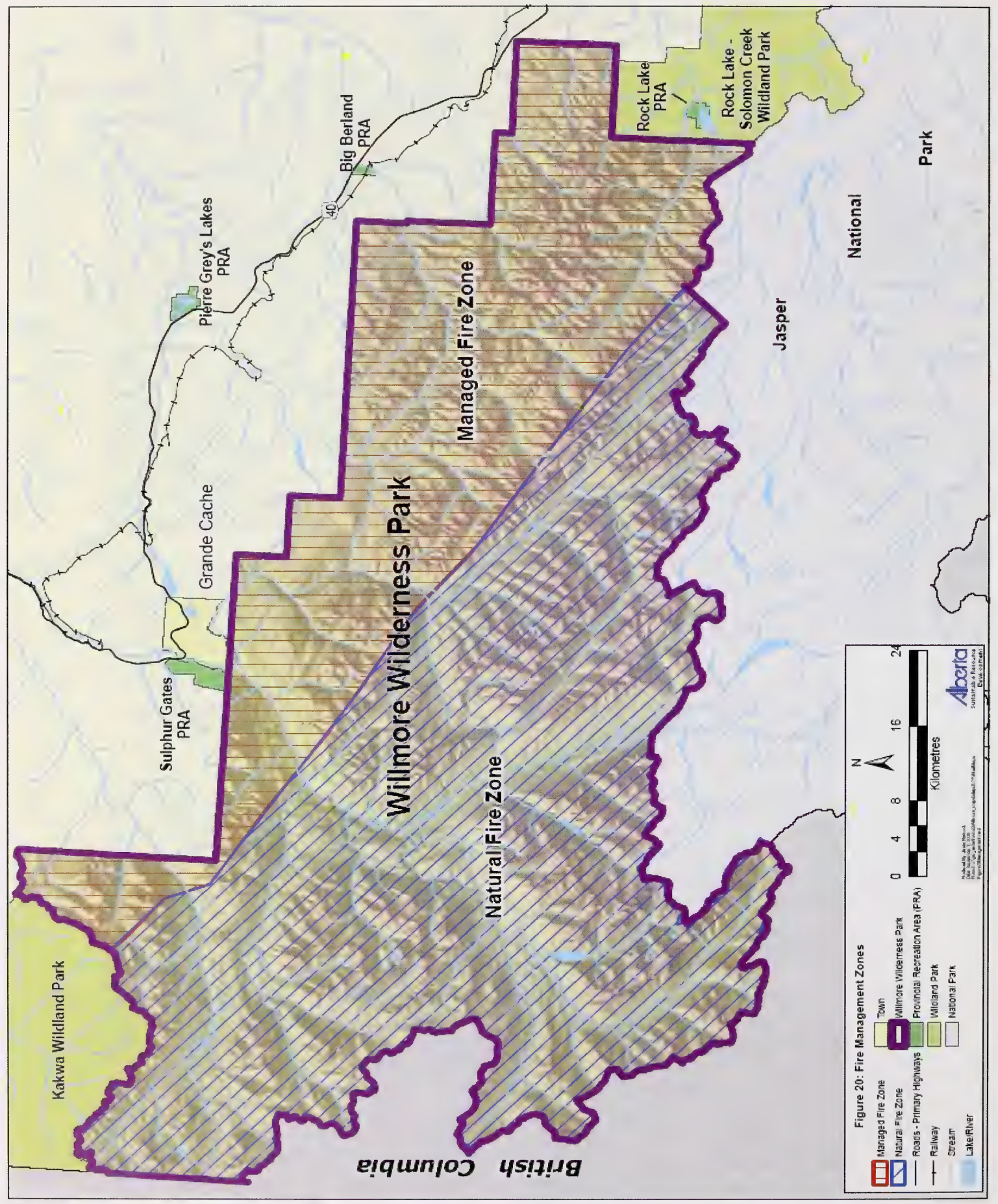

Willmore Wilderness Park Fire Management Plan - November 2006 
The intent in the long term is to explore opportunities to move from managed fire (i.e. suppression) to natural fire (i.e. "let burn") management within and adjacent to the park through the integration of fire into land and resource management planning. Pockets may exist within the managed fire zone where natural fires are feasible to occur. These opportunities may increase with shifts in fire management activities on the adjacent land base by forest companies as well as the Grande Cache FireSmart applications.

\subsubsection{Natural Fire Zone}

The natural fire zone includes the backcountry region of the Willmore Wilderness Park west of the diagonal mountain barrier (provided by the Persimmon Range and other contiguous ranges) to the B.C. border. The diagonal stretch of mountain ranges provides a topographic barrier that limits wildfire spread. This backcountry area of the park is remote with no development, low wildfire threat to human-related values at risk, but does contain ecological values at risk. The main goal is to allow natural fire processes to occur and provide the benefits of wildfire. Fire management in the natural fire zone involves limited suppression activities and minimal use of suppression resources. This can be achieved through strategically placed prescribed burn fireguards that reinforce the natural fire zone and reduce the risk of wildfire escaping into the managed fire zone where there are less natural barriers to fire spread.

All fires in this zone will be assessed at their onset to determine if they can feasibly be allowed to burn given fire conditions and risk. Ecological values at risk (e.g. caribou) will be considered when assessing how to action the fire. Fires that have the potential to become very destructive may still be suppressed but the general intent is to avoid interference in natural fire processes.

\subsubsection{Wildfire Management Decision-Making}

\section{a. Protocol}

Once a wildfire is detected in the Willmore Wilderness Park and reported to the Wildfire Management Area (WMA) Fire Centre, the WMA Duty Officer will advise the WMA Forestry Division (FD) Manager of the current situation. The WMA FD Manager will inform the Parks and Protected Areas Division (PPAD) Area Manager as is deemed necessary. A communications process (see section 11.3 Wildfire Communications) will be initiated. The Notification Protocol Matrix (Appendix II) outlines which internal and external stakeholders shall be notified in the event of a wildfire.

\section{b. Wildfire Actioning Matrix}

Wildfire management within Willmore will be conducted according to the zone: managed fire zone or natural fire zone. The Willmore Wilderness Park Wildfire Actioning Matrix (Figure 21) outlines the process and action for each zone.

- Managed Fire Zone: Full suppression of most fires within the managed fire zone involves initial and sustained action to suppress the fire with completion of an Escaped Fire Analysis Strategy (EFAS) if needed.

- Natural Fire Zone: The process for determining the level of action (or no action) in the natural fire zone involves:

- 1) Escaped Fire Analysis Strategy (EFAS)

$\circ$ 2) Joint CD/SRD decision on action

- 3) Action: a) no suppression and monitor;

b) modified suppression and monitor; or

c) full suppression. 
Figure 21: Willmore Wilderness Park Wildfire Actioning Matrix.

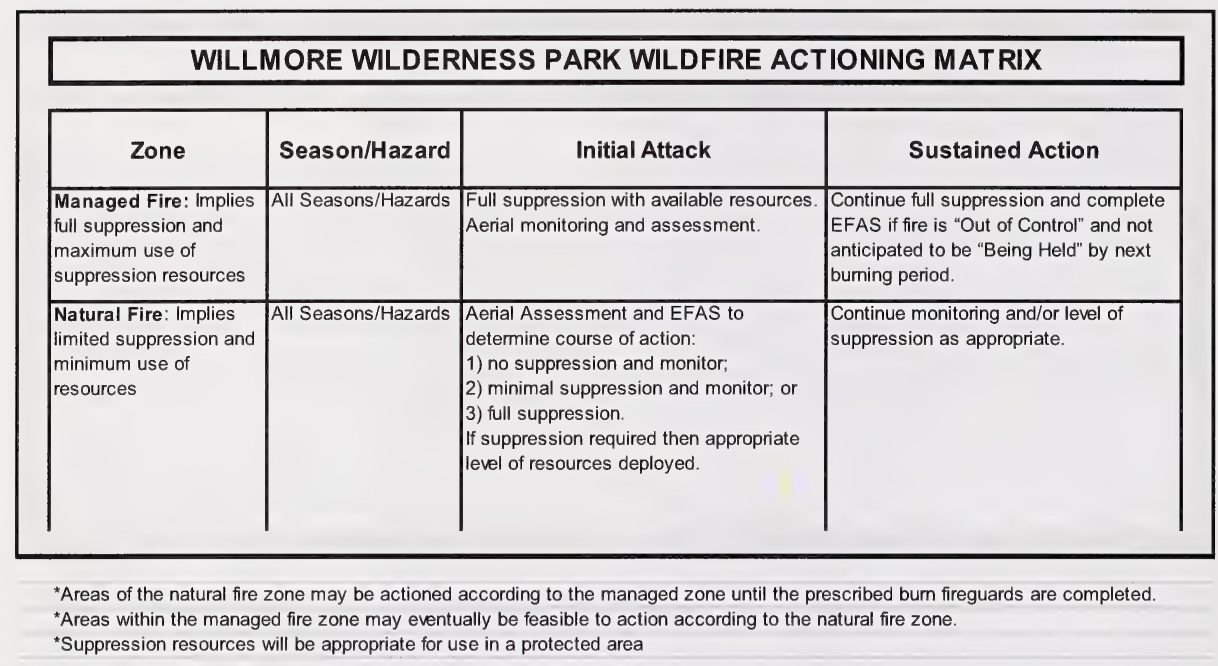

\section{c. Escaped Fire Analysis Strategy (EFAS)}

Forestry Division's Escaped Fire Analysis Strategy (EFAS) provides a template for assessing wildfires to determine appropriate suppression strategies and tactics for Willmore Wilderness Park on the basis of achieving effective control while minimizing the ecological impacts of the suppression methods. The EFAS will be completed by qualified Forestry Division (FD) staff with final approval for action by SRD (FD) and CD (PPAD).

The process for the Escaped Fire Analysis Strategy (EFAS) in Willmore is:

1. An EFAS must be completed for:

- All fires in the natural fire zone.

- All "Out of Control" fires that are not anticipated to "Being Held" (i.e. under control) by next burning period in the managed fire zone.

2. EFAS completed by personnel certified Incident Commander level 2 or greater.

3. The EFAS suppression strategy shall be based on:

- Location of the wildfire within Willmore Wilderness Park (e.g. natural vs. managed zone),

- Fire management plan and park management goals and objectives,

- Mitigation of ecological impacts (e.g. wildlife/plant species, waterways, soils)

- Potential final wildfire size,

- Fire behaviour (present and expected),

- Natural fuel breaks,

- Time of year,

- Provincial and WMA priorities,

- Suppression costs 
4. Appropriate suppression tactics and materials will be selected to minimize the ecological impact within the protected area while still allowing adequate suppression capability.

- Utilize existing topography, ecology and weather as much as possible to deliver natural suppression and minimize human intervention.

- Aircraft and ground crews will be the main modes employed.

- No new roads or access.

- Heavy equipment will not be permitted except in extreme situations (see section 8.1.3.e. Guidelines/Criteria for Heavy Equipment Use), due to risk of ecological impacts such as damage to vegetation and soil, erosion, siltation, disturbance and alteration of water courses, potential for introduction of invasive species and destruction of recreational trails.

- Water is preferred to chemicals e.g. retardants/foams.

5. The Forestry Division (SRD) and Parks and Protected Areas Division (CD) Area Managers will review and approve the EFAS recommendations.

6. Once the course of action for a wildfire is determined (i.e. full suppression, minimal suppression, no suppression) under the wildfire actioning matrix and EFAS, then Forestry Division will proceed with actioning the fire according to their operational procedures. Area closures of specified locations, including appropriate public notification and signage, will be employed if needed. Communications will proceed according to the process discussed in section 11 . Communication Strategy.

\section{d. Area Closure/Fire Ban}

An area closure (partial or full) or fire ban recommendation by FD, PPA or the Municipality/County is first reviewed by the PPA (CD) Area Manager. The request for area closure or fire ban is then submitted for a CD Ministerial Order to enact the area closure or fire ban. The area closure or fire ban may be communicated to relevant staff, public and stakeholders through means such as signs, closure tape, CD website, provincial/local media, SRD wildfire hotline and fire information officers, phone call/email to key stakeholders.

\section{e. Guidelines/Criteria for Heavy Equipment Use}

The use of heavy equipment within Willmore Wilderness Park versus other less intrusive methods will only be implemented in extreme circumstances and not as a general fire suppression tool for expediency or cost-effectiveness. In general, the topography within Willmore greatly restricts the potential for utilizing heavy equipment.

1. Use of heavy equipment within Willmore Wilderness Park will involve a joint decision by Community Development and Sustainable Resource Development after consultation between the departments to determine if conditions are warranted.

2. Heavy equipment use will be considered within Willmore Wilderness Park in extreme situations where all possible alternative methods within the park. (e.g. helicopter bucketing, ground crews, waterlines, fire lines constructed by other means, preconstructed fuel guards) or control outside the park are not deemed sufficient or timely to hold the fire.

3. Once the fireguards identified in this Fire Management Plan are in place and the Natural and Managed Fire Zones are delineated then the chance of an extreme 
situation scenario will be greatly reduced. Heavy equipment will not be required nor utilized in the Natural Fire Zone.

4. Access by heavy equipment will be restricted to existing access, with preference towards utilizing main access points and historic roads within the front country area of the park (e.g. Kvass Flats trail from Sulphur Gates PRA, Berland River Trail from Berland staging area, Indian trail from Rock Lake PRA). Fireguard construction will utilized existing disturbances where feasible.

5. The following guidelines are to be followed when employing heavy equipment.

i. The minimum type and amount of heavy equipment will be utilized to accomplish the fire control objective.

ii. The choice of heavy equipment must be suitable to the terrain to minimize damage/disturbance.

iii. All fireguard lines proposed to be built or used by heavy equipment should be carefully located and flagged to avoid wet soils and other environmentally sensitive areas. Construction of the fireguard will be supervised.

iv. All equipment must be cleaned as much as feasible (e.g. before entry, during travel, before creating a fireguard) to avoid distribution of invasive species (most trails have high equestrian use and therefore high potential for invasive species).

v. When heavy equipment is utilized, rehabilitation planning (including timelines and costing) must occur.

a. Development of a rehabilitation plan may include input from: various interdepartmental expertise e.g. CD-Parks and Protected Areas (planners, biologists, conservation officers)/Cultural and Historical Resources; SRD-Forest Division (fire operations, forest health)/Fish and Wildlife (biologists); Environment.

b. If the heavy equipment is also required for rehabilitation then it is advisable to employ the rehabilitation before removing the equipment to avoid re-entry.

c. All rehabilitation will occur in a timely manner to standards (both ecological and aesthetic) acceptable to Community Development as outlined in the rehabilitation plan.

d. Community Development will signoff when the rehabilitation is completed.

6. In general, sufficient fire suppression resources will be provided to control the fire with alternative, less environmentally damaging means. These alternative methods will be aggressively pursued and used even if they are less expedient or cost effective than more intrusive measures.

\section{f. Post-wildfire Rehabilitation}

Post-burn cleanup will be minimal (other than for safety hazards) in order to retain burned trees as habitat, allow decomposition to return nutrients to the ecosystem, and allow natural regeneration. Natural regeneration and restoration is preferable to human interference.

- A rehabilitation plan will be developed for mitigation of suppression or fire impacts if necessary.

- Mitigation of suppression or fire impacts will only be implemented if natural restoration is not likely to be successful.

- Appropriate signage may be employed to notify the public of safety hazards and lack of grazing (for equestrian users) while traveling through burned areas, or to prevent access to disturbed areas undergoing rehabilitation. 


\subsection{Prescribed Fire Strategy}

Prescribed fire is often used as a direct means to "restore" fire disturbance patterns on the landscape by initiating a set of planned, controlled prescribed burns that mimic what is considered the appropriate fire disturbance pattern. Prescribed burns may also be used for vegetation management or habitat enhancement. However, Willmore Wilderness Park provides a unique opportunity to let natural fire cycles establish the appropriate timing and disturbance patterns. Therefore prescribed fire is being utilized alternatively as a tool in this Fire Management Plan to meet multiple objectives: create fireguards to allow natural fire processes within the natural fire zone; "FireSmart" Grande Cache; and target a specific area of mountain pine beetle infestation (Figure 22). There is no intent to introduce prescribed burns to artificially create a fire pattern on the Willmore landscape. Vegetation management and habitat enhancement are not objectives of this Fire Plan but will be determined through a Park Management Plan.

In this alternative prescribed burn approach, prescribed fire is mainly used to create the fireguards that complement existing topography and delineate the natural fire and managed fire zoning that is the basis of the wildfire management strategy. These fireguards create the natural fire zone where natural fire processes may be allowed to determine the appropriate fire disturbance pattern. This zoning is key to the overall fire management within Willmore and complements the other two objectives of Grande Cache FireSmart community protection and providing potential MPB impacts.

Two small prescribed burns may be burned back from the two hand cut containment lines proposed as preliminary FireSmart fireguards in the Grande Cache Community Protection Plan (GCCPP). These prescribed burns would be employed at the time of advancing wildfire to reinforce the containment lines. The GCCPP and Fire Plan were developed so that complementary activities would meet a joint objective of community protection. Securing a fireguard for protection of Grande Cache meets the goals of this Fire Management Plan, the GCCPP, and provincial priorities for protecting life and infrastructure values at risk.

The Fire Management Strategy includes MPB under the forest health objective in order to consider potential fire management strategies that may support ongoing MPB control activities. Monitoring, surveying and then treatment, by falling and burning individual infected trees, is the main control approach being utilized throughout Willmore. However, prescribed fire or wildfire can also provide MPB control: 1 . to proactively remove vulnerable pine which may provide MPB habitat, and therefore to decrease the MPB susceptibility rating. 2. to remove a portion of habitat, such as in a valley, and create a barrier so that MPB cannot incrementally advance unless a wind event carries them over it. 3. to destroy a population of MPB if the fire is intense enough to kill them while resident within the tree. The Willmore Fire management plan utilizes one prescribed burn specifically intended for MPB control. This prescribed burn targets an area near British Columbia (B.C.) which hosts recurrent MPB infestations despite regular fall and burn control. The intent of this prescribed burn is to destroy the pocket of infestation, and remove the MPB habitat supporting the recurrent infestations and providing a MPB corridor from B.C. into Willmore. No other MPB-related prescribed burns are proposed. However, the prescribed burns that are intended as fireguards will also potentially remove MPB habitat, MPB populations and create MPB barriers. More importantly, these fireguards will enable future wildfires, which may naturally provide MPB control. The two large wildfires in the summer of 2006 provided substantial unanticipated MPB impacts by removing large amounts of MPB habitat, creating MPB 
barriers, and burning MPB. These wildfires burned more area in a short time than could reasonably be achieved through a prescribed fire approach and provided a substantial substitute for additional prescribed fires for MPB control. Therefore, additional prescribed burns are not being proposed to pro-actively remove potential MPB habitat prior to MPB infestation or to burn large infested areas (instead of the current fall and burn approach) within Willmore as that approach would require a strong rationale in terms of the ecological impacts.

\subsubsection{Prescribed Burn/Containment Line/Capping Units}

Five conceptual units (prescribed burn, containment line and capping) are proposed to address the Fire Management Plan goals: Lower Smoky River, Sulphur River, Middle Smoky River, Meadowland Creek and Sheep Creek (located outside Willmore). These proposed conceptual units are outlined in Figure 22 and listed in Table 10.

Two additional adjacent prescribed burns (mainly located outside Willmore) may be developed in conjunction with Jasper National Park: Upper Smoky River and Rock Lake. The Rock Creek prescribed burn between Jasper National Park and Willmore Wilderness Park was completed prior to this Fire Management Plan.

In general, the proposed units in this Fire Management Plan occur in areas of mainly pine, and spruce-fir mixed forests. The approximate sizes below are based on the conceptual proposed boundaries and do not account for skipped patches of forest that will be left unburned by the fire within the PB boundaries.

Table 10: Proposed conceptual units for Fire Management Plan

\begin{tabular}{lc}
\hline Prescribed Burn/Containment Line/Capping Units & Area (Ha) \\
\hline Lower Smoky River containment lines & Undetermined \\
Sulphur River PB & 1250 \\
Middle Smoky River PB & 1575 \\
Sheep Creek capping unit (outside Willmore) & Undetermined \\
Meadowland Creek PB & 11185 \\
Upper Smoky River PB (Jasper National Park) & 8570 \\
Rock Lake/Snake River PB (Jasper National Park) & 3080 \\
Rock Creek PB (Completed) & 1085 \\
\hline
\end{tabular}


Figure 22: Proposed Prescribed Burn / Containment Line / Capping Units

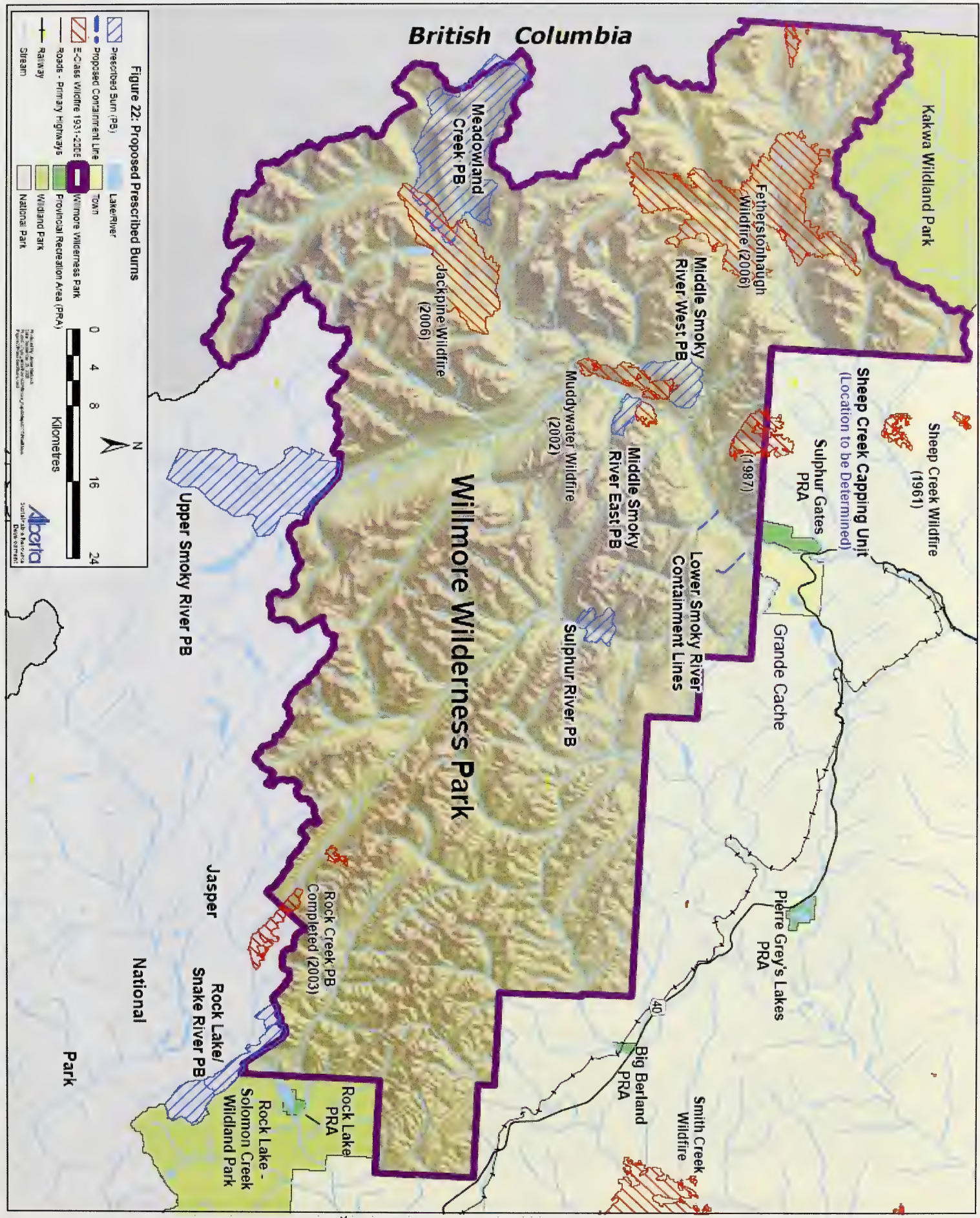




\section{a. Lower Smoky River}

The fuels on the south side of the river are mostly pine and spruce coniferous forests. These forests are continuous and extend into Grand Cache with few natural barriers. The fuels on the north side of the river are deciduous and composed primarily of aspen. These deciduous fuels are typically older than 80 years, have significant surface fuel accumulation and are known to carry crown fire in spring and fall seasons. Historical evidence suggests large stand replacing fire have occurred throughout the main valley spreading in the direction of prevailing southwesterly winds (Figure 23).

\section{Figure 23: Looking up the Smoky River valley. (Early 1900's)}

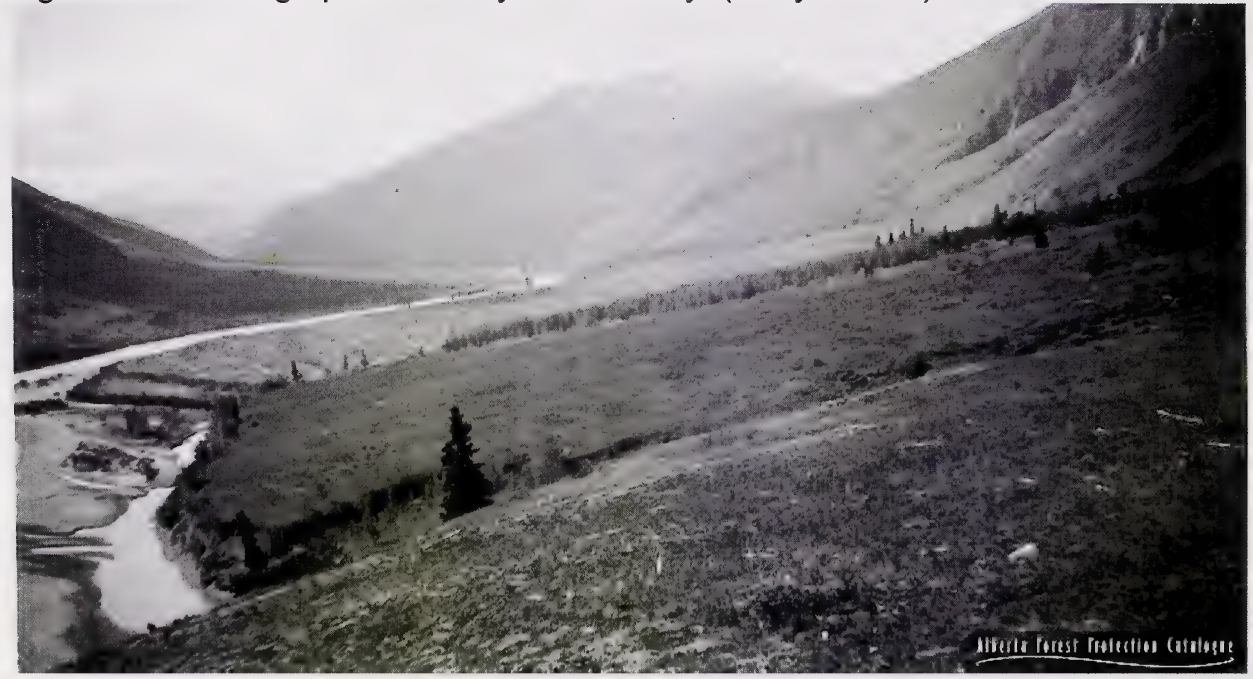

The main objective of the Lower Smoky River containment line/prescribed burn unit is to provide a fireguard for the Town of Grande Cache, which is located adjacent to the northeast boundary of Willmore. Prevailing winds from the west, and extensive contiguous forests, pose the risk of wildfire originating within Willmore to spread along the Smoky River valley towards Grande Cache.

The Town of Grande Cache initiated a Grande Cache Community Protection Plan (GCCPP) in November 2004 in order to FireSmart the Town. The planning area is a tenkilometre radius around the town including a portion of the Smoky River valley within Willmore. The GCCPP and Willmore Fire Plan were developed in parallel to complement each other and provide a coordinated approach to meeting community protection objectives. The strategy is a two-pronged approach with two initial hand cut containment lines implemented through the GCCPP, that would provide the anchors to "burn back" from in order to conduct emergency prescribed burns and create reinforced fireguards if wildfire was advancing. The prescribed burns/containment lines therefore provide primary and secondary lines of defence if wildfire is advancing towards Grande Cache.

Construction of the hand cut containment lines will minimize impact and will not involve new roads or heavy equipment. The cut trees will be left onsite (unless deemed a fire hazard) and rolled into the prescribed burn area. The prescribed burn will blacken off those containment lines when needed to reinforce that fireguard. Components of the 
GCCPP within the planning area around Grande Cache are underway. Construction of the containment lines will be implemented as soon as feasible and likely be coordinated with any preparation work for the proposed prescribed burns.

This prescribed burn/containment line approach replaces a previous proposal for a prescribed burn proposal in the Kvass Flats area and will better meet community protection goals. Initially the prescribed burn was proposed to span the area between the two containment lines. However this approach was modified due to the difficulty in conducting a large prescribed burn so close to Grande Cache (e.g. smoke issues). The reinforced containment lines were deemed to be more feasible and as a result could be implemented more quickly. Completion of the GCCPP activities and these prescribed burn/containment lines may enable future consideration of some natural fire areas in more distal areas within the managed fire zone.

\section{b. Sulphur River}

The Sulphur River prescribed burn unit is one of the three prescribed burns proposed to provide a fireguard to support the natural fire and managed fire zones. This fireguard will prevent fire from escaping the natural fire zone, along the Sulphur River valley through a gap between the Persimmon range and adjacent mountain range, and into the managed fire zone. Historical evidence suggests large stand-replacing fires did burn extensive areas of the Sulphur River (Figures 24 and 25).

Figure 24: Big Grave Flats on the Sulphur River. (Early 1900's)

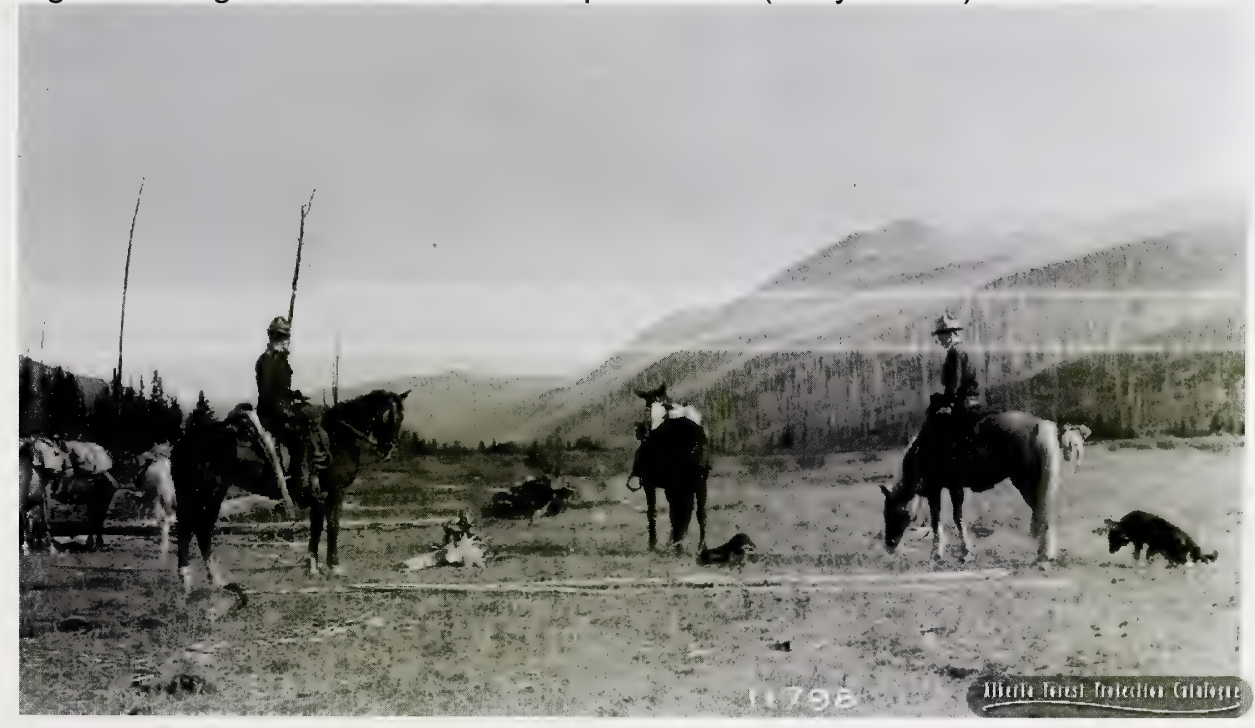

\section{c. Middle Smoky River}

This prescribed burn unit provides another of the three fireguards to delineate the natural fire and managed fire zones. This prescribed burn will effectively block off the intersection of the Muddywater, Pauline and Smoky River valleys and close that gap in the mountain ranges. This proposed prescribed burn creates a fireguard and may provide potential mountain pine beetle (MPB) barrier. This MPB barrier may hinder MPB spreading eastward along the Pauline River from the Meadowland Creek area, as well 
as along the Muddywater River and adjacent valleys. MPB have been found in these areas and prevailing winds from the west and north may transport them along the valleys. This barrier may also prevent MPB spreading further along the Upper Smoky River from Jasper where it is occurring. However, the main objective is as a fireguard.

This prescribed burn enhances the Muddywater prescribed burn of 2002 with two portions that straddle that burn to the northwest and east. Previously, a burn from 1974 has provided a firebreak for many years. Historical evidence suggests that large landscape level fire have occurred in this area (Figure 26).

Figure 25: Monoghan Creek and Sulphur River. (Early 1900's)

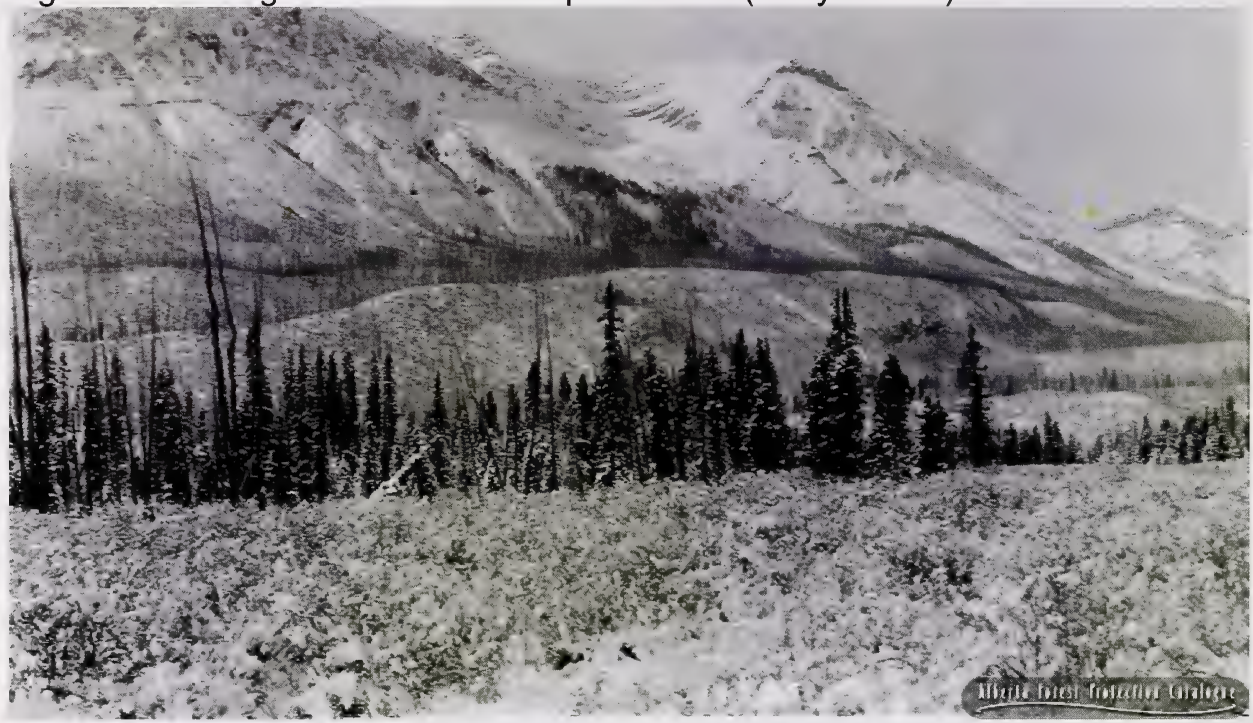

The importance of the Middle Smoky River fireguard became evident in the summer of 2006. The Fetherstonhaugh wildfire, which started in the Sheep Creek valley around Cote Creek, spread east along the Sheep Creek valley and north along Famm Creek as well as south into the Fetherstonhaugh Creek and Muddywater River valleys. The fire proceeded eastward in the Muddywater river valley towards the Smoky River that continues east to Grande Cache. However, the wildfire was held at Dry Canyon on the Muddywater River. It was anticipated that the Middle Smoky prescribed burn would have to be implemented as an emergency measure but conditions were not suitable for the prescribed burn and the wildfire remained held at Dry Canyon. The Jackpine wildfire occurred at the same time as the Fetherstonhaugh wildfire. This wildfire started near the intersection of the Jackpine and Pauline Rivers and proceeded eastward along the Smoky River. Again, the merit of having a Middle Smoky River fireguard in place was recognized but not feasible, however the wildfire was held before it reached the Middle Smoky area. 
Figure 26: Large, stand-replacing fire burned entire valley (landscape level burn). Looking up Smoky River towards Muddywater River. (Early 1900's)

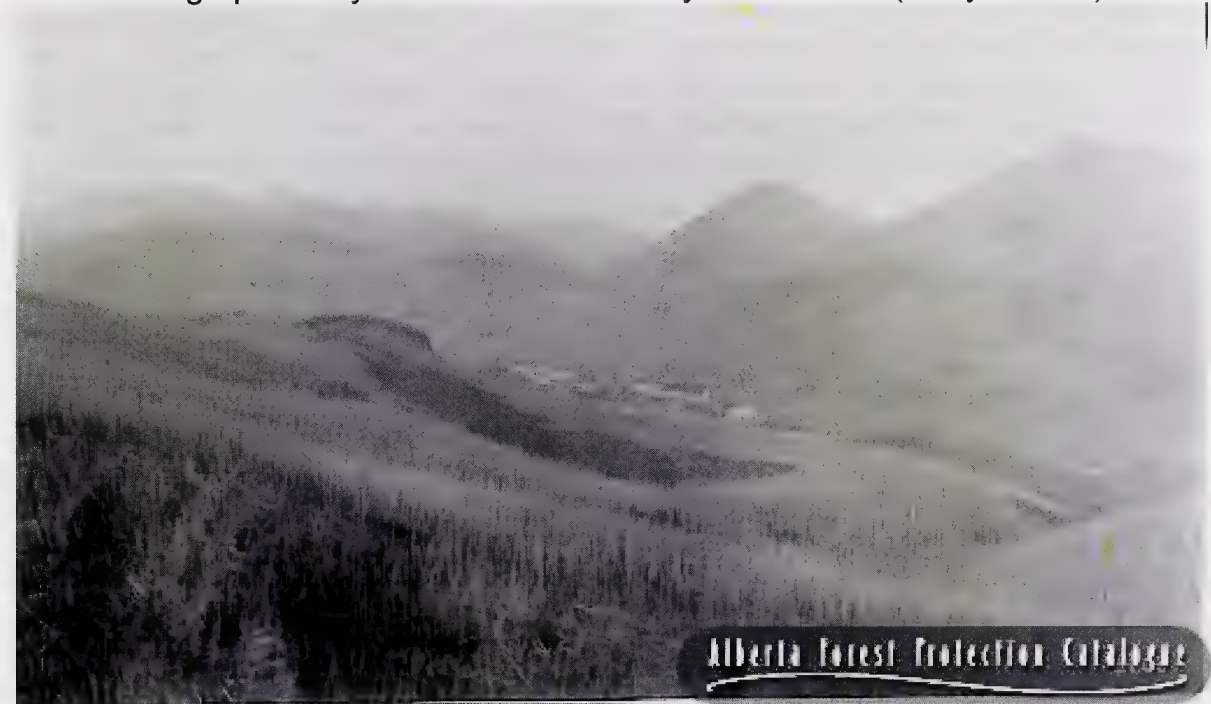

\section{d. Sheep Creek}

The Sheep Creek capping unit is the last of the three proposed fireguards. The proposed capping unit is located outside Willmore where there is a more realistic opportunity to create this fireguard. The location would be based on suitable topography and the opportunity to remove MPB (pine) habitat. This capping unit outside Willmore could be accomplished through a combination of harvesting and a prescribed burn. This fireguard is intended to block wildfire exiting Willmore along the Sheep Creek valley beyond the natural fire barriers provided by the mountain topography. The capping unit could also serve as a possible MPB barrier in the future.

The original proposed fireguard was a prescribed burn located along the Sheep Creek on the boundary between Willmore and the adjacent commercial forest lands. Approximately half of the proposed burn was located within Willmore and half outside. The cross-boundary placement of this prescribed burn, on both Sustainable Resource Development as well as Community Development lands, was to provide the opportunity to demonstrate cooperation in appropriately locating the prescribed burns, as well as to integrate fire, land and resource management planning.

However in the summer of 2006, before the Willmore Fire Plan was implemented, the Fetherstonhaugh wildfire occurred in the Sheep Creek valley west of the proposed Sheep Creek prescribed burn location. This wildfire confirmed the need for a Sheep Creek fireguard to stop wildfires from exiting the valley eastward. The Fetherstonhaugh wildfire (see description in 8.2.1.c), which started along the Sheep Creek, proceeded east along the Sheep Creek valley and then split before the east boundary of Willmore to head south along the Muddywater River and north along Famm Creek. A short emergency fireguard had to be constructed connecting the Sheep Creek trail to a nearby lake (near the junction of the Sheep Creek and Famm Creek) to prevent the wildfire from 
proceeding further east along the Sheep Creek out of the Willmore. As a result of this wildfire, a large area was burned along the Sheep Creek valley running north up Famm Creek and south along Dry Canyon in the Muddywater River valley. In order to avoid burning more area in the immediate vicinity of the recent wildfires, the location was reevaluated and relocated east outside Willmore. The exact location of the capping unit is not determined but there is the flexibility with the location outside Willmore because harvesting can be used in conjunction with prescribed fire to create this capping unit.

\section{e. Meadowland Creek}

The main goal of the Meadowland Creek prescribed burn unit is for mountain pine (MPB) beetle control. This prescribed burn is merited for a number of reasons. This burn is targeted at a recurrent MPB population that has persisted despite continual fall and burn of individual infected trees. The burn will kill the existing MPB population, remove the pine habitat that supports their reoccurrence, and create a barrier by eliminating MPB habitat between its source point in British Columbia (B.C.) into Willmore and eastward. Active infestations of MPB will be controlled through fall and burn until the prescribed burn is conducted. The detailed prescribed burn plan has been completed and implementation will be conducted with B.C. when the appropriate burn conditions occur. No other prescribed burns are being proposed specifically within Willmore to control MPB. The two significant wildfires in 2006 (outside the Meadowland Creek proposed PB area) provided the benefit of burning MPB as well as extensive MPB habitat.

\section{f. Upper Smoky River (Jasper National Park)}

This large prescribed burn unit would be mainly located within Jasper National Park (NP), although a small portion of the burn may occur in Willmore depending on where it is feasible to stop the burn. The Upper Smoky River originates in Jasper NP south of Willmore. It is an area with known MPB infestation originating from its source point in the Upper Holmes drainage of B.C. This area also poses a potential entry for fire from Jasper NP. The Upper Smoky River prescribed burn would be conducted to eliminate MPB and the pine habitat that may facilitate the MPB spread from B.C. through Jasper NP into Willmore and along the Smoky River. The MPB susceptibility model indicates most of the Smoky River to be at extreme risk. The burn would also provide a fireguard between Jasper NP and Willmore. Jasper NP has identified this prescribed burn in their fire management planning. The planning and implementation of this adjacent prescribed burn will be led by Jasper National Park in conjunction with SRD and CD.

\section{g. Rock Lake/Snake River (Jasper National Park)}

This prescribed burn unit would be located within Jasper National Park (NP), along the Snake River valley, adjacent to the Rock Lake - Solomon Creek Wildland Park. The Rock Lake prescribed burn is intended to create a fireguard to prevent fire and MPB from escaping Jasper NP into neighbouring provincial crown land, including Rock Lake Solomon Creek Wildland Park. This fireguard allows Jasper NP to conduct other prescribed burns if needed to meet their fire management planning goals. If MPB establishes in the Lower Athabasca River, there is a high probability that the MPB infestation will spread north and exit northeast along the Snake River into the Rock Lake area. This prescribed burn will provide a barrier for the MPB spread. Jasper NP has identified this prescribed burn in their fire management planning. Jasper NP will lead the planning and implementation of this prescribed burn in conjunction with SRD and CD. 


\section{h. Rock Creek}

The Rock Creek prescribed burn was initiated prior to the development of this Willmore Fire Management Plan. The burn was a cooperative effort between SRD, Jasper National Park (NP) and CD. The burn was conducted in phases with phase two completed in 2003. The burn was considered successful in achieving its objectives of providing an opportunity for a cross-boundary, interagency prescribed burn to create a fire barrier between Jasper National Park and Willmore Wilderness Park.

Figure 27: Rock Lake prescribed burn in progress, Jasper National Park, 2003

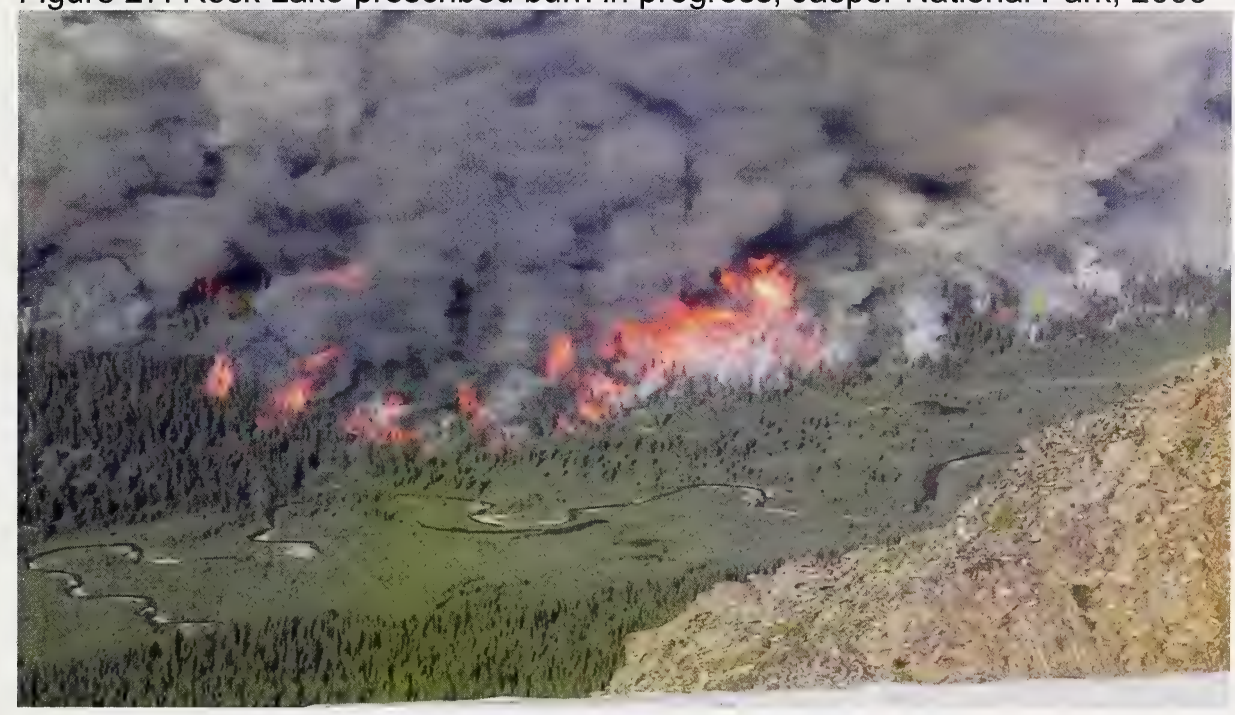

Figure 28: Rock Lake prescribed burn after three years, July 2006

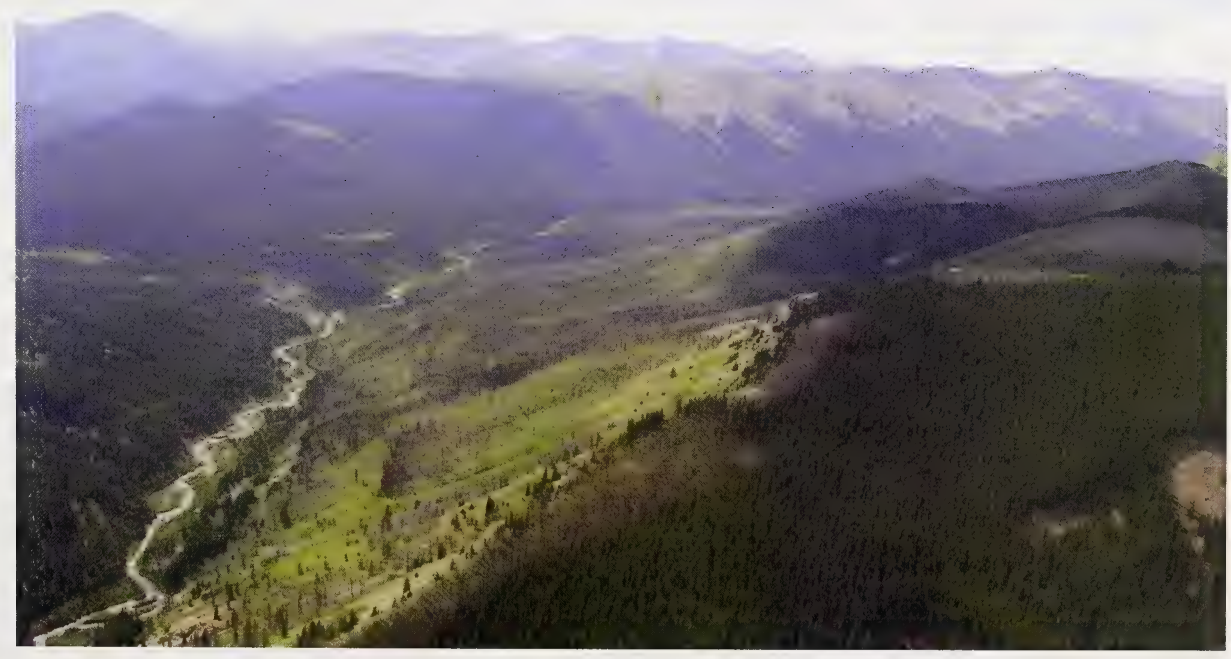




\subsubsection{Prescribed Burn Implementation}

Detailed operational prescribed burn plans, including their associated communication strategy, will be prepared for each prescribed burn. Approval by CD and SRD is required before the prescribed burns are initiated and pre-burn preparation begins. Staff involved in conducting the prescribed burns will be familiar with the objectives and philosophy of the Willmore Fire Management Plan, including the ecological considerations for conducting a prescribed burn within Willmore Wilderness Park.

The detailed operational prescribed burn plans will incorporate ecological conditions relative to implementation within a protected area. The detailed plans will assess the impact of the prescribed burn with respect to soil damage, tributary siltation, slope destabilization, potential invasive plant invasion, wildlife impacts or any other environmental considerations. Since the prescribed burns are intended to provide landscape level ecological benefits mitigation of all impacts may not be reasonable.

Ecological considerations will also be built into the operational aspects of conducting the prescribed burn. Impacts will be minimized by:

- Avoiding use of camps, or using low impact camps;

- Minimizing use of retardants/foams;

- Using safeguards such as containment trays to avoid fuel or ignition fluid spillage, and ensuring that emergency cleanup procedures are in place;

- Providing bear awareness measures and electric fencing (if needed) for crews and camps or worksites;

- Hand cutting containment lines;

- No new or upgraded roads, heavy equipment or motorized vehicles;

- Access via helicopter, horseback or foot;

- Avoiding key wildlife areas or adjusting timing of activities relative to wildlife patterns (e.g. caribou migration, nesting birds);

- Adjusting ignition patterns to avoid trapping wildlife, selecting suitable timing to avoid burning young wildlife which may not be mature enough to escape, and adopting any other modifications if recommended to minimize wildlife mortality;

- Modifying actions around fragile areas if possible (e.g. engineering the burn to draw it away, or using hand cut lines as barriers);

- Fallen trees from containment lines will generally be rolled back to burn within the prescribed burn;

- Post-burn clean-up will be minimal (other than for safety) to retain burned trees as habitat, allow decomposition to return nutrients to the ecosystem, and allow natural regeneration of the burned area;

- Mitigation of operational impacts will be employed only if natural restoration is not likely to be successful

- Post-burn invasive plant management if required

- Adopting other necessary precautions or mitigation if identified

Other considerations include:

- Ensuring human safety through proper public communications (e.g. public notices, trail and kiosk signage), area closures and helicopter patrols before burning

- $\quad$ Timing the PB to minimize smoke affects; 
- Protection of historic sites or structures (e.g. cabins) with sprinklers or other means; and

- Post-burn cleanup of trails and nearby hazard trees.

Preparation for a prescribed burn will include scheduling the requisite pre-burn research and data collection (see section 9. Pre \& Post Burn Research, Data Collection and Monitoring) and creating containment lines if needed. Post burn assessment and research will be scheduled after the burn. Information from this research will supplement future fire management planning.

The sequence and timing of the proposed prescribed burns will depend on the priorities of the fire management plan goals; staff workloads relative to developing and delivering prescribed burn plans for approval; research resources and timing; preparation work; communications timelines; and is entirely dependent on having the appropriate burn conditions in the various locations to provide the "window" for burning as well as the resources to successively conduct and control the prescribed burn. Some prescribed burns may be delivered in phases within the year or spanning multiple years. Overall, the various prescribed burns will be carried out over several years as opportunities arise. 


\section{PRE \& POST BURN RESEARCH, DATA COLLECTION AND MONITORING}

Pre and post burn research, data collection and monitoring is a prerequisite for each prescribed burn (inventory work may be required for the Lower Smoky containment lines) and will be incorporated into timing and budget considerations. Pre and post burn research, data collection and monitoring provides a valuable opportunity to gain ecological knowledge that can later be applied to future fire management planning and activities within Willmore, other protected areas, or on the working landscape.

A Willmore Fire Research Planning Team, consisting of SRD and CD staff, has been established in order to ensure the successful delivery of the commitments of this Fire Management Plan to pre and post burn research, data collection and monitoring as well as broader research to reflect that Willmore fire management is at a landscape level beyond the prescribed burn boundaries, includes wildfires, and recognizes ecosystems. The Fire Research Team has developed a Terms of Reference that outlines their objectives, process, goals and responsibilities. The intent is to develop a Fire Research Strategy that coordinates joint opportunities to conduct ecological and fire research.

The Fire Research Strategy will provide the pre and post burn methodology and set the minimum research standards required for sign-off of individual prescribed burns. The Fire Research Team will ensure that the preburn work is accounted for when the timing of the prescribed burns is being determined. The Fire Research Team will also identify and coordinate broader level research opportunities within Willmore, such as assisting in designing the biophysical research that will be conducted by CD.

The large, protected wilderness of the Willmore provides a unique area to pilot preburn and post burn research, data collection and monitoring methodology. The prescribed burns are opportune research locations with pre-defined locations and boundaries, controlled timelines, no prior human disturbance, and post burn disturbance left unaltered. The prescribed burns also provide opportunities to test fire mitigation or control methods (if appropriate within Willmore i.e. no chemicals or heavy machinery) because the fire encompasses the research site.

Wildfires in Willmore, particularly when allowed to occur naturally without suppression, provide excellent post-burn opportunities for studying fire ecology and fire behaviour. This research also provides more refined knowledge and understanding of the fire regime within Willmore.

The preburn and post burn research and data collection will incorporate Parks and Protected Areas Division (PPAD) research guidelines and objectives as well as Forestry Division (FD) provincial prescribed burn sampling protocols that are currently under development. Many research interests are shared by PPAD and different divisions of SRD (e.g. Fish and Wildlife division) so collaboration will be fostered where possible. PPAD and SRD objectives and sampling protocols will be merged to create a joint preburn research venture with shared locations for research plots, shared research measures, and coordinated timing, whenever possible, in order to maximize research coordination and efficiency, minimize costs, optimize transportation resources, and provide integrated research results. The pre and post burn research, data collection and monitoring should be expected to evolve and expand as the research experience increases, new information or methodology is gained, and opportunities arise. 
PPAD objectives include (but are not limited to):

Vegetation monitoring

- Vegetation inventory and establishment of permanent monitoring plots (includes collection of general site information and photo documentation);

- Focused vegetation inventory (e.g. whitebark pine, rare vascular \& non-vascular species- Haller's applemoss and Porsild's bruym, rare plant communities);

- Inventory of invasive plants within or in vicinity of prescribed burn area (i.e. may $\underline{\text { Soils }}$ need invasive plant management as part of prescribed burn plan)

- Soil sampling in connection with vegetation plots;

Wildlife

- General wildlife observations and focused inventory (e.g. specific speciescaribou, harlequin duck, wolverine, bull trout) - may be done in collaboration with Fish \& Wildlife (SRD);

Photography

- Landscape photography for each prescribed burn site (using methodology of Rocky Mountain Repeat Photography project)

\section{SRD objectives include (but are not limited to):}

Vegetation monitoring

- Preburn and post burn photography series - photos taken in four cardinal directions in each plot;

- Forest floor depth measurements;

- Line intersect for sampling dead-down woody fuels;

- Weight estimates for herbaceous vegetation;

- Shrub stem tally;

- Tree overstory and understory, and regeneration measurements

- Whitebark re-establishment on burned sites

Wildlife

- See bullet under PPA objectives

Fire research

- Fire weather

- Fire behaviour and post burn fire ecology

- Fire regime analysis

- Forest Engineering Research Institute of Canada (FERIC) research on FireSmart techniques, e.g. structural protection methods, fuel management

- Fuel validation on fireguard prescribed burns to determine if and when future treatment is needed to maintain fireguard effectiveness

- Success of prescribed burn in meeting intended Fire Mgmt Plan objective MPB

- Assessment of beetle brood success in scorched green trees, heat-damaged green trees, and fire-killed trees

- Assessment of scorched trees as MPB-magnets 
Post burn research, data collection and monitoring will follow-up on the preburn work and provide a comparison with the preburn baseline data. In particular, post burn monitoring should assess the success of the prescribed burn in meeting its intended objectives. Post burn research, data collection and monitoring will link the preburn conditions and observed fire behaviour to the fire effects in terms of biodiversity, regeneration/succession, and ecological processes. The results will give an indication of the resiliency of the ecosystem in that location. Post burn research on wildfires may explore the fire behaviour and fire ecology of natural fires, especially without the influence of suppression. Post burn research, such as fuel validation, is important for the fireguard prescribed burns in order to track the regeneration (e.g. pine regrowth) in order to determine when or if future treatment (e.g. burn) is required to maintain the effectiveness of the fireguard. Retreatment is likely most essential within the first 4-5 years and may require at least one surface burn in that time. However, the fireguards may be found to naturally maintain themselves. All post burn research and monitoring will be scheduled immediately following the burn, within a year or two, and then every five or ten years as appropriate. 


\section{ADJACENT FIRE MANAGEMENT}

Willmore Wilderness Park is bordered by Jasper National Park in the south, Rock LakeSolomon Creek Wildland Park to the southeast, Forest Management Area (Hinton Wood Products/West Fraser, and Alberta Newsprint Company FMA's) forest to the east, Town of Grande Cache to the northeast, Forest Management Units (E8 and E10 FMU's) to the northeast, Kakwa Wildland Park to the north and British Columbia commercial forest land to the west. Therefore fire management in Willmore Wilderness Park cannot be independent of the protected and working landscapes that surround it. Consultation and communications regarding the Fire Management Plan, implementation of the prescribed burns, and communication during wildfires will involve these neighbouring jurisdictions.

The Willmore Fire Plan will provide the opportunity to work with neighbouring FMA companies and FMU quota holders, to encourage integration into their forest and fire management planning, so that their activities complement and support the Willmore Fire Management Plan. This integrated approach may provide opportunities for expansion of the natural fire zone into the current managed fire zone and therefore reduce interference in natural fire processes. The Sheep Creek capping unit, located outside Willmore (location to be determined), will utilize a combination of commercial harvesting and prescribed fire as appropriate.

The Grande Cache Community Protection Plan (GCCPP) includes a portion of Willmore within their planning area. The Willmore Fire Management Plan identified community protection for Grande Cache as a goal. The GCCPP FireSmart activities within the Willmore mesh with the overall Willmore Fire Management Plan. The GCCPP provides the containment lines that will be blackened off, when needed, to provide fireguards as identified in the Willmore Fire Management Plan. Delivery of these fireguards may allow opportunities within the managed fire zone to minimize suppression.

The Willmore Fire Management Plan provides a central anchor for fire management planning in the various adjacent protected areas. Recently, Willmore Wilderness Park became part of an interprovincial park with Kakwa Wildland Park in Alberta, and B.C.'s Kakwa Provincial Park. Although management of the three parks will still follow their individual legislated intents, formation of this interprovincial park will likely encourage coordination of some management activities (such as fire management) where compatible. Alberta's Kakwa Wildland Park is managed by CD, but located within a different planning region and under different legislation than Willmore Wilderness Park. It does not have a fire plan but development of a future fire plan would be complementary to the Willmore Fire Plan so that the fire management strategy and process is contiguous across the parks. The Kakwa Wildland Park geographically is an extension of the mountain ranges and topography of Willmore Wilderness Park. A continuation of the natural fire zone of Willmore may be possible if supported by suitable topography or fireguards.

Rock Lake-Solomon Creek Wildland Park is managed by CD within the same planning region as Willmore Wilderness Park and the same legislation as Kakwa Wildland Park. It does not have a management plan or fire plan, however development of the fire plan component would be integrated with the Willmore and Jasper NP Fire Plans. Due to its 
smaller size, front country location, and embedded Rock Lake PRA (i.e. campgrounds), fire management is likely to be highly managed similar to Willmore's managed fire zone.

British Columbia is expected to play a greater role partnering with Alberta in combating the spread of mountain pine beetle into Alberta. B.C. will be involved in implementation of the Meadowland mountain pine beetle prescribed burn in Willmore, which may potentially incorporate some of the adjacent area in British Columbia. In addition, fire management between Alberta and B.C., may be further coordinated as a result of the recent Kakwa-Willmore Interprovincial Park.

The Willmore Fire Management Plan is expected to complement the Jasper National Park Fire Management Plan and vice versa. Two Jasper National Park proposed prescribed burns, Upper Smoky River and Rock Lake/Snake River, border on Willmore and will involve cooperative efforts between Jasper National Park, SRD and CD.

Overall, the development of the Willmore Fire Management Plan should provide a framework and impetus for complementary forest and fire management planning in the surrounding landscapes. Integration and opportunities for joint activities should be enhanced as a result of the delineation of the objectives and strategies for fire management within Willmore Wilderness Park. 


\section{COMMUNICATION STRATEGY}

The Communication Strategy for the Willmore Wilderness Park Fire Management Plan includes three components of communications:

i. Referral strategy for the draft Fire Plan review;

ii. Communication plans for prescribed burns;

iii. Wildfire communications.

The main intent of this Communication Strategy is to define the Referral Strategy component for this Fire Plan. The Prescribed Burn and Wildfire communications are briefly described in this Fire Plan and will be further developed as part of the implementation of this Fire Plan. Communications staff will be familiar with the intent and objectives of the Fire Plan as well as the communication strategies outlined for the prescribed burns and wildfire.

\subsection{Referral Strategy}

The draft Fire Management Plan was initially developed at a project team level incorporating ecological and park management, fire, and mountain pine beetle expertise from $C D$ and SRD. The Referral Strategy targets primary, secondary and tertiary stakeholders for referral on the draft plan or distribution of the final plan.

- Referral Phase - gathers input from primary stakeholders through a mail out of the draft Fire Plan, invitation to a presentation, and opportunities to submit input;

- Distribution Phase - provides the final approved Fire Plan to all stakeholders either directly through mail out of final Fire Plan to primary stakeholders or indirectly to secondary and tertiary stakeholders via CD and SRD websites.

\section{Stakeholders}

Primary stakeholders include:

- Key CD and SRD staff;

- Jasper National Park;

- B.C. Ministry of Forests \& Range; B.C. Ministry of Water, Land \& Air Protection;

- FMA holders (Hinton Wood Products/West Fraser, Weyerhaeuser, Alberta Newsprint Company) and FMU quota holders (Foothills Forest Products);

- Municipalities; MLAs;

- Local First Nations;

- Trappers (local and Alberta Trappers Association);

- Willmore Wilderness Foundation (includes most of the commercial hunting outfitters and commercial trail riders); commercial trail riders; commercial hunting outfitters (local and Alberta Outfitters Association);

- Provincial ENGO's (Canadian Parks and Wilderness Society, Alberta Wilderness Association, Wildcanada.net, Federation of Alberta Naturalists; Athabasca Bioregional Association);

- Interest Groups (local/provincial Fish \& Game Association, Alberta Conservation Association, Rocky Mountain Elk Foundation, Foothills Model Forest);

- Interested public. 
Secondary stakeholders include:

- CD and SRD staff;

- Service Alberta staff;

- Residents of nearby communities: Grande Cache, Hinton, local villages/hamlets;

- Travel Alberta; Tourism Information Centers for nearby communities;

- Commercial Tourism Operators/Tourist User Groups;

Tertiary stakeholders include:

- Residents of other communities in the vicinity: Jasper, Edson, McBride, B.C. and Dunster, B.C.

- Willmore Wilderness Park Visitors;

- Interested Public;

- Alberta Media.

a. Referral Phase:

- Mail out to primary stakeholders of the draft Fire Management Plan with invitation to attend a presentation of the Fire Management Plan 2-3 weeks later

- Presentation to provide overview of the draft Fire Management Plan with the opportunity for questions and answers, feedback and general discussion

- Written feedback accepted for 2-3 weeks following the presentation

- Feedback reviewed, draft Fire Management Plan edited and finalized for approval

- Approval by both collaborating departments (CD and SRD) to release Fire Management Plan for implementation and to proceed to distribution phase

\section{b. Distribution Phase:}

- Development of public website with downloadable Fact Sheet and final version of Fire Plan

- Mail out of final Fire Management Plan and Fact Sheet to primary stakeholders

- Indirect distribution to secondary and tertiary stakeholders via CD and SRD websites via local news release for nearby residents, email to CD/SRD staff and tourism agencies (with website address for Fire Plan/Fact Sheet), as well as Fact Sheets posted and available at local CD/SRD and town offices, Tourism Information Centers, and posted at Willmore staging area kiosks.

- Provincial media will be contacted to suggest a feature story. 


\subsection{Communication Plans for Prescribed Burns}

Individual detailed communications plans will be developed as part of the Operational Prescribed Burn (PB) Plan for each prescribed burn identified within this Fire Plan. These communication plans will outline the steps, timelines and audience for the various communication activities specific for each prescribed burn. The intent of the communication plans is to ensure that the public is effectively notified (e.g. public notices, media, trail/kiosk signage) in a timely manner prior to the implementation of the prescribed burn. These communication plans will be approved as part of the approval for each Prescribed Burn Plan, and the steps in the communications plan must be implemented according to the timeline before the prescribed burn will proceed.

Development and implementation of the prescribed burn communications plans will be led by the regional communications officer within the Fire Management Plan Project Team and coordinated with $C D$ and SRD Communications staff in Edmonton when necessary. The PB public communications process will involve both regional and provincial SRD and $C D$ staff as outlined in the "SRD-CD Prescribed Burn/Wildfire Communication Flowchart" (Appendix III). The Project Team will be aware of all communications activities and products before their implementation.

The audience for notification of a prescribed burn will be developed from the list below to include only those stakeholders that are relevant to the specific prescribed burn (e.g. access closure, smoke):

- Key CD and SRD staff;

- Nearby communities-town administrators, residents, hospitals (re: smoke issues), tourism information centres, local media (newspaper, radio)

- Alberta-Grande Cache, Jasper, Hinton, Edson, local villages/hamlets;

- British Columbia-McBride, Valemount, Dunster;

- Municipality of Greenview, Yellowhead County, MLA-West Yellowhead;

- Local First Nations;

- Jasper National Park;

- B.C. Ministry of Forests \& Range; B.C. Ministry of Water, Land \& Air Protection;

- FMA holders (Hinton Wood Products-West Fraser, Weyerhaeuser, Alberta Newsprint Company) and FMU quota holders (Foothills Forest Products);

- Specific trappers (local and Alberta Trappers Association);

- Willmore Wilderness Foundation (includes most commercial trail riders/outfitters);

- Commercial trail riders; commercial hunting outfitters (local and Alberta Outfitters Association); adjacent tourist lodges;

- Provincial ENGO's/interest groups (Canadian Parks and Wilderness Society, Alberta Wilderness Assoc, Wildcanada.net, Federation of Alberta Naturalists, Athabasca Bioregional Assoc, local/provincial Fish \& Game Assoc, Alberta Conservation Assoc, Rocky Mtn Elk Foundation, Foothills Model Forest);

- Service Alberta staff; Travel Alberta;

- Alberta Media;

- Willmore Wilderness Park Visitors (through signage, media and tourist information centres); 


\subsection{Wildfire Communications}

Communications for wildfires within Willmore Wilderness Park will follow a modified version of SRD's wildfire "Notification Protocol Matrix" (Appendix II). The modified version will incorporate notification of $C D$ through the Parks and Protected Areas West Central Area Manager who will notify relevant regional staff. CD Communications staff will be notified by SRD Communications staff and/or through a CD liaison (e.g. Fire Plan team member). CD and SRD Fire Management Plan project team members should be notified and consulted during the actioning of the wildfire to ensure that measures taken are compatible with the intent and objectives of this Fire Management Plan.

The wildfire public communications process will involve both regional and provincial SRD and $C D$ staff as outlined in the "SRD-CD Prescribed Burn/Wildfire Communication Flowchart" (Appendix III). A current stakeholder list will be circulated to SRD and CD communications staff as well as anyone else making stakeholder contact. Key stakeholders will be notified by phone calls and/or email. Wildfire updates will be provided regularly to an email list of relevant stakeholders. Local or provincial media will be contacted as needed. The regional communications officer will track the communications steps and notification to ensure consistency and avoid duplication.

Wildfire messaging will be collaboratively developed between SRD and CD staff in Edmonton, with review by the Project Team for consistency with the Fire Plan messaging and to provide current operational details. Messaging will be reflective of a Parks perspective and public sensitivities regarding protected areas, as well as providing consistency with Fire Plan messages and current fire management operations.

The audience for notification of a wildfire will be developed from the list below to include those stakeholders that are impacted by the wildfire (e.g. access closure, smoke):

- Key CD and SRD staff;

- Nearby communities-town administrators, residents, hospitals (re: smoke issues), tourism information centres, local media (newspaper, radio)

- Alberta-Grande Cache, Jasper, Hinton, Edson, local villages/hamlets;

- British Columbia-McBride, Valemount, Dunster;

- Municipality of Greenview, Yellowhead County, MLA-West Yellowhead;

- Local First Nations;

- Jasper National Park;

- B.C. Ministry of Forests \& Range; B.C. Ministry of Water, Land \& Air Protection;

- FMA holders (Hinton Wood Products-West Fraser, Weyerhaeuser, Alberta Newsprint Company) and FMU quota holders (Foothills Forest Products);

- Specific trappers (local and Alberta Trappers Association);

- Willmore Wilderness Foundation (includes most commercial trail riders/outfitters);

- Commercial trail riders; commercial hunting outfitters (local and Alberta Outfitters Association); adjacent tourist lodges;

- Provincial ENGO's/interest groups (Canadian Parks and Wilderness Society, Alberta Wilderness Assoc, Wildcanada.net, Federation of Alberta Naturalists, Athabasca Bioregional Assoc, local/provincial Fish \& Game Assoc, Alberta Conservation Assoc, Rocky Mtn Elk Foundation, Foothills Model Forest);

- Service Alberta staff; Travel Alberta;

- Alberta Media;

- Willmore Wilderness Park Visitors (through signage, media and tourist information centres); 


\section{FIRE MANAGEMENT PLAN MONITORING}

The Willmore Fire Management Plan is a long-term plan. Implementation of the various components (i.e. natural fire-managed fire zoning, prescribed burns) will be distributed over several years depending on provincial priorities and feasibility to meet the objectives.

In order to ensure accountability in implementation it is useful for staff to complete an annual monitoring report. This annual monitoring report is not intended to be onerous and will involve a 1-2 page table format. The template is included in Appendix IV.

The report will generally review:

- What activities were prioritized for that year and why

- What activities were deferred and why

- What steps were completed that year towards achieving the prioritized activities

- Comments about successes, challenges or reasons the activity couldn't be completed, and future recommendations in conducting those priorities.

The report will be compiled In November after completion of the fire season (April 1-Oct 31 ) at a meeting of the Fire Plan project team, PB project team and other involved staff. This Annual Report meeting will also set the priorities and timing for activities for the following year. The report will be submitted to the SRD and CD Areas Managers. Information updates will be posted on the public website.

\section{ADAPTIVE MANAGEMENT ADDENDUM}

The Willmore Wilderness Park Fire Management Plan is a landscape level, long term plan based on the best available science and current rationales. Therefore the Fire Plan is a living document and, recognizing that over time better science and more information may arise or wildfires may occur, an adaptive management approach will be incorporated in the implementation of this Fire Plan. This approach considers future modifications if they improve the ecological management of Willmore.

Substantial changes would necessitate revisiting the entire approved Willmore Fire Plan. However, most modifications could be adopted through review and approval of an "Adaptive Management Addendum". The template is included in Appendix V. The addendum would be referred to the relevant stakeholders and departmental staff and signed off by the CD and SRD Area Managers for implementation. The addendums would be added to Appendix $\mathrm{V}$ of the Willmore Wilderness Fire Management Plan and updated on the public website. 


\section{RECOMMENDATIONS}

This Fire Plan provides an important component to be incorporated into an overall Willmore Wilderness Park Management Plan once it is completed. The development of the Fire Plan was beneficial in accelerating staff familiarity and knowledge about Willmore Wilderness Park by providing opportunities to view the site from the air as well as through the process of background preparation. This background preparation will be a valuable contribution to the extensive background preparation needed for developing the Park Management Plan. It is recommended that CD resources be directed towards expanding on this background preparation (e.g. biophysical inventorying), in order to build on the ongoing fire planning and research/data collection/monitoring activities, as well as current staff experience and knowledge, in order to prepare for future development of a Park Management Plan.

Willmore is a vast, complex and relatively unaltered protected area with unlimited opportunities to study the ecological processes as well as the variety of plant and animal species comprising its biodiversity. This Fire Plan should provide the impetus to identify and execute meaningful research as well as data collection and monitoring, in order to capitalize on this unique opportunity both in terms of fire management and biophysical knowledge. Willmore provides a benchmark for comparison to working landscapes. Forest and fire management in the working forest or protected areas adjacent to Willmore should be encouraged to complement and support this Fire Plan as well as to support the ecological integrity that makes Willmore a benchmark.

Implementation of this Fire Plan should lend priority to dedicating resources to conduct biophysical work and complete the requisite Ecological Land Classification (ELC) that precedes the biophysical. This biophysical work is needed in Willmore to refine the general biophysical descriptions and to identify unique, significant, or rare vegetative and wildlife species and communities for database records and tracking. The biophysical work will provide baseline data in order to be able to measure the benefits and impacts of natural fires when they occur. Due to the large and varied landscape of Willmore, this biophysical research will be broken down into manageable portions conducted over multiple years. Planning for a three-year biophysical project has been initiated and fieldwork is anticipated for summer of 2007.

Specific vegetative species merit research focus. Inventorying and monitoring of rare or significant species or communities of interest within Willmore is valuable in order to provide preburn baseline data so that if a fire occurs in those locations then post burn research can be conducted for those species or communities. Research projects (e.g. university students) on vegetation should also be encouraged and scheduled when opportune.

Surveying to determine the extent of whitebark pine within Willmore Wilderness Park has been initiated, and completion of the inventory should be a priority, particularly in light of MPB infestation. Inventorying should include groundtruthing to assess its health condition (re: blister rust), GPS and mapping of locations, as well as transfer of data to the provincial whitebark pine inventory database. A strategy should be developed to mitigate threats to the healthy populations and to investigate the impacts or benefits of fire. 
Significant wildlife species such as woodland caribou, grizzly bear, wolverine, Harlequin duck and others inhabit Willmore. Research, data collection and monitoring of those species should be encouraged so that preburn baseline data can be used for post burn monitoring of the effects of the natural fire regime approach. Continuation of past, or ongoing, research initiatives within/adjacent to Willmore should be supported and encouraged within Willmore. Provision of support (e.g. helicopters) may allow for valuable research partnerships with outside agencies to fulfill Willmore research needs. Harlequin duck and Wolverine monitoring was conducted in 2006 and anticipated to continue.

The Willmore, and particularly the PB locations, provides a unique area to pilot pre and post burn biophysical research, data collection and monitoring methodology as well as test appropriate FireSmart, fire mitigation or fire control methods. This pre and post burn biophysical and fire research, data collection and monitoring should be encouraged in order to gain these valuable opportunities from the Pubs. Research collaboration between $C D$ and SRD should also continue in order to optimize progress.

It is recommended that a Fire Regime Analysis be conducted in Willmore to provide further insight into fire dependent ecosystems. The fire regime analysis would provide an important benchmark that would be tested by future natural fires to validate or refine current understanding of fire cycles in Willmore's subregions. This information may be transferable to other areas expected to have a similar fire regime. This benchmark may be important for monitoring climate change impacts. The fire regime analysis provides a benchmark for measuring the results of implementing this Fire Management Plan.

A proposal for completion of the Alberta Vegetation Inventory (AVI) within Willmore has been submitted. This AVI should be completed if the data is required for accurate modeling within Willmore. If other data collection is more suitable then that data collection should be conducted instead.

Willmore is bordered by Jasper National Park, Rock Lake-Solomon Creek Wildland Park and Kakwa Wildland Park. It is appropriate that management of these protected areas, whether federal or provincial, should be complementary to each other. Cooperative and cross-boundary fire management plans and activities are likely to be mutually beneficial. The Willmore Fire Plan can serve as a model, if appropriate, for the adjacent Wildland Parks that currently do not have fire plans. These adjacent areas may have different fire management needs but their fire plans should still be integrated. Communication between federal and provincial park agencies should continue to be fostered.

The Willmore Fire Plan provides a supporting role in mitigating wildfire risk to commercial forestry and communities outside Willmore. Therefore, forest management of commercial timber, as well as other industrial activities or community development, in the adjacent working landscapes in Alberta or British Columbia should be encouraged to recognize and support the Fire Plan activities in Willmore. In particular, harvesting or prescribed burning outside Willmore should be designed to reinforce the objectives of the prescribed burns planned within Willmore. Discussion with industry to increase awareness and understanding of the Fire Plan should be initiated and maintained. 
Development of a pre-suppression plan for the managed fire zone is recommended in order to predetermine optimal locations for containment lines/fireguards in the situation of advancing wildfire. The current managed fire zone should be examined to identify pockets where natural fire management (i.e. minimal or no suppression) may be feasible using existing topography and/or containment lines. Once suitable external fire management and FireSmart activities are implemented then the overall location of the natural fire-managed fire boundary should be reassessed for potential expansion of the natural fire zone.

Finally, sufficient resources in terms of budget and staffing must be supported by both departments (CD and SRD) in order to facilitate the high demands of the detailed planning, communications, research and recommendations associated with successful implementation of this plan. 


\section{CONCLUSION}

Willmore Wilderness Park is an important protected area in Alberta's network of parks and protected areas. The Willmore contains extensive and remote wilderness landscapes with important ecological as well as backcountry recreational values that provide environmental, social, and economic benefits. The Willmore Wilderness Park Fire Management Plan was created recognizing these values.

Willmore Wilderness Park contains subregions of both the Rocky Mountain and Foothills Natural Regions with their related landscapes, topography, weather patterns and fire regimes. Historic evidence indicates fire on the landscape with fire cycles ranging from $100-120$ years to $180-200$ years. Fire suppression in some areas may have influenced the fire cycle but generally was not a major influence, particularly in the backcountry. Therefore the majority of the extensive forests of Willmore contain relatively old, evenaged trees interspersed with older trees that survived previous fires. These extensive forests support the biodiversity that is associated with older forests.

Natural fire plays a role in maintaining and protecting those ecological values and exclusion of natural fire does not necessarily ensure protection of the ecological values. Fire plays an important ecological role in the forest regime and provides important benefits such as nutrient cycling, decomposition, stimulation of new vegetation, pest impacts, and shifts in the biodiversity composition. Impeding natural fire processes through fire suppression upsets the balance; however allowing natural fire processes enables the balance to be restored. Allowing the benefits of fire, as well as reducing the demand for fire suppression resources, is beneficial for both departments as well as the ecology of Willmore Wilderness Park.

This Fire Plan precedes the Willmore Wilderness Park Management Plan. However the Fire Plan was a timely and beneficial preliminary step in order to provide interim fire management in order to suit the intent and ecological management of the Willmore. The development of the Fire Plan built relationships between CD and SRD staff, and resulted in increased $C D$ and SRD staff familiarity with Willmore as well as improved understanding of Willmore fire cycles based on existing information. These CD-SRD staff relationships, as well as having a draft Fire Plan for overall guidance, proved beneficial when assessing strategies for dealing with the wildfires in 2006 . Development of the Fire Plan and its implementation is also resulting in initiation of research, data collection and monitoring initiatives that will provide useful ecological and management information that extend even beyond the scope of the Fire Plan. In addition, the Fire Plan will provide an important section to be incorporated into the Park Management Plan once completed.

The fire management strategies within this Fire Management Plan are intended to mitigate wildfire threat to community and ecological values at risk, minimize threats to forest health (e.g. MPB); and allow natural fire regimes to occur naturally on the landscape, while prioritizing ecological integrity. These objectives are addressed through the Wildfire Management Strategy and the Prescribed Fire Strategy.

Prior to the Fire Plan, the entire Willmore Wilderness Park was being managed under a policy of full suppression therefore it was entirely a managed fire zone. The Wildfire 
Management Strategy in the Fire Plan delineates the wildfire management in Willmore between a natural fire and a managed fire zone. The natural fire zone provides the opportunity to allow natural fires to burn, while the managed fire zone will generally remain under fire suppression with some potential for natural fires to be considered on case-by-case basis. Expansion of the natural fire zone may be possible in the future depending on adjacent fire management activities. The Wildfire Management Strategy sets out the process and notification protocol for assessing and actioning wildfires in each zone.

The Prescribed Fire Strategy identifies five proposed units (prescribed burn, capping unit, containment lines) intended to target the Fire Plan objectives. These units include:

- The Lower Smoky River containment lines to provide a fireguard to burn back from in the future if needed to stop advancing wildfire threat to Grande Cache;

- The Meadowland Creek prescribed burn to remove resident mountain pine beetle (MPB) populations, reduce MPB habitat and create a barrier to MPB entry from British Columbia;

- The Sulphur River and Middle Smoky River prescribed burns, and the Sheep Creek capping unit (outside Willmore) to reinforce the natural fireguard created by the Persimmon and adjacent mountain ranges to delineate the natural fire zone and provide a barrier to MPB spread.

Detailed operational prescribed burn or containment line plans and their individual communication plans will be developed and jointly approved by CD and SRD. All PB and containment line plans will be developed and implemented to meet the ecological considerations outlined in this Fire Plan to minimize the impacts on the ecological integrity of Willmore. Timely implementation of the components of the communication plan (including effective public notification and signage) as well as completion of the preburn or pre-containment line (if needed) research, and data collection, is a prerequisite to the prescribed burn or containment line proceeding. After the prescribed burns, post burn research and monitoring will be scheduled.

Minimal human interference and a landscape level fire management approach to meet broad high level objectives is intended to allow ecological benefits so that ecological management is realized. This Fire Management Plan provides the mechanism to develop the management actions that are necessary to translate this philosophical shift in fire management into acceptance and implementation. 


\section{APPENDICES}

1. Project Planning Team - Terms of Reference

II. Notification Protocol Matrix

III. SRD-CD Prescribed Burn/Wildfire Communication Flowchart

IV. Fire Plan Progress Monitoring Report

V. Adaptive Management Addendum

VI. References 


\title{
I. PROJECT PLANNING TEAM - TERMS OF REFERENCE
}

\author{
1.0 Introduction and Project Rationale \\ The aim of this project is to develop a comprehensive fire management plan for the Willmore \\ Wilderness Park. Alberta Sustainable Resource Development (Forest Protection) and Alberta \\ Community Development (Parks and Protected Areas) initiated this project in November 2004.
}

The Willmore Wilderness Park is approximately $400 \mathrm{~km}$ northwest of Edmonton, Alberta and adjacent to Jasper National Park in the Canadian Rockies. The planning area encompasses over 450,000 hectares $(460,400$ ha), approximately 245,860 ha of which are forested. The park was originally set-aside in 1959 and in 1965 was named after the late honourable Norman A. Willmore. It is legislated under the Willmore Wilderness Park Act. Aboriginals, trappers, hunters and resource prospectors historically have utilized the region. It is now used for recreational activities such as backcountry hiking, trail riding and hunting, as well as supporting commercial trail riding operations, commercial outfitters, and trappers. Situated in the Canadian Rocky Mountains the park has representative samples of Montane, Sub-Alpine and Alpine Natural Subregions.

The Willmore Wilderness Park encompasses extensive and remote natural landscapes. While capable of supporting wilderness recreation, preservation of natural heritage values is the main goal. Management guidelines focus on maintaining ecological integrity and function.

Preservation and wilderness objectives will be sustained or enhanced. Motorized use is prohibited and development is limited to primitive facilities appropriate to a wilderness experience, such as trails and backcountry campsites.

It is deemed prudent to evaluate fire management strategies to mitigate the wildfire threat to values at risk, minimize the threat of mountain pine beetle infestation, and allow natural fire regimes to occur. Fire management objectives will be achieved through a variety of approaches.

\subsection{Process}

Development of the Willmore Wilderness Park Fire Management Plan is a collaborative effort between the Department of Community Development (CD)-Parks and Protected Areas Division (PPA), and the Department of Sustainable Resource Development (SRD)-Forest Protection Division (FPD) and Public Lands and Forest Division (PLFD). Representatives from all these three agencies will lead and actively participate in the planning efforts.

The team will develop values, goals, objectives and targets to drive the planning process and to monitor the progress and define success. The plan will be coordinated with the surrounding jurisdictions including Jasper National Park, FMA holders, B.C. Ministry of Forests, and Municipalities. Identified stakeholders and the public shall have an opportunity to provide comments on the draft plan.

\subsection{Project Goals}

The goal of this project is to:

a. Protect human life and communities from wildfire within and adjacent to the planning area.

b. Preservation of the parks natural heritage values.

c. Reduce the threat of a large mountain pine beetle outbreak.

d. Reduce the threat of large-scale, catastrophic wildfire to existing and adjacent values.

e. Allow natural wildfire processes to occur where possible

f. Develop the fire management component of the Willmore Wilderness Park Management Plan

g. Demonstrate a collaborative and effective interagency approach to the development of the fire management plan 


\subsection{Roles, Responsibilities, and Obligations of Participants}

Community Development (CD), as the land manager for the Willmore Wilderness Park, sets the direction and mandates the activities (including fire management activities) permitted within the Willmore Wilderness Park. CD will therefore play an active role in providing input and direction to the development of the Fire Management Plan to ensure that it is compatible with the intent and objectives for the Willmore Wilderness Park.

Sustainable Resource Development (SRD) is responsible for wildfire management across the provincial forest protection area, including the Willmore Wilderness Park. SRD will play an important role by providing the forest protection, fire management planning and operational expertise that is needed to develop an effective Fire Management Plan for the Willmore Wilderness Park.

Planning Team Sponsors

Kyle Clifford, CD-Parks and Protected Areas, West Central Area Manager

Brent Schleppe, SRD-FPD Fire Manager, Foothills Wildfire Management Area

The roles of the sponsors are to:

1. Approve the terms of reference for the project

2. Ensure the program strategy and approach are carried out

3. Ensure resource and budgetary requirements

4. Approve the planning process and provide direction as required

5. Mitigate escalated risks, filtering to ADM and Directors level if necessary

6. Communicate with ADM and Directors on progress and facilitate decision making

7. Approve the stakeholder and public involvement process

8. Resolve team conflicts

\section{Planning Team Members:}

\section{Planning Team Co-Team Leaders}

Kevin Quintilio SRD-FPD, Provincial Wildfire Science Forester

Laura Graham CD-PPA, West Central Area Planning Team Leader

The roles of the co-team leaders are to:

- Lead core project team

- Ensure the project strategy and approach are carried out

- Be accountable for deliverables of core team and decision documents

- Manage Fire Management Plan objectives, scope, progress, and issues/risk mitigation

- Monitor and coordinate deliverables to ensure that timelines are met

- Ensure the quality of the process and the product

- Review and confirm major work products for the project

- Ensure a comprehensive communication strategy is implemented

- Coordinate completion of regular status reports

\section{Planning Team Members}

Gordon Glover

Roderick Negrave

Erica Lee SRD-FPD, Wildfire and Air Operations Officer

CD-PPA, NW/NE Area, Resource Specialist

SRD-PLFD, Forest Health Officer

Andy Vanlmschoot
CD-PPA, District Conservation Officer Team Leader

The roles of the team members are to:

- Acts as a "wise sounding board" to the co-team leaders

- Provide high-level, strategic advice and support to the co-team leaders 
- Assists the project co-team leaders to prioritize high-level work plan, tasks and deliverables

- Serve as a resource to communicate to entire SRD department, CD department and other industry and municipal departments

- Act as advocates for the project

- Produce deliverables

- Work to ensure timeliness are met

\begin{tabular}{|c|c|c|}
\hline Name & Organization/Title & Role in Team \\
\hline Kevin Quintilio & $\begin{array}{l}\text { SRD-FPD, Provincial Wildfire } \\
\text { Science Forester }\end{array}$ & $\begin{array}{l}\text {-Team co-lead } \\
\text {-Meeting facilitation/alternate } \\
\text { chairperson } \\
\text {-Project process management } \\
\text {-Fire modeling } \\
\text {-PB planning } \\
\text {-Data analysis coordination } \\
\text {-Communicate FPD needs } \\
\text {-Team writer }\end{array}$ \\
\hline Laura Graham & $\begin{array}{l}\text { CD-PPA, West Central Area } \\
\text { Planning Team Leader }\end{array}$ & $\begin{array}{l}\text {-Team co-lead } \\
\text {-Meeting facilitation/alternate } \\
\text { chairperson } \\
\text {-Project performance } \\
\text { monitoring } \\
\text {-Communicate PPA needs } \\
\text {-Ensure consistency of Fire } \\
\text { Mgmt Plan with PPA's } \\
\text { provincial fire direction } \\
\text {-Integrate Fire Mgmt Plan into } \\
\text { future Willmore Wilderness } \\
\text { Park Mgmt Plan. } \\
\text {-PB \& FireSmart planning } \\
\text {-Contact for consultation } \\
\text { groups } \\
\text { - Team writer }\end{array}$ \\
\hline Gordon Glover & $\begin{array}{l}\text { SRD-FPD, Wildfire and Air } \\
\text { Operations Officer }\end{array}$ & $\begin{array}{l}\text {-PB planning and coordinator } \\
\text {-Fire Modeling } \\
\text {-Communicate FPD needs } \\
\text {-Team writer }\end{array}$ \\
\hline Roderick Negrave $^{21}$ & $\begin{array}{l}\text { CD-PPA, NW/NE Area, } \\
\text { Resource Specialist }\end{array}$ & $\begin{array}{l}\text {-Provide ecological and fire } \\
\text { expertise } \\
\text {-PB planning } \\
\text {-Communicate PPA needs } \\
\text {-Team writer }\end{array}$ \\
\hline Erica Lee $22 /$ Brooks Horne & $\begin{array}{l}\text { SRD-PLFD, Forest Health } \\
\text { Officer }\end{array}$ & $\begin{array}{l}\text {-Forest health modeling } \\
\text {-Communicate PLFD needs } \\
\text {-Team writer }\end{array}$ \\
\hline
\end{tabular}

${ }^{21}$ Participated November 2004-January 2005 (left due to job transfer and not replaced on planning team).

${ }^{22}$ Brooks Horne became replacement in Summer 2006. 


\begin{tabular}{|l|l|l|}
\hline Andy Vanlmschoot & CD-PPA, District Conservation & -Communicate PPA needs \\
Officer Team Leader & -Provide PPA operational \\
& & expertise \\
& & -PB \& FireSmart planning \\
& -Contact for consultation \\
& groups \\
& & - Team writer \\
\hline
\end{tabular}

\section{Planning Team Organization}

All team members are committed to the project plan philosophy, goals, objectives and process. All team members will participate in the planning process, attend team meetings, and meet goals and milestones defined by the team.

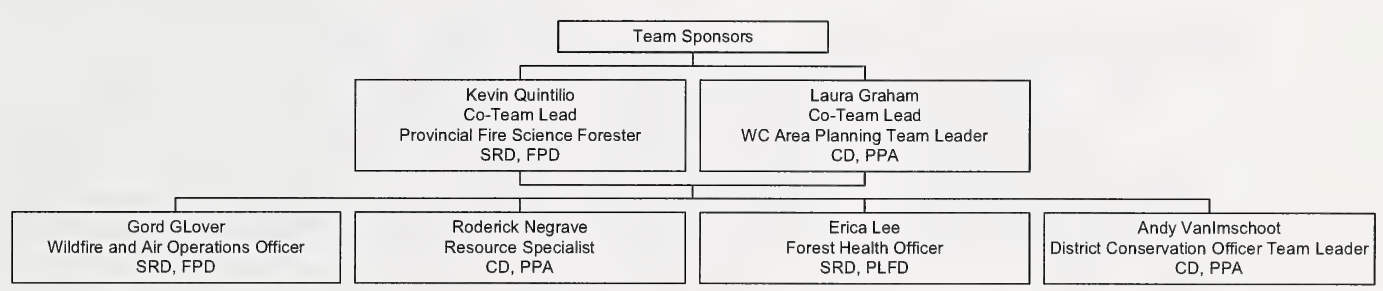

\subsection{Planning Team Success}

Team success will be measured using the following criteria:

1. Conceptual Fire Management Plan Draft completed by June 2005

2. Final Fire Management Plan approval by June 2006

3. Implementation of Fire Management Plan recommendations

4. Collaborative team approach to Fire Management Plan development

\subsection{Dispute Resolution Process}

The Fire Management Plan is intended to be developed in the spirit of collaboration, which encourages cooperative discussion and decision making in order to accomplish both $C D$ and SRD goals. The Team Leaders will facilitate this collaborative approach and provide direction or, if necessary, decisions. The Team Leaders will also seek direction and decisions from team sponsors as needed.

\subsection{Timelines and Milestones}

\section{Detailed Project Plan}

\section{Meeting Frequency}

The project team will meet approximately every month, with more frequent meetings or sub-group meetings if needed. During the fire season, when fire priorities will likely supersede, the frequency of meetings and progress is anticipated to be slower.

\section{Initial Planning Team Development November 2004}

Introduce team members to project including broad goals, direction and planning process. Team members provide fire management and protected area philosophies and perspectives. As a team, define and identify project planning requirements. Identify how are we going to convert project philosophy into a product. Determine if project should proceed and develop recommendation/project rationale. 
Discuss with respective managers and receive project concept endorsement to pursue a fire management plan.

\section{Initial Planning Team Meeting December 2004}

Define team member expectations, initial terms of reference and the project management process. Finalize team member involvement, stakeholder process and participants that would be involved in the planning process.

\begin{tabular}{|c|c|}
\hline Date & Milestone \\
\hline November, 2004 & $\begin{array}{l}\text { - Initial team development } \\
\text { - Develop plan objectives and overall process } \\
\text { - Project concept endorsement by respective } \\
\text { managers }\end{array}$ \\
\hline December, 2004 & $\begin{array}{l}\text { - Initial team meeting } \\
\text { - } \quad \text { pomplete initial terms of reference and } \\
\text { project plan for approval by plan sponsors. } \\
\text { - } \quad \text { Finalize team member involvement } \\
\text { in the planning process }\end{array}$ \\
\hline January, 2005 & $\begin{array}{l}\text { - ToR approved by team sponsors and signed } \\
\text { off } \\
\text { - Develop detailed plan outline and planning } \\
\text { team member responsibilities/workload }\end{array}$ \\
\hline June, 2005 & - Conceptual draft plan completed \\
\hline June, 2006 & - Final plan completed \\
\hline
\end{tabular}

*Planning milestone dates imply the end of the month

\subsection{Participation of Experts, Other Interests and Government}

Experts outside the planning team may be used to evaluate certain components or provide necessary knowledge within the fire management plan. The team will use consultants and internal staff as needed.

\section{Consultation Groups}

Jasper National Park

B.C Ministry of Forests

SRD - Fish and Wildlife

Weldwood

Weyerhaeuser

Foothills Forest Products

Foothills Model Forest

Willmore Wilderness Foundation

Willmore Park Outfitters

Local Trappers

Local First Nations

Town of Grande Cache

\subsection{Internal and External Communication}

Team members are responsible for reporting the team's activities to their respective Departments. The team meeting minutes will also be distributed to the sponsors for review. The team will determine the best external communication conduit as part of the public communication plan. In addition, stakeholders may receive mail outs of updates during the planning process and the team may meet individually with selected stakeholders. 


\subsection{Mechanisms to Adjust the Process}

The timeline outlined in section 1.6 identifies that the terms of reference and the project process will be reviewed by January 2005 . At this time, the preliminary planning process and development will be in the process of evaluation. The sponsors will have a chance to comment on the initial terms of reference. The sponsors must approve any future changes to the process.

\subsection{Access to Information}

All planning team members are provincial Government Department staff and shall share all information with other team members. Access of data and information shall be under existing data sharing agreements. If new data is obtained for this project, a data sharing agreement may be created to outline the data's use and distribution.

\subsection{Review of Plan Components}

The sponsors will review the plan components throughout the process and recommend approval of the final plan. Meeting minutes will be sent to all team members and the sponsors. Team members will update the sponsors as needed. The minutes will include the details of the meetings, progress to date, the timelines and milestones for the future, the public involvement plan, the progress of the initial plan evaluation, and an update of the team members participation. The sponsors will review the progress and revise the direction, components, and timelines as necessary.

Kyle Clifford

CD-Parks and Protected Areas

West Central Area Manager

Brent Schleppe

SRD-FPD

Fire Manager

Foothills Wildfire Management Area 


\section{NOTIFICATION PROTOCOL MATRIX}

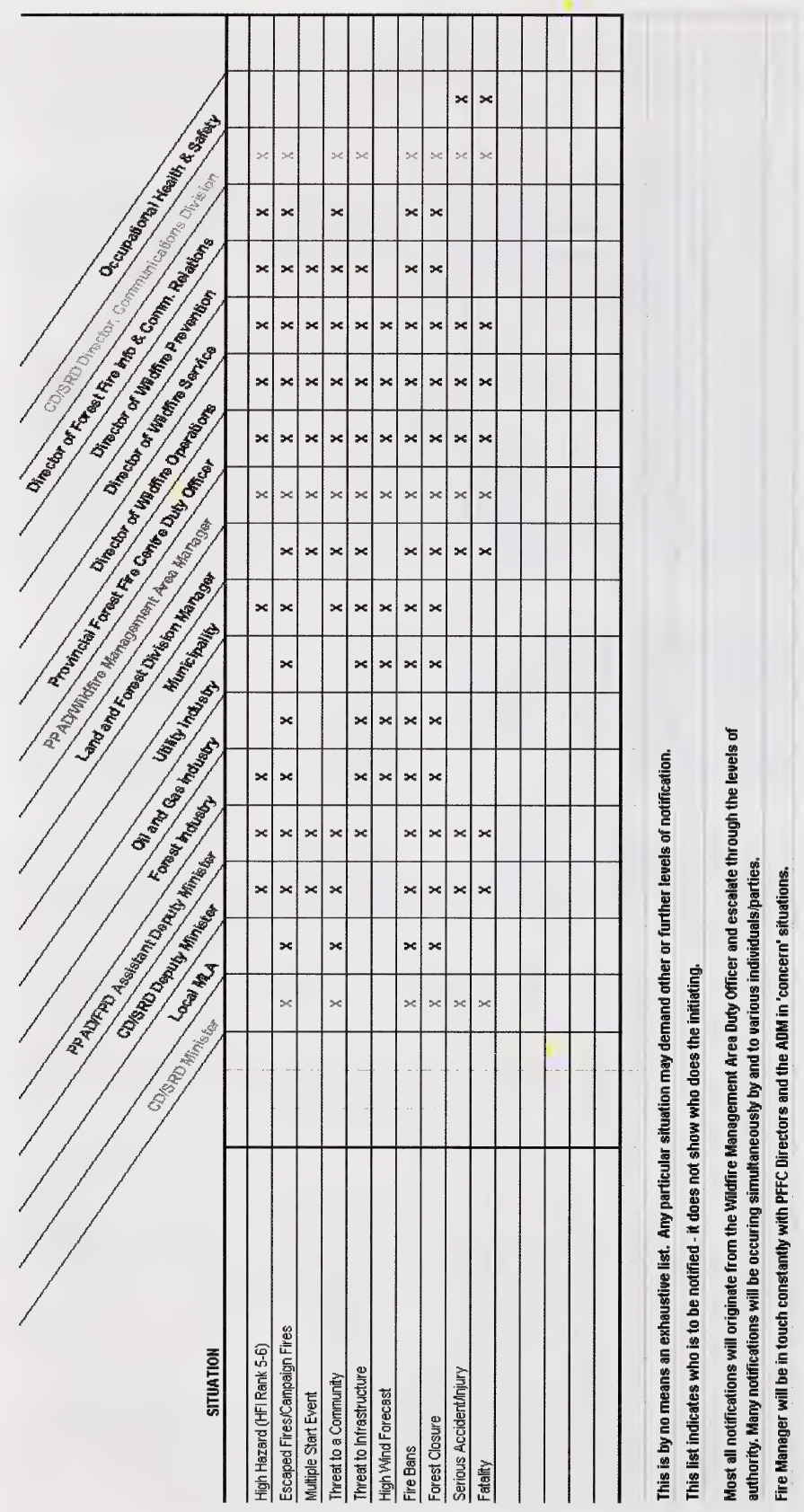




\section{SRD-CD PRESCRIBED BURN/WILDFIRE COMMUNICATION FLOWCHART}

\section{SRD Wildfire Information Officer (WIO)}

Responsible for:

- Local public communication

- Local industry/stakeholder communication

- Local media

- Internal communication(incident updates, etc)

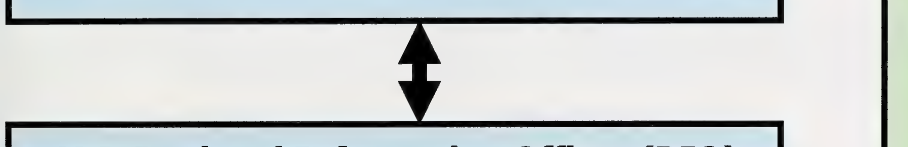

\section{Local/Regional PPA liaison (e.g. Planner, Conservation Officer)}

Responsible for:

- Informing PPA Area manager, regional staff, Edm staff, CD Communications as needed.

\section{SRD Regional Information Officer (RIO)}

Responsible for:

- Regional public communication (communities beyond the fire)

- Regional industry/stakeholder communication

Regional media (multi-fire related)

- Internal communication (region specific)

\section{SRD Provincial Information Officer}

Responsible for:

- Provincial media (multi-fire related)

- Product development \& approval coordination

- Internal communication (AB specific, region wrap-up)

- Working with FIO/RIO to share roles as needed*:

- signage development \& placement,

- access closure,

- local \& regional stakeholder communication

\section{車}

-

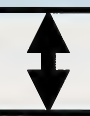

\section{SRD Corporate Communications}

Responsible for:

- Provincial media (policy \& budget related)

- Approvals \& coordination

News releases

- Coordination with CD Ministry 


\section{FIRE PLAN PROGRESS MONITORING REPORT}

\section{TEMPLATE}

Fire Plan Progress Monitoring Report: Insert Year

\begin{tabular}{|c|c|c|c|c|}
\hline $\begin{array}{c}\text { Activity } \\
\text { (May be } \\
\text { current or } \\
\text { deferred) }\end{array}$ & $\begin{array}{c}\text { Projected } \\
\text { Timelines } \\
\text { (Current or } \\
\text { deferred) }\end{array}$ & $\begin{array}{c}\text { Activity } \\
\text { Team } \\
\text { (CD/SRD staff } \\
\text { implementing } \\
\text { the activity) }\end{array}$ & $\begin{array}{c}\text { Progress } \\
\text { (insert } \\
\text { completion date, } \\
\text { partially } \\
\text { completed, or not } \\
\text { completed) }\end{array}$ & $\begin{array}{c}\text { Comments } \\
\text { (Briefly describe successes, } \\
\text { challenges and recommendations. } \\
\text { If activity was partially or not } \\
\text { completed then discuss reasons } \\
\text { why. Discuss deferred activities). }\end{array}$ \\
\hline & & & & \\
\hline & & & & \\
\hline
\end{tabular}

Note:

- Activities/Project Timelines: To be determined for each following year at the year-end Annual Report meeting. Deferred activities can also be listed with future Projected Timelines and Comments about reason for deferral.

- Activity Team: List CD and SRD staff responsible for implementing the activity.

- Progress: Insert either completion date, "partially completed", or "not completed".

- Comments: Discuss successes, challenges and recommendations. If activity was partially or not completed then discuss reasons why. Reasons for deferring activities can be mentioned. 


\section{ADAPTIVE MANAGEMENT ADDENDUM}

\section{TEMPLATE}

\section{ADAPTIVE MANAGEMENT ADDENDUM \\ INSERT TITLE OF PROPOSED MODIFICATION \\ INSERT DATE}

\section{Proposed Adaptive Management Addendum: \\ (Brief description of the modification/addition/deletion being proposed)}

\section{Background/Rationale:}

(Provide rationale/science to support the modification and potential issues including: reports, data, figures or maps)

\section{Recommendation:}

(Description of what the modification entails)

\section{Referral:}

(Description of referral process i.e. relevant stakeholders, departmental staff)

\section{Comments:}

(Outcome of referral process and final recommendation)

Management Addendum:

(Statement of final recommendation)

Kyle Clifford

CD-Parks and Protected Areas Division

West Central Area Manager
Brent Schleppe

SRD-Forestry Division

Foothills 


\section{REFERENCES}

Achuff, P.L. 1994. Natural Regions, Subregions and Natural History Themes of Alberta, A Classification for Protected Areas Management. Parks Services, Alberta Environmental Protection.

Alberta Community Development. 2001. Willmore Wilderness Park

Alberta Community Development/Alberta Sustainable Resource Development. 2003 (reprint). Willmore Wilderness Park map. ISBN 0-7785-0003-9; Pub No. I/670.

Alberta Sustainable Resource Development. FireSmart Landscapes, a discussion paper. (draft)

Baskin, Y. 1994. Ecosystem function of biodiversity. Bioscience, 44: 657-660

Bork, E. 1994. Ecological classification and management of native range in Willmore Wilderness Park. Alberta Environmental Protection. Forest Management Division. Edmonton, AB. 65pp.

Cade-Munun, B.J., Berch, S.M., Preston, C.M. and L.M. Lavkulich. 2000. Phosphorus forms and related soil chemistry of Podzolic soils on northern Vancouver Island II. The effects of clear-cutting and burning. Can. J. For. Res. 30: $1726-1741$.

Dumanski, J, Macyk, T.M. Veauvy, C.F. and J.D. Lindsay. 1972. Soil Survey and Land Evaluation of the Hinton-Edson Area, Alberta. University of Alberta Bulletin No. SS-14, Research Council of Alberta Report No. 93, Alberta Institute of Pedology Report No. S-72-31.

Jasper Interface Steering Team (Parks Canada, Foothills Model Forest) Hot Topic! Community fire protection and forest restoration program (fact sheet).

Holland, W.D., Hillman, G.R. and D.T. Allen. 1982. Physiography. In Holland, W.D. and G.M. Coen (eds.), Ecological (Biophysical) Land Classification of Banff and Jasper National Parks, Volume II: Soil and Vegetation Resources. Alberta Institute of Pedology Publication No. SS-82-44. Edmonton. pp $12-17$.

Lane, C. and M.G. Willoughby. 1998. Rangeland monitoring in Willmore Wilderness Park. Department of Environmental Protection. Land and Forest Service. Edmonton, AB. 9pp.

Merrill, D.F. and M.E. Alexander. 1987. Glossary of forest fire management terms. National Research Council of Canada, Publication No. 26516. 91 pp.

Negrave, R. 2005. An Outline of Physical Resources in Willmore Wilderness Park.

Parks Canada. Fire in Canada's National Parks (brochure) 
Pyne, S. 1996. Introduction to wildfire. John Wiley \& Sons Inc, New York, NY.

Rogeau, M-P. Fire history study of the Willmore Wilderness Park. Foothills Model Forest. Hinton, AB. 7pp.

Taylor, W.S. 1982. Geology. In Holland, W.D. and G.M. Coen (eds), Ecological (Biophysical) Land Classification of Banff and Jasper National Park, Volume II: Soil and Vegetation Resources. Alberta Institute of Pedology Publication No. SS-82-44. Edmonton. pp 17-20.

Twardy, A.G. and I.G.W. Corns. 1980. Soil Survey and Interpretations of the Wapiti Map Area, Alberta. Soils Department, Alberta Research Council and Alberta Institute of Pedology. Bulletin No. 39. Edmonton.

Tymstra, C., D. Wang and M-P Rogeau. 2004. Wildfire Regime Analysis (Draft). Sustainable Resource Development, Forest Protection Division. Wildfire Science and Technology Report PFFC-01-04.

VanWagner, C.E. 1977. Conditions for the start and spread of crown fire. Canadian Journal of Forest Research 7:23-34.

Walker, B.D., Allan, D.T. and W.S. Taylor. 1982. Geomorphology. In Holland, W.D. and G.M. Coen (eds.), Ecological (Biophysical) Land Classification of Banff and Jasper National Parks, Volume II: Soil and Vegetation Resources. Alberta Institute of Pedology Publication No. SS-82-44. Edmonton. pp $20-61$.

Walker, B.D., Holland, W.D. and G.M. Coen. 1982. Chapter II, Soils. In Holland, W.D. and G.M. Coen (eds.), Ecological (Biophysical) Land Classification of Banff and Jasper National Parks, Volume II: Soil and Vegetation Resources. Alberta Institute of Pedology Publication No. SS-82-44. Edmonton. pp $62-69$.

Walker, B.H. 1992. Biodiversity and ecological redundancy. Conservation Biology 6:18-23.

Willoughby, M.G. and D. Smith. 1998. Range plant community types and carrying capacity for the Sub-Alpine Subregion. Department of Environmental Protection. Land and Forest Service. Edmonton, AB. 108pp. 




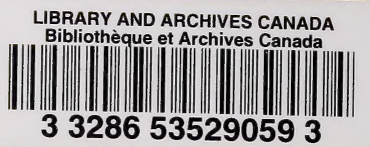

